

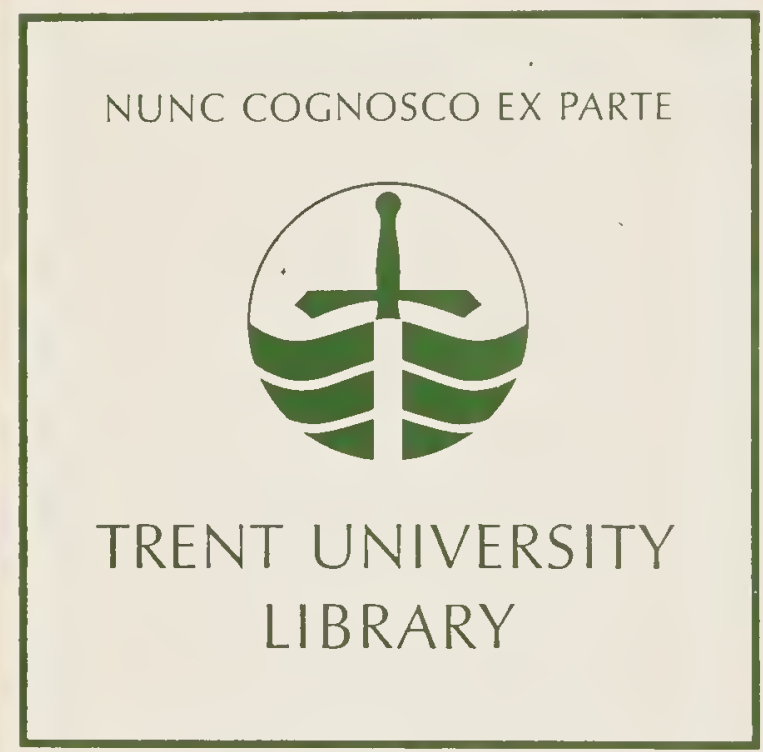

PRESENTED BY

Mrs. H.H. Graham 
Tuss H H Grodere 

THE CONTROL OF LIFE 
Digitized by the Internet Archive in 2019 with funding from Kahle/Austin Foundation 


\section{THE CONTROL OF LIFE}

BY

J. ARTHUR THOMSON, M.A., LL.D.

Professor of Natural History in the University of Aberdeen

ANDREW MELROSE, LTD. LONDON \& NEW YORK 
HM106.T5 1921 


\section{PREFACE}

THIS book is a vindication of the thesis that Science 1 is for Life. Its central idea is that a new freedom may be reached by bringing more brains, as well as more good-will, to bear on "the relief of man's estate" and the enlargement of everyday life. By the application of Science to practical problems Man can get rid of many hindrances that slow his progress-which, in its higher reaches, means the fuller realisation of the True, the Beautiful, and the Good. Our hope is that the book may make it more vividly clear that increased biological knowledge implies increased possibilities of controlling life. The biological control of life is indeed to the theory of organic evolution as works to faith. But what is here illustrated with particular reference to Biology holds true also in regard to the other sciences.

The hopefulness of our outlook and the contribution the book makes to a theory of progrcss may seem to some to be sanguinc; we submit, however, that our position is that of a sound scientific meliorism. In any case, the book contains a rcadily intelligible introduction to a study of questions which must be faced by every educated citizen-questions in regard to our 
natural inheritance, the correlation of 'nature' and ' nurture,' the general biology of health, the individual life-history, the changes in population, and the factors in man's evolution.

\section{J. Arthur Thomson.}

UNIVERstTy of ABERDEen,

January, 1921. 


\section{CONTENTS}

CHAP.

PAGE

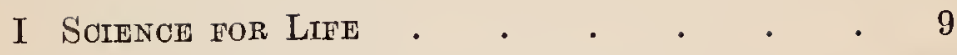

II The Biological Control of Life • . 30

III Our Natural Inheritance . . . . 45

IV The Influences of Nurture . . . . 82

V The Biology of Health . . . . . 123

VI The Individual Life Cycle • . . 158

VII Population Problems . . . . . 190

VIII The Kingdom of MaN . . • . . 222

IX Progress in Evolution . . . . . 256 



\section{CHAPTER I \\ SCIENCE FOR LIFE}

$\S 1$. What is Meant by Science.- $-\S 2$. Scienco and Human Life.- $\S$ 3. The Dangers of Short-sighted Utilitarianism. - $\$$ 4. The Higher Services of Science to Human Welfare.$\S$ 5. The Larger Ends.

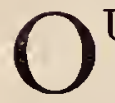

UR age is marked by two very strong tendenciesthe democratic and the scientific. Some keywords of the democratic tendency are 'liberation,' ' solidarity,' ' participation,' ' equal opportunities.' Some key-words of the scientific tendency are 'accuracy,' 'verification,' 'systematization,' 'control.' Secure progress in the years ahead will in great part depend on increased interaction between these two powerful tendencies, - that democratic movements become better informed and more thoroughly imbued with the scientific spirit, and that scientific interests be increasingly socialized and directed towards the relief of man's estate.

\section{§1. What is Meant by Soience}

Ever since man began to find himself, he has been applying knowledge to the securing of wealth and 
health; the foundations of agriculture and medicine, for instance, are pre-historic; and there is no clear line to be drawn between the empirical and the scientific stage. But what is distinctively modern is the idea of an all-round utilisation of Science as a basis for action, the determined attempt to substitute the rational for the empirical, the growing habit of focusing scientific inquiry on practical puzzles, the recognition of scientific investigation as an agency likely to produce well-being as well as enlightenment. Our present thesis is, that Science can do far more for human life than it has hitherto been allowed to do or asked to do.

In illustrating this thesis we do not take any narrow view of Science. For we mean by Science-all systematised, verifiable, and communicable knowledge, reached by reflection on the impersonal data of observation and experiment. Science is precise, co-ordinated knowledge about all of reality that can be studied by recognised methods of measurement, registration, and experiment. One of the best definitions is that given by Dr. Trotter in his Instincts of the Herd- " a body of knowledge derived from experience of its material, and co-ordinated so that it shall be useful in forecasting and, if possible, directing the future behaviour of that material."

But only omniscience could draw a circle including all scientific knowledge and excluding all else. Different orders of facts are unequally amenable to measurement, experiment, and other scientific methods. For this reason, and for historical reasons, the Sciences 
differ greatly in their degree of development, in the exactness of formulation which they have received, and in the possibilities that they afford for prediction. Contrast gravitational astronomy-wellnigh perfectwith the young science of animal behaviour; you can predict with almost perfect precision the return of $\mathbf{a}_{\mathrm{a}}$ comet, but not how the cat will jump. Yet the student of animal behaviour may be as 'scientific' as his colleagues in the astronomical observatory or in the chemical laboratory.

It is unfortunately necessary to point out that a theory which appeals to the data of science is not necessarily ' scientific.' This is a common but fallacious use of the word. To the theory that all human progress depends on the conflict of races, or to the theory that all dreams have a sexual origin, one may give more or less consideration, but to call either scientific means merely that it is not fanciful.

\section{§2. Science and Human Life}

What can Science do for Life? The answer is to be found partly at every turn in our modern day, and partly in the history of those applications of Science which have changed, or are changing, the occupations and environment of mankind. But when we reflect on what has been achieved and how it has been brought about, and when we consider some hints of incipient new controls, we see that the question is unanswerable. We cannot tell what Science may not do for Life. Before 1896 it would not have seemed rash to say: 
"This at least will remain beyond our powers, no one will ever discern the contents of a closed wooden box." But now they find the pearl in the unopened oyster and locate the bullet buried in the bone.

It was a fine epitaph that they put on the tomb of Fraunhofer, the discoverer of spectroscopy- " $A p$ proximavit Sidera"; but in how many other ways has modern science enabled man to annihilate distance. He has made the ether carry his messages; he can hear from afar the cry of the ship in distress upon the sea; he can make Niagara drive mills and illumine cities hundreds of miles from the Falls. Science has harnessed electricity to man's chariot, and added the depths of the sea and the heights of the air to his navigable kingdom. Already Science is making bread out of the thin air, working miracles in the conquest of plague and pestilence, and controlling the inheritance of generations unborn.

The late Sir William Ramsay said: "Real gain, real progress consists in learning how better to employ energy-how better to effect its transformation." It is an often told story how Science has enabled man to tap one reservoir of energy after another, and to do so with increasing economy. The less wasteful utilisation of our coal supplies is certain to be one of the great changes of the near future (1921). The raw material must be used more carefully; gas and coke must be made more economically; the by-products must be appreciated even more keenly than now; perhaps there will be more power-production in the 
immediate vicinity of the mines; these and other problems are being discussed by experts. We are almost sure to discover new and better ways of harnessing winds and tides. Experts speak of the possibility of unlocking the imprisoned sub-atomic energies of which radio-active substances have given us so impressive a glimpse, and hint that it is not an absurdity to think of drawing from the supply of energy represented by the stresses of the ether. In any case this is certain, that in the domain of things Science is giving man an increasing control of power.

It is progress, we suppose, to make in considerable quantity and economically what was previously procurable in small quantity and wastefully. Thus the Tyrian purple of the sea-snail is replaced by a similar product of coal-tar. But far more important is getting nitric acid and ammonia by tapping the free nitrogen of the atmosphere. In 1892 Sir William Crookes showed that a strong electric current passed through air produced nitrous and nitric acids, and this was the beginning of the fixation of nitrogen which has been developed in many countries on a practical scale for the production of explosives on the one hand and fertilisers on the other. In Lord Rhondda's words, "If we are to feed ourselves, we must begin by securing a continual provision of the fixed nitrogen which is necessary to feed our best food, and which we can begin to make for ourselves, whenever we please." (See 3rd edition [1918] of The Wheat Problem by Sir William Crookes.) How life-saving has been the abstract 
science which has led to the new metallurgy, to the understanding, for instance, of what happens when parts of a machine suffer from 'fatigue-stress,' and to a discovery of how this may be prevented. Many illuminating instances will be found in the essays entitled Science and the Nation (Cambridge University Press, 1917).

In the realm of organisms, as in the domain of things, Science is giving man more control. Thus the progress of the science of heredity has supplied levers which can be used with great practical effect in regard to cereals, root-crops, and fruits, cattle, sheep, and poultry. To the interesting problems of forestry, which are of great importance from the occupational as well as from the economic side, the methods of genetics and bionomics have only begun to be applied. Professor Oliver and others have shown how 'waste places,' like sandy heaths, pit-heads, and salt marshes, may be made profitable. (See The Exploitation of Plants. Edited by F. W. Oliver. London, 1918.) And there are many other points d'appui. It may be that some discovery in biochemistry will change the whole economic problem of food-supply.

In the next chapter we shall illustrate other aspects of the rapidly growing biological control of life. Here it must suffice to mention the conquest of many microbic or parasitic diseases, from malaria to bilharziasis; the development of serum therapeutics, so important in connection with diphtheria and tetanus; the utilisation of the secretions of the ductless glands of other organisms 
to supplement deficiencies in our own; and the beginning of the application of the young science of Psychobiology to very subtle problems of life.

§3. The Dangers of Short-sighted Utilitarianism

To apply the results of scientific inquiry to the amelioration of human life is certainly the trend of evolution, and to focus scientific intelligence on practical puzzles is obviously common sense. Yet there are many who shake their heads over making a definite policy of 'Science for Life.' Their objections are, (1) that the advances that count in the long run are made by Pure Science, pursued for its own sake; and (2) that preoccupation with, and glorification of practically useful results suggests, especially to the careless, an entirely wrong view of the aim of Science.

There is no doubt that the chief end of Science is Understanding. Its aim is intellectual,-to describe things and occurrences, co-existences and sequences, as completely as possible, as simply as possible, as consistently as possible. This endeavour leads to the discovery of order, uniformity, inter-relations, and chains of sequence which are systematised in formulæ and laws. "If this, then that," is what Science is always saying. It aims at thought-models, common denominators, unifications; it seeks to reduce the obscure, the discrepant, the anomalous. Now, if the end of Science be Understanding, Science for light 
rather than for life, is there not danger in bringing the criterion of practical value into prominence? Will not the democratisation of Science tend to stop the unfolding of its finest flowers? A picture painted to tell a story is apt to be bad art; a novel written as a piece of propagandism is likely to be bad literature ; and so, they say, scientific investigation pursued with a directly utilitarian end in view is apt to defeat itself. Now, a reference to the history of Science makes it quite plain that the kind of questioning which is rewarded in the first instance by illumination is also the surest and sometimes the shortest road to increased practical mastery. The quiet thinkers in the scientific cloisters are often, like the poets, "the makers and shakers of the world." Professor A. N. Whitehead remarks :" It is no paradox to say that in our most theoretical moods we may be nearest to our most practical applications." It is admirably shown in Sir R. A. Gregory's Discovery, that wireless telegraphy, the telephone, aeroplanes, radium, antiseptics, antitoxins, spectrum analysis, and $\mathrm{X}$-rays were all discovered in the course of purely scientific and very theoretical investigation. Lord Kelvin, pre-eminent alike in theoretical insight and in practical applications, once said: "No great law in Natural Philosophy has ever been discovered for its practical applications, but the instances are innumerable of investigations apparently quite useless, in this narrow sense of the word, which have led to the most valuable results."

For eighteen centuries many great minds gave their 
lives to studying conic sections. Had this devotion any reward beyond the thrill of enlightenment? Not to speak of projectiles, the answer is given by our great bridges, by the curves of our ships, by the rules of navigation, and by much more besides. It was not for practical purposes that William Smith tramped over England exploring the strata, yet how much of the exploitation of mineral resources of many a country has had its origin in Smith's maps and their successors. Over and over again, both in peace and war, the stratigraphical geologist has saved a difficult situation. Far-reaching recent improvements in metallurgy originated, though no one saw the seed sown, in 1861, when H. C. Sorby in Sheffield began out of sheer inquisitiveness to cut microscopic sections of rocks and meteorites. When Professor William Thomson published in 1853, in the Philosophical Magazine, a stiff bit of mathematical analysis, which laid the foundation of the study of electric oscillations, there can have been few who saw in it one of the steps towards wireless telegraphy. Or perhaps we should go further back still to Lagrange, who led on to Thomson and Clerk Maxwell, as these to Hertz. As Professor E. W. Hobson writes (Science and the Nation, p. 92), Lagrange's work in purely abstract mathematics "was an essential link in a chain of investigation which led, on the practical side, to the invention of wireless telegraphy."

Pasteur's researches form an intellectual chain of which the first link was a study of molecular dissymmetry and the crystalline forms of tartrates. What would the 
Democratic Council's Committee on Biological Research have said of Pasteur's first link? Or of Darwin's earliest discovery on the larvæ of the sea-mat? At the French Revolution they executed Lavoisier, the founder of modern chemistry, saying, "The Republic has no need of Savants."

The modern treatment of cretinism and the like was founded on a very technical inquiry into the function of the ductless glands, and the modern treatment of diphtheria and plague on a very theoretical inquiry into the meaning of immunity. A few years ago zoologists were laughed at, who solemnly counted the hairs on the backs of flies and quarrelled over the specific distinctions between one gnat and another. And could there be for able-minded men a waste of time more scandalous than cutting sections of the entrails of ticks? Yet it has been this sort of knowledge of flies and gnats and ticks that has made it possible to open up tropical Africa and complete the Panama Canal. The historical facts should be weighed, for there is danger ahead. With a hastily educated democracy, naturally eager for immediate results, with a conventionally educated parliament, knowing little of what Science means, and not humble enough to learn, there will be a tendency to starve 'Pure Science,' while so-called 'Applied Science' is subsidised. But as Huxley always insisted, "What people call Applied Science is nothing but the application of Pure Science to particular classes of problems." And it must be remembered that the advance of Pure Science depends on the con- 
tinued activity of a kind of mind which has never been common, which seeks after knowledge with more than a passing love, which has vision as well as patience. The lesson of history is clear: if any really big changes are to come about, it is likely to be through discoveries in Pure Science, and the priceless people are those who have brains enough to be discoverers of Pure Science. There is, of course, nothing but good in applying the results and methods of Science to immediate difficulties and limitations; the danger is of a false valuation, of ignoring the lesson of history that, even for practical ends, it is theory that pays, and of diverting the real discoverer from the quest of understanding. No question arises as the rôle of inventors who devise some useful application of a new knowledge which the discoverers have established, but the danger is letting inventors over-shadow discoverers. A thousand people know of Marconi, for one who knows on whose shoulders the Italian inventor nimbly and with perfect fairness perched himself. Ten thousand people know of Edison, for one who has heard of Willard Gibbs-one of the greatest physicists of the nineteenth century.

What, then, shall we say? (1) The first-class makers of first-class new knowledge are so few and far between that nothing too much can be done for them. It is a tragedy that a man with a first-class mind should be hampered as regards his scientific pursuits by having only a third-class purse. On the master-minds the question of utility should never be allowed to intrude. (2) As to the second-class and third-class makers of 
second-class and third-class new knowledge, some democratisation or socialisation of their activities might be useful, especially if it came about voluntarily, not coercively. We cannot believe that every investment of scientific time and ingenuity is equally likely to yield interest affecting man's estate. Some is only quantitatively, not qualitatively new. It would be no tyranny to ask that an investigator, faced by equally attractive theoretical problems, should give the preference to those holding some promise of benefit to mankind. The democratic check on luxurious specialism would not be unjust which pressed a consideration of Spencer's epigram - "Science is for life, not life for Science." (3) It is possible to make a bogey of the danger of socialising scientific inquiry. One may be too jealous for the safety of the ark, it is not so capsisable. Bacon was right: "This is that which will indeed dignify and exalt knowledge if contemplation and action be more nearly and strictly conjoined and united together than they have been." No small part of Science, even of geometry and astronomy, sprang from tackling practical problems, and this may be expected to continue. In his interesting Janus and Vesta (1916), Mr. Benchara Branford writes: "Science ultimately sprang, and is continually springing from the desires and efforts of men to increase their skill in their occupations by understanding the eternal principles that underlie all dealings of man with Nature and of man with his fellowmen." There is an unceasing reciprocal relationship : occupations produce and stimulate science; science 
improves and creates occupations. Even the great discoverer is not likely to impair his genius by being something of a citizen; and to those of humbler rank it gives a spice to work to know that it may perhaps be of practical use to mankind. Some people speak as if it was almost a taint in a piece of work to have obvious utility; but sounder sense is talked by some of the discoverers themselves; thus Professor W. H. Bragg writes: "Pure Science may be developed by itself, but it is the gainer if its workers are alive to the inspiration which is to be found in watching its application."

Perhaps the matter may be put in another way by distinguishing between end and motive, for several great discoverers have admitted that in the background of their minds there was ever the conviction that Science is for the relief of man's estate as well as for the glory of God. Thus one of the prominent physicists of the Kelvin period, Professor Henry A. Rowland, in an address on "The Highest Aim of the Physicist," writes that while the investigator "strives to understand the Universe on account of the intellectual pleasure derived from the pursuit," he is upheld in his work by the conviction that "the study of Nature's secrets is the ordained method by which the greatest good and happiness shall finally come to the human race." Bacon said the same in speaking of the aim of Salomon's House in the New Atlantis:-"The end of our foundation is the knowledge of causes and the secret motions of things; and the enlarging of the bounds of human empire to the effecting of all things possible." 
Perhaps, however, there is more to be feared from the second risk involved in the thesis that Science is for Life-the risk of suggesting to the careless and unlearned a falsely partial criterion. Speaking of the educational value of Science, Professor Bateson has recently written (Cambridge Essays in Education): "There is something horrible and terrifying in the doctrine so often preached ... that Science is to be preferred because of its utility." Perhaps there is a bit of a bogey here too, for "science" and "utility" are both great words, no narrow meaning of which can be tolerated; and it is never for very long that man can forget that he does not live by bread alone. But the risk is undeniable, and the remedy is a continual re-appreciation of values. It was in recognition of the risk we are discussing that Bacon drew a distinction between those results of Science which are light-giving (lucifera) and those which are of direct practical utility (fructifera), and said so nobly: "Just as the vision of light itself is something more excellent and beautiful than its manifold use, so without doubt the contemplation of things as they are, without superstition or imposture, without error or confusion, is in itself a nobler thing than a whole harvest of inventions."

\section{§4. The Hrgher Services of Science to Human WELL-BEING}

We have given many illustrations of what Science can do for Life, but the thesis is wider than we have yet indicated. 
(a) There is the possibility, some would say desirability, of more definite scientific instruction in the art of life. Education is in part intended to shorten the individual's recapitulation of racial history, by enabling him, for instance, to utilise the enregistered wisdom of the ages; yet for lack of knowledge we often muddle along, making all sorts of anachronistic and gratuitous mistakes. It is idle to pretend that there is discipline in ignorantly forging shackles for ourselves. In most schools the instruction in the laws of bodily and mental health is still very far from being adequate ; in many it is still conspicuous by its absence.

In urging the consideration of this we need not fail to appreciate the fine note of William James's Energies of Men, that ideas are "dynamogenic," that an ideal or a resolve may lift a tired man for weeks on to a higher level of energy. But, granting this, we submit that Science has often a good work to do in showing how to remove gratuitous hindrances which often spoil the splendid adventures of the spirit. Carlyle would have been greater than he was if his eyes had been rightly looked after in his youth.

To emphasise the value of Science in the conduct of life, is not to be thought of as implying any depreciation of the supreme value of good-will in the widest and highest sense, or of the other than scientific springs whence good-will flows. But while Science cannot create good-will, it may help to guide it, especially in difficult situations and on the occasion of new departures where people, both old and young, often perish for lack 
of knowledge. Truly, knowledge is not virtue, but a little more of it might sometimes help a man or a community away from vice. Science will not induce a man to love his neighbour as himself, but it sometimes shows him how to do it.

(b) We must not be drawn from our thesis by the red herring of the rival claims of Science and the Humanities. This is too like making an antithesis between fresh air and meals. We need in our education both Science and the Humanities, and more of both, time for enjoying which would be readily procurable with better methods of teaching and learning, based in part on the physiology thereof. The antithesis is a false one, for the Humanities have their scientific side, and every Science has a Humanity as its halo. In his descriptions and formulations, the scientific investigator must, indeed, hold feeling at a spear's length; but if he has any bodily and spiritual leisure at all, he is bound to attempt a more synoptic view, trying, as Plato said, to take " a survey of the universe of things." The study of the magnalia Naturce is a brain-stretching discipline, but it also enriches the life of feeling.

(c) Beyond the additional control which the new chemistry, the new physics, the new biology, and so on, are giving into man's hands, there is, we have said, the enrichment of the inner life of thought and feeling. But beyond this again, in the social kingdom of man there is the slowly growing systematisation of truth, to which the contributions of Science are fundamental, though one may not call them supreme. There is like- 
wise the diffusion of a scientific mood which will insist on basing all sorts of action-personal and communal, national and international-on securely established facts. Our hope is in Science as well as in the sciences, as a way out of our traditional muddling through.

In years to come, we believe, the State will habitually and as a matter of course summon the scientific expert to her aid, an expedient which has already begun to be tried. In face of every difficult problem, the first demand will be for the facts and an understanding of them. In many cases, at present urgent, the needed counsel cannot be given, for the requisite knowledge does not exist. We need more Science. On the other hand, the extent to which already available knowledge is left unused is deplorable, and the results have been very costly. When we think of the more effective and less wasteful exploitation of the earth, or of gathering the harvest of the sea, or of making occupations more wholesome, or of beautifying human surroundings, or of exterminating infectious diseases, or of raising the health-rate, or of improving the physique of the race, or of recognising the physiological side of education, we are amazed at the non-utilisation of valuable-though confessedly incomplete-scientific knowledge. Much has been done, but it must be confessed that Man is slow to follow Science into the possession of his kingdom. Part of the reason is that we have not become accustomed, except in some directions, e.g. medical treatment, to believe in Science; but a great part of 
the reason is a deficiency of character, that we do not care enough, that we lack resolution.

\section{§5. The Larger Ends}

Some critical minds may have been thinking that all this beating of the scientific drum implies the naïve assumption that more and more Science and application of Science is necessarily for the good of mankind.

"Is it certain, for instance, that Science leads us to the truth?" One remembers how Ruskin in Fors Clavigera poured out the vials of his wrath on a Botany which showed that there is no such thing as a flower, and a Psychology which proclaimed the uselessness of the soul. The widest answer is probably to go back to where we began: that the chief end of Science is to describe things and occurrences as completely, simply, and consistently as possible, and that this is only on the way to Truth-a noble term which is best reserved for the reward of a synoptic vision. It is contrary to philosophy and to ordinary experience to believe that man can come near exhausting the reality of any order of facts by scientific methods only. In many cases in everyday life we are helped by feeling to an understanding that is beyond Science. But while Science is not Truth, it contributes certain component rays to its sunlight; and Truth apart from Science has an inconvenient way of turning into moonshine. Superstition lies in wait for the unscientific; and the anti-scientific invite it.

These applauded advances of Science that have 
given man so much mastery of natural wealth and natural power, are they really for his good? Were they not used of late to bring about the most terrifying abomination of desolation the world has ever seen? This raises a large question, but the general answer is clear. Firstly, the soundness of operations in any given field has to be judged by certain criteria relevant to that field. Thus any exploitation of physical energy that is notoriously wasteful is self-condemned. But, secondly, the soundness of operations in any given field has always to be judged in terms of values in any higher field that is affected. What is quite sound physically may be illegitimate biologically; what is admirable biologically may be ruinous socially. Ultimately, all operations have to be judged before the tribunal of the highest values-the true, the beautiful, and the good.

There is no reason to be afraid of any application of science if the end be a better kind of life. There is no reason to be afraid of organisation as such as long as it leaves man free, and as long as its end is more than productivity, and more than comfort. There is no reason to be afraid of harnessing Science to the chariot of civilisation if the end be the liberation of the spirit. We shall return to this in the last chapter.

\section{In Conclusion}

Hear, then, the conclusion of the whole matter. Many of the shadows that blot out the sun and many of the stumbling-blocks that trip us up are quite gratui- 
tous, and may be got rid of when Man pleases, leaving him more free for higher adventure. "Many evils," said Maarten Maartens, "are not of God's appointing, but of man's approving." Science can bring about great amelioration in the domain of things, in the realm of organisms, and even in the kingdom of Man. Our hope is that action will be increasingly based on scientific facts, and that the habit of mind which insists on this will spread. For knowledge is foresight, and foresight is power.

It has bcen said that there are two main views of this world of ours, that which regards it as a swamp to be crossed as quickly as possible, and that whick regards it as a marsh land to be reclaimed. There is no doubt which is the scientific view. Man must continue the long-drawn-out struggle against inhibitions and limitations-the campaign which living creatures have been engaged in for millions of years; he must press on in the cndeavour to bring the inorganic into the servicc of the organic, to bring the body-mind into subordination to the mind-body, to liberate individuality in the bonds of neighbourliness; he must seek to eliminate the disorderly, the ugly, the discordant, the involutionary at each and every levcl; he must try, not despairing of his weaknesses, to lean his weight on the side of the integrative or evolutionary.

Professor John Dewey dcclared the other day that " the future of our crvilisation depends upon the widening spread and deepening hold of the scientific habit of 


\section{SCIENCE FOR LIFE}

mind." We should be inclined to broaden the dictum, but in hoc signo laboremus. In the diffusion of the scientific mood and habit of mind there is great hope. Without it we shall go on as before, pathetically like the coloured gentleman who averred that he did not know where he was going, but that he was on his way. Another modern philosopher, Professor L. T. Hobhouse, has declared that the mundane goal of the evolutionary movement is "the mastery by the human mind of the conditions, internal as well as external, of its life and growth." And so it appears to us, though for " mind" we should read " organism." In other words, it is Man's part to continue building up a scientific systematisation of knowledge which will increasingly form the basis of a control of life. For Life is not for Science, but Science for Life. 


\section{CHAPTER II}

\section{THE BIOLOGICAL CONTROL OF LIFE}

$\S 1$. The Idea of Evolution. - $\S 2$. The Idea of Controlling Life.$\S 3$. Illustrations of the Control of Life.- $\$ 4$. Faith in Science.

\section{§1. The Idea of Evolution}

$\mathrm{O}^{\mathrm{NE}}$ of the biggest intellectual legacies from the nineteenth century was the theory of Organic Evolution. By this is meant not only the general idea that the present is the child of the past and the parent of the future, but the conviction that the plants and animals of to-day have arisen from an antecedent realm of plants and animals of (on the whole) rather simpler type, and that the change has been brought about by a co-operation of definite natural processes, such as varying and sifting, comparable to processes which can be seen going on to-day. The realm of organisms has had a history, but, more than that, a natural history which is in its essential features still continuing and therefore observable. It is true, indeed, that we do not as yet know much about the causes of varying among living creatures, but we are sure that variations crop up frequently in 


\section{THE BIOLOGICAL CONTROL OF LIFE 31}

wild life, and that they are subject to subtle sifting in the struggle for existence. This is a theory of evolution clear enough to be going on with. It is a theory in terms of factors which are verifiable to-day and open to experimental study. Now, this theory of evolution must, of course, apply to Man, who is no ' Grand Exception '; and in this special case, just as in general, there are two propositions. In the first place, Man is an antique, the long result of time, the outcome of a complex pedigree. He is solidary with the rest of creation, though also strangely apart. He is affiliated to mammals, though "in apprehension how like a god." In the second place, Man has a natural history behind him, and, ignorant as we are, it is possible to say something clear and firm in regard to the factors in the great ascent. Man's precise origin is hidden in obscurity, but we know in a general way the pit whence he was digged and the rock whence he was hewn-namely, the Primate or Simian stock of mammals. We cannot tell with any precision how he won his way upwards, but we have more than glimpses of some of the factors, and the inquiry-still very young-is full of promise. Both for Man and for the whole realm of living creatures, two things are practically certain : first, that the present has grown out of the past in a continuous way, with jerks now and then, perhaps, but with no gaps; and, second, that some of the factors in the process have been discovered, that more are likely to be discovered, and that those we know have their counterparts in actual operation to-day. 


\section{§2. The Idea of Controlling Life}

For ages before Darwin's day, it had been the practice of shrewd men to look out for 'sports' among dogs and horses, pigeons and poultry, and so on ; or for 'novelties' among apples and roses, cereals and cabbages, and so on. These sports and novelties, whose origin still puzzles the biologist, were used as the starting-points of valuable breeds of animals and varieties of plants. The secret of domestication seems to have been lost, though it may be that the number of domesticable animals was never large; but the practice of improving breeds and making new breeds of domesticated animals has been for a long time familiar, as in the case of cattle, horses, sheep, dogs, and poultry. Additions to the number of cultivated plants have continued into modern times and the improvement of old-established races has never ceased.

But the theoretical side of this control was slow of being discerned. There was no vivid realisation of the fact that all the aristocrats of the apple-orchard are the descendants of the sour plebeian crab-apple of the wayside, or that all the quaint fantails and pouters, turbits and tumblers of the dovecot are the descendants of the rather conventional rock-dove (Columba livia) of the shore-cliffs. The significance of what cultivator and breeder had achieved was not appreciated till it was seen in the light of Darwin's generalisation, that the present has evolved from the past, that the factors in the process are discoverable and like those in operation now. In the light of this, it could not but occur to 


\section{THE BIOLOGICAL CONTROL OF LIFE}

thoughtful minds that if the evolution of domcsticated animals and cultivated plants can be controlled-in proportion to our discernment of the factors-the same must hold good in some measure at least for the futurc evolution of Man. Thus arose a new idea, or an old idea in a new form,- the scientific or biological control of life. This practical idea of control is the outcome of the theoretical idea of evolution, and it is an incipient characteristic of the age in which we live.

It is true, of course, that medical practitioners had been controlling life since the times of Hippocrates, that educationists, moralists, and religious teachers had been working for ages towards a firmer control of life, but the modern idea is rather different. Its view of Man's nature is wider than that prevalcnt in medical practice; thus it considers not the individual only, but the race or stock as well. It differs from educational, ethical, and religious control in bringing to bear on the problcm of Man's bctterment the resources of the modern scicnce of biology and the encouraging stimulus of the idea of evolution-which, though of ancient origin, had not gripped men's minds before modem times. There were indeed glimpses of it, as when Bacon wrote in rcgard to Salomon's House in the New Atlantis: "The end of our foundation is the knowledge of causes and the secret motions of things; and the cnlarging of the bounds of human empire, to the effecting of all things possible." And again in a famons passage in The Advancement of Leaming he said: "This is that which will indeed dignify and exalt 
knowledge if contemplation and action be more nearly and straitly conjoined and united together than they have been; for men have entered into a desire of learning and knowledge, sometimes upon a natural curiosity and inquisitive appetite; sometimes to entertain their minds with variety and delight; sometimes for ornament and reputation; and sometimes to enable them to victory of wit and contradiction; and most times for lucre and profession; and seldom to give a true account of their gift of reason to the benefit of man; as if there were sought in knowledge a couch whereupon to repose a searching and a restless spirit; or a tarasse for a wandering and variable mind to walk up and down with a fair prospect; or a tower of state for a proud mind to raise itself upon; or a fort or commanding ground for strife and contention; or a shop for profit or sale; and not a rich storehouse for the glory of the creator and the relief of man's estate." The idea of using knowledge for "the relief of man's estate" is the idea of the scientific control of life; but in Bacon's day the available biological knowledge was scanty, and the evolution clue was not in Man's hand.

Now just as the theoretical advance implied in the theory of evolution is fitly and conveniently associated with the name of Darwin (though there were other pioneer evolutionists), so the idea of the biological control of life may be fitly associated with the name of Pasteur. He was neither a breeder nor a cultivator, neither an evolutionist nor a eugenist, in the ordinary sense, but he was the sublime peasant who tamed and 
cultivated Bacteria and made them serve his purposes; he gave us the secret of the conquest of many kinds of diseases, and he had a Darwin-like appreciation of the subtlety of inter-relations in the web of life.

Darwin had shown that the forms of life which seemed so stable were in process of racial flux-though the change might be as imperceptible as the movement of a glacier. The individual, moreover, was shown to be plastic (technically, modifiable) for better or for worse, under the influence of changed surroundings and changed habits, both in the way of use and in the way of disuse. Thus the whole aspect of things was changed. The outlook became vividly dynamic, and the idea of the controllability of life began to grip. If flowers and pigeons can be controlled so effectively, then why not human life also? If Man can evolve out of some sort of wolf the domesticated dog, the dependable guardian of the flocks, may he not hopefully try to evolve the wolfish out of himself? Are there not organic shackles which may be dealt with biologically, setting Man free for higher adventures? When men were asking such questions, usually in a half-convinced way, Pasteur began a series of achievements which were inspired by the idea of the biological control of life. Beginning with the silkworm disease, which was ruining the South of France, he advanced to such terrible maladies as splenic fever and hydrophobia, conquering by understanding. With object-lessons on a grand scale he convinced all intellectual combatants who cared to understand that the days of fatalism and folded hands 
were over, and that it was for Man, with Science as torch, to enter bravely into fuller possession of his kingdom.

\section{§3. Illustrations of the Control of Life}

Speaking of cockchafer-beetles and the local famines which their ravages sometimes brought about in bygone days, Professor A. Giard recalls the fact that they used to be dealt with by ecclesiastical, not by scientific authority. "In 1479 they were summoned before the ecclesiastical tribunal of Lausanne and defended by an advocate from Fribourg. After deliberation, they were banished from the territory. O tempora!" This may serve as a diagrammatic, and thcrefore extreme, illustration of oldworld methods, in which the control of life was attempted, but not along the lines of scicnce.

Another phase, still extant a few years ago, may be illustrated by reference to locust plagues in South Africa. The critical moment in dealing with these voracious insects, which find a countryside a garden and lcave it in a few days a desert, is while they are still wingless foot-passengers. They travel in great hordes, but if concerted opposition is organised they can be destroyed in millions by digging moats and by other methods. Thus the crops may be saved and the multiplication of the locust race checked. Everything depends, howevcr, on concerted action, on sending word of the approach of the locust infantry, and on forming something equivalent to a barrage to stop their offensivc. This can be donc effectively; yet only a 
few years ago quite a number of religious and worthy Boer farmers-unconsciously impious-refused to join in with the Anti-locust league, giving for their reason that it was attempting to stay the hand of God. So did some religious people in Scotland protest against the use of chloroform in childbirth.

The definitely modern phase may be illustrated with reference to the checking of malaria. This disease, whose name, meaning bad air, takes us back to the days before it was understood, is due to a microscopic animal (Plasmodium) which was demonstrated by Laveran (1880) in the red blood corpuscles. The parasite forms spores in the corpuscles, and these spores are set free in the blood, their behaviour corresponding to the patient's chills and fevers. In 1894 Grassi showed that part of the life of the malaria parasite is spent within the mosquito, and the details of the story are complicated. By their bites the mosquitos become infected and by their bites they also infect. In 1898 Ross proved that fogs and vapours and marshes are merely of indirect moment in producing the disease, which can only be acquired if an infected mosquito introduces some of the parasites into man. If man can protect himself, with mosquito-curtains or the like, from mosquitobites, he protects himself ipso facto from malaria. Moreover, the larval mosquitos live in water-pools, and have to come to the surface to breathe. If a little petrol be poured on the pool, it forms a surface-film to which the breathing-tube of the larval mosquito cannot adhcre. Thus the young mosquitos are suffocated 
and malaria is checked. The success of this method has been dramatically illustrated in connection with the making of the Panama Canal and on a smaller scale around places like Khartoum. Now, the point is, that this method of controlling life was discovered by turning scientific investigators on to the problem, and by basing practical action on the facts discovered.

The same kind of story might be told in regard to some other diseases. Thus at the beginning of the twentieth century Walter Reed showed that a mosquito called Stegomyia fasciata carries the virus of yellow fever. Bitten people die, whilst those who used their bedding but were not bitten did not take the disease. Similarly Bruce showed that the tsetse fly is the carrier of the microscopic animal (Trypanosoma evansi) which causes sleeping sickness, from which 200,000 may die in one year.

Among the most troublesome of human parasites are the hookworms, insidious Nematodes which are able to make their way through the skin, and are very common in many warm countries. One kind especially affects miners, for the moisture and high temperatures of underground workings are favourable to the development of the hookworm eggs which are excreted from man. A knowledge of the life-history of the parasite has led to the suggestion of measures to prevent the pollution of water and soil, and, thanks in great part to the American Rockefeller Foundation, the disease has been brought under control. The first step is to kill the worms in the individual patients; the second is to prevent 


\section{THE BIOLOGICAL CONTROL OF LIFE 39}

pollution of the soil so that the microscopic parasites may not be there to continue the infection. In some mining areas the number of victims has been reduced in twelve years (1902-1914) from 25 to 3 , or $22 \cdot 8$ to 1.2 per cent., which are eloquent figures.

One of the striking features of the early years of the twentieth century has been the progress in the experimental study of heredity. It received a great stimulus in 1900 with the rediscovery of Mendel's epoch-making investigations, which had been strangely lost sight of since their publication in 1865. A clue has been put into the hands of breeders and cultivators, which has enabled them and will increasingly enable them to contribute to the betterment of man's estate -as far as his domesticated animals and cultivated plants are concerned. From Professor James Wilson's admirable Manual of Mendelism (1916) we take two or three illustrations.

The average yield of wheat in Britain is about 32 bushels to the acre. Professor Wilson tells us that it might be raised to 40 or even 50. "For every day by which the life of a variety of wheat is shortened between seedtime and harvest, the wheat-growing area in Canada reaches fifty or sixty miles farther northwards. A vigorous, early ripening and highly productive oat, together with a turnip having the same characters, might increase the returns from many a northern or high-lying farm in Britain and might even be the means of causing many a pasture field to revert once again to the plough without the artificial and precarious 
stimulus of a protective duty." "The work done in Denmark shows how the wealth of our country [Britain] so far as it proceeds from dairy cattle might be nearly doubled." These are but diagrammatic examples of the kind of progress which the practical application of Mendelian methods might immediately realise.

We take another illustration from a lecture by Professor William Bateson, one of the leaders of experimental inquir: to the physiology of heredity and variation, a stids: now spoken of as genetics. "No practical dog-breeder or seedsman can see the results of Mendelian recombination without perceiving that here is a bit of knowledge he can immediately apply. No sociologist can examine the pedigrees illustrating the simple descent of a deformity or a congenital disease, and not see that the new knowledge gives a solid basis for practical action by which the composition of a race could be modified if society so chose." And again :- "If we want to raise mangels that will not turn to seed, or to breed a cow that will give more milk in less time, or milk with more butter and less water, we can turn to Genetics with every hope that something can be done in these laudable directions. But here I would plead what I cannot but regard as a higher usefulness in our work. Genetic inquiry aims at providing knowledge that may bring, and I think will bring certainty into a region of human affairs and concepts which might have been supposed reserved for ages to be the domain of the visionary." Professor Bateson here alludes to the change of outlook that must follow the demonstration that this 
or that human characteristic is transmitted to offspring according to definite predictable rules.

Another illustration may be taken from a very different field. For many years scientific attention has been directed to the puzzling occurrence of dull, dwarfish children called 'cretins,' who are sad failures in their main business of growing up. After many years of inquiry it was discovered that the common feature in these defective children from different places and different races was an imperfect development of the thyroid gland or 'throat-sweetbread'-a small paired organ which lies beside the larynx or Adam's apple and furnishes to the blood passing through it an indispensable internal secretion or hormone. This small organ, which certainly does not look as if it were of much importance, is essential to the health and normal development of both body and mind. This knowledge gained, the practical application speedily followed. It was found that the cretin children, and others tending in the same direction, could be rescued by giving them, as part of their food, the thyroid glands of sheep. As Sir William Osler, one of the masters of modern medicine, put it, "The results as a rule are most astounding-unparalleled by anything in the whole range of curative measures. Within six weeks a poor, feeble-minded, toad-like caricature of humanity may be restored to mental and bodily health. The skin becomes moist, the pulse-rate quickens, and the mental torpor lessens." And this is not an isolated instance of medical magic. 


\section{§4. Fatth in Science}

Obvious common sense it seems, when confronted with difficulties and limitations, to get at the facts, to work at them till they are understood, and then to apply in practice the science thus gained. This is what man has always been doing in a rough and ready way in his primary occupations, as hunter, shepherd, gardener, fisher, and so on. Out of the practical lore there has evolved the criticised, systematised, communicable knowledge which we call Science. Up to a certain point and along certain lines men believe in this science, and do not dream of dispensing with its aid. To build a bridge or a ship, to make a dam or a canal, to fashion a lens or a big gun, without utilising the available science is reckoned madness; why, then, does one require to plead for more scientific control of life?

The answer is threefold. (a) In the first place, the sciences that are relevant to the control of things are much more advanced, much more exact, much more reliable than those that are relevant to the control of life. It is not merely that they or their foundations are older; it is that the material is more readily subjected to an analysis which for practical purposes (though perhaps not for philosophical purposes) has attained or can attain to a high degree of exhaustiveness. It is easier to predict the movements of a comet than those of a cat. (b) The second reason is that in dealing with living creatures and with himself, it is temptingly easy for man to muddle along. The farmer 
may not be getting out of the soil anything like what the application of scientific agriculture would makc possible; but crops are forthcoming, and in prosperous times they may suffice. Necessity is the mother of invention, and when men of certain temperaments are getting along comfortably without applying much science, they prefer to let things be. When the pinch begins to be felt, a belated appeal is made to Science. (c) The third reason is to be found in a strange distrust of new ideas, for the idea of actively directing human evolution in the light of Science must still be called new. In face of a difficult human problem it will occur to many to lend a helping hand and to put energy, enthusiasm, good-will, tears, and prayers into the business, but it still occurs to few to put scientific inquiry at work. Legislation, coercion, personal persuasion, religion will all be tried, before scientific investigators are sct to work to get at the facts, to win an understanding of them, and to bring this understanding and previously established science to bear on their control. The appointment of commissions is, of course, a familiar device, but these are not of themselves of avail unless they include an adequate representation of men accustomed to scientific inquiry, and unless the finding scientifically arrived at is effectively put into practice.

The non-scientific view of life inevitably leads to fatalism, which a doctrine of providential interventions is often invoked to relieve. We find this old-fashioned view of extrinsic evils lying in wait to destroy the life which deserved a better fate, vividly expressed in the 
reverie of the hero of Turgenev's Torrents of Spring. "He did not picture life's sea, as the poets depict it, covered with tempestuous waves; no, he thought of that sea as a smooth, untroubled surface, stagnant and transparent to its darkest depths. He himself sits in a little tottering boat, and down below in those dark oozy depths, like prodigious fishes, he can just make out the shapes of hideous monsters : all the ills of life, diseases, sorrows, madness, poverty, blindness. $\mathrm{He}$ gazes; and behold, one of these monsters separates itself off from the darkness, rises higher and higher, stands out more and more distinct, more and more loathsomely distinct. . . . An instant yet, and the boat that bears him will be overturned. But behold, it grows dim again, it withdraws, sinks down to the bottom, and there it lies, faintly stirring in the slime. . . But the fated day will come, and it will overturn the boat."

Times and ideas are changing, however, and there is a broadening recognition that Science is for Life, not Life for Science. Even the philosophers have begun to tell us with their wonted clarity that the systematisation of knowledge for the evolution of a more perfect society is Man's supreme duty. 


\section{CHAPTER III \\ OUR NATURAL INHERITANCE}

1. The Three Fates.- $\S 2$. The Elements of Our Inheritance.- $\$ 3$. Fundamental Facts of Heredity.- $\$ 4$. Recent Advances in the Study of Heredity.- $\$ 5$. Different Modes of Inheritance.- $\S 6$. Statistical Study of Heredity.- $\$$ 7. Inheritanee and Disease

\section{§ 1. The Three Fates}

A $\mathrm{S}$ far as biology is concerned there are three A determining factors in life. First and forcmost there is our flesh and blood relation to parents and ancestors (Heredity); second, there are all sorts of surrounding influences (Environment), along with which may be included opportunities; and third, there are our habits (Function), both positive and negative, doing and not-doing-for sluggishness moulds the body as surely as strenuous exercise. As all the three factors-we may say Three Fates-are powerful and always operative, it is not very urgent to argue about the order of their importance. Men cannot make bricks without clay-that is, the natural inheritance. Neither can they make them without heat-that is, the environmental factor. A living creaturc cannot realise its initial self, i.e. its inheritance, without ac- 
tivity or exercise, without food, or without the stimulus of appropriate surroundings, but the way in which the creature uses the influences that play upon it, the way in which it girds up its loins to work or lets itself go in play, is in part determined by what it owes to parents and ancestors. In part, not wholly; and that for two reasons: first, because peculiarities in the circunstances count for something in themselves, being often provocative to effort and often deadening in their dullness; and second, because each new creature, while owing everything to the past, has in some measure an individuality of its own and thus an element of unpredictability.

Here we touch one of the most difficult of intellectral problems, the harmonising of facts which point to determinism with facts which point to individual freedom of action, but all that we need notice at present is that a child is often very obviously a distinctive personality that cannot be accounted for in any rough-and-ready way as the necessary resultant of component factors observable in its parents. It is a familiar fact (not difficult to explain) that brothers are often very dissimilar in nature. It is also well known nowadays that a pair of grey mice, the oftspring of a grey father and a white mother, will have in one litter both grey and white progeny. But there is a broader fact-the likelihood that the young life will be in some measure a new pattern, a fresh unification, an individuality. Variability is a big fact of life. Moreover, it is of fundamental importance in human life to understand 
clearly that whenever we begin to trade with our surroundings (and who shall say how early that begins?), to adjust ourselves actively to our environment, to play the great game, we build new elements into ourselves, so that next time we act not only because of our hereditary nature, but also because of what we have ourselves made of it. This is particularly true of Man, because of his fine brain and strong social predispositions, but it is also true of dog and of starfish.

The fundamental thing is the natural inheritance, by which is meant everything that, in some way inconceivable to us, lies implicit in the fertilised egg-cell. There, in a microcosm whose outlines alone are visible, our inheritance lies latent, and the quality of it, whether rich or poor, depends on parental and ancestral contributions, though the unification of these sometimes yields, as we have said, unexpected and unpredicted results. For while great geniuses are rare, minor geniuses are not uncommon.

But though the foundations of our constitution are laid down for us by our relation to parents and ancestors, the outcome depends on the way in which we-the unified organisation-relate ourselves to air and food, sunshine and rain, work and play, exercise and rest, and to the social heritage which is registered in institutions and traditions, literature and art, and the framework of society itself. The number of talents we get to start with is settled beforehand, but it is within limits open to us to increase their value by trading. The living creature or organism is a concrete reality 
before our eyes; so is the complex of external influences which we eall the environment; function is a general term for the actions and reactions between them, and for the internal aetivities sueh as the beating of the heart and thinking which go on without obvious stimulation from outside. Sometimes the organism acts on its surroundings in a masterly way, as when beavers cut down trees and build dams; or when a sheep devours part of its environment, namely, the grass; or when a liehen eats into the surface of the roek. This might be represented by the formula, as Professor Patriek Geddes suggests, $O \rightarrow f \rightarrow e$. At other times the environment seems to get the upper hand, impressing changes upon the organism, inciting it by warmth to more rapid ehange or slowing down by eold the vital proeesses, now indueing change of colour and again effeeting deeper dints. This might be represented by the formula $E \rightarrow \dot{f} \rightarrow 0$; and thus we reach Professor Geddes's useful idea, that living is a continual adjustment of a twofold dynamic relation: $\frac{O \rightarrow f \rightarrow e}{0 \leftarrow f \leftarrow E}$. In a dry seed that has been lying for several seasons in the granary, in a desiccated paste-eel that has remained in a state of latent life for years, the twofold dynamic rclation has stopped altogether or is so near interruption that no evidenee of its persistence can be found. But the organisation that makes living possible has not disappeared, as is easily proved by planting the hard seed in the ground or by surrounding the brittle paste-eel with water. 
It is unnecessary to linger any longer over preliminaries, provided it be clear that it is only for purposes of convenience that we can separate off organism, inheritance, environment, and function. An organism cannot live without an environment; function is action and reaction between organism and environment; the organism and its inheritance are, to begin with, one; heredity is the organic relation between a creature and its ancestry. All this is biologically commonplace; we separate off these 'aspects' for convenience of study. But the trouble is that when we pass to the problems of human life we either ignore the biological fundamentals altogether, and imagine, or act as if we imagined, that human children can be rightly reared in inhuman environment, or we lay emphasis on one factor, and make a fetish of it, out of relation to the others, as when we say that if we could only put an end to this or that pernicious function then all would be well with mankind. The condonation of the second error is that different aspects of betterment appeal to different minds and that few people can do more than one thing at a time. None the less we must bear in mind that the realities are living creatures acting and reacting in certain surroundings, and not only affiliated to ancestors but responsible for descendants.

\section{§2. The Elements of Our Inheritance}

Inheriting suggests an heir and a legacy, but our inheritance is at first the whole of us. As will afterwards become clear, it is not very accurate to continue 
using the convenient phrase that a parent transmits gifts and blemishes to his offspring. For parents are not so much the immediate producers of children as the custodians or trustees of germ-cells which develop into children.

It is natural to ask : What makes up our inheritance? and modern investigation has begun to answer the question. (a) Within the circle of the normal, we all start with a stock of old-established human characters which exhibit little essential change from generation to generation. Thus every child has a certain structure of heart or lung, of brain or eye, which is characteristic of mankind, which is not departed from in any essential way except on rare occasions. Many of these fundamental characters have their counterparts in all ordinary backboned animals, every type having them, but having them in some distinctive form. Thus part of our inheritance includes a backbone, a structural item of inconceivable antiquity; but what we have is not only a backbone, it is a mammal's backbone. More than that, it is a Primate backbone; more precisely still, it is a humanoid backbone-that and nought else. Or again, while mon differ greatly from one another in wits, every child has as part of its inheritance a brain, and this is not merely a Vertebratc's brain, it is a Mammal's brain, a Placental Mammal's brain, a Primate brain, a humanoid brain, and in all ordinary cases a brain characteristic of the ' modern man typc.' There are between man and man great differences in the relative size and weight of the brain in proportion to the body; there are 
differences in the minute details of the brain; there are differences in the rate at which the brain works, and so on; but, barring accidents, there are no differences in the general architecture of the brain. And so for other parts. Thus we may picture in every human inheritance a sort of fundamental organisation which has ceased to show more than detailed variations.

Along with the common stock of human organisation there is, of course, a common stock of human capacities. The two aspects of form and function, structure and activity, are inseparable. Just as all ordinary mammals have a capacity for being 'warm-blooded' (i.e. regulating production and loss of heat so that an approximately constant temperature is sustained), and a capacity for profiting by experience, so all normal human beings have a capacity for speech and a considerable capacity for intelligent inference. The Zulu, a fine physical type, is alert, quick to put two and two together, shrewd within the limits of his knowledge and interest, but not much given to poetry or philosophy. Experiments in education have shown, however, that in the Zulu, and in similar cases, the imaginative and reflective capacities are there all right. One may say that the power of intelligent inference is a universal human character, part of the common stock of heritable qualities, though it varies greatly in its expression according to educational opportunities, according to the general pitch of the life and according to diversity in the more superficial and variable elements in cerebral endowment. The same 
holds in regard to capacities for making pictures or imagery, remembering and associating these, for building up general ideas or concepts, and for relating these experimentally to one another. Again it seems legitimate to say that our common human inheritance includes a number of fundamental appetites and instincts which we share with all our fellows. Here, more than in the field of intelligence, we recognise the touch of common nature that makes all mankind kin. Among the fundamental appetites are such as hunger and love: Among the fundamental instincts are such as the selfpreservative instinct to avoid danger and resist assault ; the maternal instinct to care for offspring; and the herd instinct or kin instinct leading to gregariousness and solidarity. These instincts are very generalised in contrast to the particularised instincts of, say, ants and bees, for intelligent control has in big-brained organisms taken the place of instinctive guidance. In Man, in particular, the old-established hereditary. instinctive predispositions have an impulsive rather than a directive rôle. The great difference between man and man as regards instinctive predispositions is in part due to the fact that the instincts are nowadays in great part under-currents in Man; they have to work their way up through upper currents of controlled thought which differ greatly with individuals. In this connection a middle course must be found between ignoring the part which the instinctive under-currents play in human life and depreciating the controlling efficacy of thoughtful consideration. It seems that all 
normal human beings have these fundamental instincts. Even St. Anthony does not get away from sex-impulses, and the call of kinship echoes in the hermit's cave. Many 'old maids,' as they are called, are supremely maternal, and the crusty bachelor has often a love of children that even a philoprogenitive father might envy. The possibility of shunting, transforming, symbolising, transfiguring instinctive impulses which are not directly satisfied, is well known; and it strengthens our faith in our humanity that while the thwarting of fundamental instinctive impulses may lead to morbid repression, it sometimes leads to ennoblement. The psychical inheritance includes, besides intellectual capacities and instinctive predispositions, an emotional endowment. This expresses itself in such emotions as courage and fear, joy and sorrow, sympathy and jealousy. The æsthetic emotion is a good example of a hereditary human character varying greatly in intensity and refinement, but practically universal. ?

(b) Rather different from the old-established bodily and mental characters which we may almost call specific characters of Homo sapiens, there are features or traits of a less fundamental, more superficial sort, of later evolution, such as the colour of the eyes, the shape of the nose and the ear, the proportions of the lips, the kind of hair, the type of hand and so on. The general specific organisation is very constant, but the minor features differ greatly from race to race, from stock to stock, just as the decorations on a series of buildings may be diverse though the general 
architectural style or plan is the same in all. Some of the minor fcaturcs which are crisply defined bchave in a rcmarkable way in inheritance, refusing to blend with corresponding but contrasted characters. They are continuous from one generation to another, appearing in more or less intact expression in a certain proportion of the offspring, and being quite absent from others. They behave like entities, as if (in typical cases) they could neither be split up nor blended. They have been compared to chemical radicles (e.g. $\mathrm{NH}_{4}$ ) which can enter into many different associations, but behave as unities. Such characters are called 'unit-characters' or Mendelian characters. Recent work has shown that many of our more superficial characters are of this nature. We are in some measure composed of strands of ' unit-characters,' a familiar instance being the colour of the eye. It is possible that the stable fundamental block of the inheritance (the specific hereditary organisation) is made up of a very large number of coherent unit-characters firmly linked together. To some students of heredity it seems rather as if the stable foundation block were made up of a blend of ancestral contributions. In either case, the result of ages upon ages of sifting has been that there is now little or no alternative as regards the gencral human features. It is thercfore probable that the variations, e.g. in the human brain, that the future may have in store for mankind must be congruent with the general style of brain architecture which has, as it were, come to stay forever. There is a growing body of evidence that some of 
our mental peculiarities belong to the unit-character type. Thus there is a quitc definitc 'roving' impulse, distinguishable from mere restlessness or lack of perseverance, which 'runs in families.' The same may be true of well-defined temperaments-e.g. excitable or nervous, phlegmatic or quiet; of curious mental twists that make their possessors see everything crooked; and of those agreeable idiosyncrasies and originalities which add a charm to life.

It is not, of course, to be assumed that any character is a unit-character; that has to be proved by its behaviour in inheritance. It looks as if cven our more superficial features, whether bodily or mental, included more than non-blending unit characters. For there are some, such as colour of hair and colour of skin, which appear to blend when contrasts are paired. Thus mulattoes apparently illustrate, as to colour of skin, a blend of the skin colour characteristics of the white father and the black mother. We say 'apparently' because the matter is not nearly so simple as it seems.

(c) Thirdly, besides the old-established racial characters and the well-defined but more superficial traits that run in families, the inheritance includes individual peculiarities or idiosyncrasies. These new departures, novelties, or variations are of great intercstthey form the raw material of progress or of retrogression, or of merely indifferent change. They vary from trivial peculiarities such as crinkly hair, to momentous mutations, such as we see in genius. Some are rather quantitative, a little more of this and a little less of that; 
others are rather qualitative, some novel pattern. They are individual variations. Whether they have come to stay or not time will show.

Under the breeder's supervision a single variant may become the source of a constant race, as was the case with the once famous short-legged Ancon sheep (1791), the American Polled Herefords (1889), the Californian seedless orange, and so on. To obtain a pure race of wheat or the like, e.g. with qualities suited for particular soils, it is now usual, as at Nilsson's Institute at Svalov in Sweden, to start from the seeds of one promising head. But it does not always happen that a variant in itself very promising is able to 'hand on' its good qualities to its offspring. In Professor Raymond Pearl's work on goodlaying hens (up to the 200 eggs a year standard) it was found necessary to make sure not merely that the mother hen was a very good layer, but that her daughters were so likewise. An individual excellence is not necessarily continued in the next generation.

\section{§ 3. Fundamental Facts of Heredity}

(1) Heredity is a flesh and blood linkage, a germinal continuity, binding generation to generation. It is a term for a biological relation of offspring to ancestry. It has nothing directly to do with tradition or with culture legacies handed on outside the organism.

(2) The natural inheritance is carried, we cannot picture how, in the form of initiatives, or factors, or determinants in the egg-cell (the ovum) and the sperm- 
cell (the spermatozoon) which unite at the beginning of each new life.

(3) The inheritance, contained implicitly in the fertilised egg-cell, requires an appropriate nurture if it is to develop aright. Development is the making visible or actual of what has lain in the germ-cell in an invisible or potential state.

(4) In mammals, and in some other cases, e.g. flowering plants, the developing embryo may be influenced very early by its immediate surroundings within the mother, but that influence is part of nurture, not part of the hereditary nature.

(5) Apart from a few exceptional cases, e.g. virgin birth (parthenogenesis), which is restricted in natural conditions to backboneless animals, every inheritance is dual, partly paternal and partly maternal. The mother certainly contributes in the cytoplasm or the extra-nuclear substance of the egg-cell the greater part of the initial building material, the sperm-cell being very much more minute. It is highly probable that many old-established generic characters have their vehicle in the cytoplasm of the ovum. As regards those hereditary items which are carried in the nuclei of the sex-cells, it is interesting to notice that the nuclear-bodies (chromosomes) are usually equal or nearly equal in number in sperm and ovum. Each kind of organism has a definite number of chromosomes which is usually the same in all the cells, except the unripe ova and sperms, which have double the normal number. There is nothing in the number itself, which 
is the same in quite unrelated organisms, e.g. white man and slug; the point is the constancy of the number.

(6) The paternal and maternal contributions form the warp and woof of the web which composes the organism, and each sex-cell carries a complete set of the essential hereditary qualities. In the course of development, however, the offspring may 'take after' one side of the house as regards one character, and may 'favour' the other side of the house as regards some other character. It may be like the father in its hands, like its mother in its hair. Thus we have to distinguish between the inheritance or 'genetic composition' which the organism has to start with, and the expression of that inheritance in development.

(7) Strictly speaking, an inheritance is multiple as well as dual, for there may be demonstrable ancestral contributions which did not find expression in the parent. Resemblance to a grandparent is a common and, as we shall see, readily explicable phenomenon. Characters sometimes lie latent for a generation, or for several generations, which again brings out the difference between the implicit inheritance and the developmental expression of it.

(8) The largest fact of heredity is that like tends to beget like. The hereditary relation between successive generations is such that a general resemblance is sustained. A particular kind of organisation, associated with a particular kind of activity, persists from generation to generation. These are simply different ways of saying the same thing; that all inborn characters 
(except sterility) are heritable and may be handed on. But 'may' cannot be changed into 'must,' for the unexpected often happens.

\section{§ 4. Recent Advances in the Study of HeREDITY}

There are three modern ideas that have profoundly influenced our views of heredity. (a) The first is the idea of germinal continuity, which we owe especially to Sir Francis Galton and Professor August Weismann. The reason for like begetting like is to be found in the persistence of a specific organisation through a lineage of unspecialised germ-cells. The germinal material of the fertilised ovum forms the basis of the building material out of which the body of the offspring is built up, undergoing, in a puzzling way, not only a huge increase in quantity but a qualitative differentiation into nerve and muscle, blood and bone. But while this is going on, a residue of the germinal material is kept intact and unspecialised to form the beginning of the reproductive organs of the offspring, whence may be launched in due time another similar vessel on the adventurous voyage of life. The sex-cells produced in the reproductive organs are the descendants of unspecialised embryonic cells, which did not share in bodymaking, which did not become specialised. In short, these germ-cells remain like the fertilised egg-cell from which the organism started; they continue the specific tradition intact. As it has been put, instead of saying that the hen gives rise to the egg, we should say the egg 
gives rise to the hen and to the eggs which the hen's body contains. So we see that the parent is rather the trustee of the germ-plasm (the germinal basis of the specific organisation) than the producer of the child. In a new sense the child is a chip of the old block. Or as Professor Bergson puts it in less static metaphor, "Life is like a current passing from germ to germ through the medium of a developed organism." This continuity of the germ-plasm, by cell-division after cell-division, along a lineage of unspecialised cells, explains the inertia of the main mass of the inheritance, which is carried on, as we have seen, with little change, as it were en bloc, from generation to generation. Men do not gather grapes off thorns, or figs off thistles. Similar material to start with; similar conditions in which to develop; therefore like begets like.

(b) The second very important modern idea, which we owe to Mendel and Professor de Vries, is that of unit-characters already alluded to. Some have compared its importance to that of the Atomic Theory in chemistry. An inheritance is, in part, built up of numerous, more or less clear-cut, crisply defined, nonblending characters, which are continued in some of the descendants as discrete wholes, neither merging nor dividing. A definite type of very intelligent dwarf has been known to reappear for four or five generations. The persistence of the Hapsburg lip is a well-known instance of a trivial unit-character that came and stayed. An abnormal peculiarity like having six fingers may defy dislodgment for six generations. These unit- 
characters or Mendelian characters behave as if they were discrete entities which can be shuffled about and distributed to the offspring in some degree independently of one another and which can be reunited in new combinations. They must be represented in the germcell by 'factors' or 'determinants' or organisational peculiarities of some sort. One of the latest names for a hereditary 'factor' is 'gene.'

(c) The third very important idea that has been brought into prominence in modern times is that bodily modifications-dints and imprints-acquired by an individual as the direct result of peculiarities in nurture are not readily transmissible, if at all, and, in any case, are not usually transmitted. Every care must be taken to a void dogmatism, but it is certain that individually acquired modifications (in the technical sense) are not commonly transmitted to any observable extent. We must go further and say that it is exceedingly difficult to find incontrovertible evidence showing that they may be even occasionally transmitted.

It will be necessary to return to the subject when we discuss 'Nurture' ; in the meantime the dominant scientific opinion may be stated, that in our discussions and reflections on heredity we are not warranted in taking for granted, as has often been done in the past, that modifications individually acquired by an organism can be handed on to its offspring, either as such or in any representative degree. An individual living creature often exhibits modifications directly due to some peculiarity or change in surroundings, food, 
activities, habits, use and disuse, and so on. These ' modifications,' as they are now technically called, are structural changes that persist after the inducing conditions have ceased to operate. Thus a lifelong tanning of the skin, a callosity on a much pressed part of the skin, a strengthening of a muscle by use, a degeneration of a muscle by disuse, an accumulation of fat as the result of gluttony, a strain of the eyes through overwork, may serve to illustrate 'modifications.' They are often very important for the individual, both for good and ill, but they do not seem of much, if any, direct racial importance, since the evidence of their transmission is rare or unsatisfactory, or emphatically absent. They are to be thought of as dints impressed from without, and contrasted with outcomes expressed from within. The latter are called variations, mutations, or new departures, and are often highly transmissible. They result from changefulness inherent in the germ-cells, provoked into expression, it may be, by penetrating stimuli from without, and they form the raw material of organic evolution. Whether we believe in the transmissibility of 'dints' or not, we know that they are not commonly transmitted in any measurable manner. We also know that it is of practical as well as theoretical importance to distinguish what is due to peculiarities of 'nurture" from what is the expression of inborn ' nature.'

\section{\$5. Different Modes of Inheritance}

(a) In starting a breed of domesticated animals, such as Polled Angus cattle or Ancon sheep, the breeder 
has often had to begin with a very small number of similar forms. There has to be close inbreeding. If fresh blood is introduced and offspring are born which do not conform to the desired type, they are at once got rid of. This elimination of divergent forms and this inbreeding of similar forms may be continued for many years until a large 'pure-bred' herd is established. It is marked by great uniformity and constancy of character. As regards the features to which the breeder has attended, each individual has what all the rest have, none has what the others have not. Every one is as good as his neighbour. They are pure-bred and they breed true. If we could see into the invisible architecture of the germ-cells we should find that each had the same equipment of similar 'factors' or 'determinants' or 'genes.' If two members of the herd are paired, or if the members of two herds of similar history are paired, the offspring are like the parents. Now, among the various modes of inheritance this is one extreme-strong hereditary resemblance, complete as regards many characters, and appearing to the inexperienced eye complete through and through.

(b) Another phenomenon, however, is the emergence of something distinctively new. An offspring is born that is in some respects very unlike its parents and its kindred. It exhibits some novel pattern, some new departure, a qualitative variation or mutation. In mankind this is illustrated by children with marked originality, with great mathematical or musical ability, or with less desirable idiosyncrasies. 


\section{Digression on the Origin of Novelties}

The conditions of the appearance of these novelties are not known, but the problem is the subject of interesting speculations. There is no great difficulty in understanding how quantitative variations may arise-a little more of this and a little less of that-for the germcells go through a complicated process of maturation in which the number of nuclear-bodies or chromosomes is reduced to half the normal number, so that when the sperm-cell and the egg-cell unite in fertilisation the normal number is restored. Now, if these nuclearbodies or chromosomes be vehicles (or the vehicles) of the factors of the hereditary characters (or some of them), the numerical reduction in the course of the ripening of the germ-cells may be a condition of variation. If we compare the nuclear-bodies or chromosomes to a pack of cards, there is in maturation a shuffling of the cards and a division of the pack into two half-packs. In the case of the ovum one half-pack is always lost altogether. In fertilisation two half-packs are brought together to make a new whole-pack. The metaphor of the shuffling of the cards may serve without further detail to suggest how quantitative variations might readily arise by the dropping out of factors in the process of maturation. So one might try to account for a hornless calf in a horned race, or for an albino child.

It is well known that novclties sometimes follow the crossing of two dissimilar forms, and this serves as a basis for the theory that the permutations and combinations involved in the fertilisation of the egg-cell by 
a sperm-cell of somewhat different genetic history may account for the emergence of new patterns.

Experiments show that a single-celled organisma Protozoon or Protophyte-may be changed by changes in the medium in which it lives. Similarly it may be that the egg-cells or sperm-cells within the body of the parents are influenced by changes in the complex medium (the blood or the lymph) by which they are kept alive.

There is also some very suggestive evidence that environmental influences of a searching sort, such as changes of climate and food, may saturate through the organism and act as variational stimuli on the germcells, pulling the trigger of their changefulness. It may be in this way that some poisons are able to exert a more or less direct deteriorative influence on the germcells and thus on the next generation.

It may also be that since a germ-cell is a living cell with a very complicated endowment of hereditary factors, it spontaneously experiments with these, arranging them in different ways, just as a slipperanimalcule may break down and reorganise its nuclear structure, just as an arenaceous Foraminifer may apparently pick and choose extcrnal materials-microscopic pebbles, sponge spicules, mica platelets, and so on in building up its external shell. But, as we have confessed, biologists are only nibbling at the problem of the origin of the distinctively new. Applying this to mankind, we sce that it is impossible to suggest any recipe for the production of genius. At the same time, 
it seems permissible to doubt the wisdom of mediocrity mating with precisely similar mediocrity. Though a happy marriage usually implies a certain community of taste and conviction, there is much to be said for what is in point of fact very frequent-namely, the marriage of dissimilars.

It is likely enough that true genius is the result of a fortunate merging of two fine inheritances, the result being an unusual intensification of certain qualities, and something of a new pattern without there being disharmony. Of high importance as regards the race is the mating of the wholesome, well-balanced, vigorous types, with at least a spark of originality. Other things equal, we should expect genius to result from such unions rather than from others.

\section{Modes of Inheritance (continued)}

To return, however, from this digression to the main line of discourse, we have taken account of two extreme modes of inheritance- $(a)$ almost complete hereditary resemblance, and (b) marked variation in the offspring. Between these two extremes there are perhaps three modes of inheritance: blending or averaging, alternative or Mendelian, and reversionary or harking back.

(c) Blending inheritance is a descriptive term for cases where certain characters in the offspring appear to illustrate an intimate mingling of the corresponding patcrnal and maternal characters. Thus, though the case is not so simple as it looks, a mulatto is often regarded as a blend as far as skin colour is concerned. 
In crosses between long-eared lop rabbits and a shorteared breed, Professor Castle found that the offspring were intermediate in length of ears and in a number of skeletal measurements. Many plant hybrids are very exact blends of their parents, and the same mode has been well illustrated in crossing two cockatoos belonging to different genera.

(d) Mendelian inheritance has to do with unit-characters and their distribution in the progeny. If a normal mouse is crossed with a Japanese waltzing mouse, all the hybrid offspring, (first filial generation $F_{1}$ ), are normal. Normal behaviour or its factor is said to be dominant as compared with waltzing behaviour or its factor, which is spoken of as recessive. If the hybrids be inbred, or bred with others of similar lineage, about a quarter of the progeny are waltzing mice and these waltzers might be sold as 'pure' waltzersalthough both their parents and one of their grandparents showed the normal behaviour. The rest of the progeny in this second filial generation $\left(\mathrm{F}_{2}\right)$ appear to be quite normal, but experiment shows that about a third of them are 'pure' normals, while about two-thirds are like the hybrid generation $F_{1}$, with every appearance of being normal, but with the waltzing character latent - up the animal's sleeve, as it were. If the pure normals, or, as they are technically called, "pure dominants," are bred together or with others like themselves, they will yield again the proportions observed in the second filial generation, namely, 25 per cent. pure normals plus 50 per cent. impure normals 
and 25 per cent. pure recessives. Or, using the contractions $\mathrm{D}$ and $\mathrm{R}$ for dominant and recessive respectively, the Mendelian formula for the result of crossing two pure-bred organisms differing in a pair of contrasted characters is $\mathrm{D} \times \mathrm{R}=\mathrm{D}(\mathrm{R})$. But if the $\mathrm{D}(\mathrm{R})$ 's be mated, the result will be 25 per cent. $\mathrm{D}+50$ per cent. $\mathrm{D}(\mathrm{R}),+25$ per cent. $\mathrm{R}$.

One of the cases that Mendel began with was that of two pure-bred races of peas which differed in staturea giant race and a dwarf race. When these were crossed the offspring were not intermediates, like those of the long-eared and short-eared rabbits already mentioned, they were all tall. Thus Mendel spoke of tallness as dominant and dwarfness as recessive in this case. When the hybrid tall peas were left to self-fertilise (as happens in peas, corresponding to inbreeding in animals), the members of the second filial generation $\left(\mathrm{F}_{2}\right)$ were with remarkable exactness in the following proportions-25 per cent. pure talls +50 per cent. impure talls, + 25 per cent. pure dwarfs.

The two cases we have instanced illustrate what is called complete dominance. That is to say, the offspring of the normal mice and the waltzing mice were all normal; the offspring of the tall peas and the dwarf peas were all talls. But it is not necessary that the dominance in Mendelian inheritance should be complete. Thus if a Black and a White Andalusian fowl be crossed, the progeny arc what are called Blue Andalusians, illustrating incomplete dominance. These Blue Andalusians might be hastily regarded as Blends, but the 
erroneousness of such an interprctation is evident when Blue Andalusians are paired with Blue Andalusians, for then they yield 50 per cent. Blacks and 50 per cent. Whites. This could never be the result of pairing two similar Blends. This simple example must serve, however, to suggest that results which have been described as Blending Inheritance may turn out to be cases of incomplcte dominance in Mendelian Inheritance. It is necessary to have information in regard to the $\mathrm{F}_{2}$ generation. Another point must be understood. The original parents may differ from one another in two contrasted characters (technically called allelomorphs), such as tallness and dwarfness, yellow seeds and green seeds, short hair and Angora hair ; or they may differ inasmuch as the one has a unit-character which the other has not, as we see in cattle with or without horns, fowls with or without crest, wheat with or without beard, and so on. The two kinds of contrast will work out in the same kind of rcsult - the unit-character that is present may act as a dominant or recessive to its own abscnce. It must also be pointed out that the two parents belonging to two pure-bred races are likely to differ from one another as regards several distinct sets of contrasted characters, and that this will necessarily complicate results. Thus Mendel crossed a Tall Yellowseeded Pea with a dwarf green-seeded Pea, Tallncss (T) and Yellowness $(\mathrm{Y})$ being dominants in relation to dwarfness (d) and greenness (g), which are in this case recessives. The hybrid offspring $\left(F_{1}\right)$ will all be Tall with Yellow seeds (say TY). But what will be the nature of 
the second filial generation? If we suppose, for simplicity's sake, that there are 16 of them, 12 of these must be Tall and 4 dwarf. But of the 12 Talls, 9 must have Yellow seeds and 3 green seeds. And of the dwarfs, 3 must have Yellow seeds and 1 green seeds. So the formula will run: $-9 \mathrm{TY}+3 \mathrm{Tg}+3 \mathrm{dY}+1 \mathrm{dg}$.

One of the diagrammatic examples of a unit-character in Man is night-blindness. It is a peculiarity of the eye, apparently associated with a lack of visual purple in the retina. Those affected by the peculiarity find it difficult to see in dim light. There are records of an occurrence of night-blindness in one Jean Nougaret in 1647 , and of its regular recurrence in a certain proportion of his descendants for more than three centuries. No normal member of the lineage who married a normal type had any night-blindness among his descendants. The character is either there or not there.

The inheritance of eye-colour is on Mendelian lines, and the mode is also illustrated in the case of brachydactylism, where all the fingers are like thumbs in having two joints instead of three. What is known as presenile cataract seems to be a Mendelian character, and so are certain kinds of feeble-mindedness and epilepsy. A reference to eye-colour may be useful.

When there is abundant pigment in the iris, the eyes are brown; when the factor or determiner for brown is not part of the inheritance the eyes are blue, i.e. with little pigment in the iris. The children of two parents with brown-eyed ancestry will have a double dose or duplex inheritance of brown. The children of blue-eyed 
and brown-eyed will have weak brown pigmentation of the iris, receiving the brown factor or determiner from only one side of the house, a single dose or simplex inheritance of brown. If a member of a simplex stock marry a member of a duplex stock the children will be half simplex, half duplex, all brown. If a member of a simplex stock marry a member of a simplex stock, the children will be in the proportion of 1 duplex brown: 2 simplex brown: 1 blue-eyed nulliplex. If a member of a simplex stock marry a blue-eyed person half of the children will be simplex and half blue-eyed (nulliplex). And finally, if blue-eyed marry blue-eyed, all the children will be blue-eyed.

Increasing knowledge of Mendelian inheritance lessens the impression of almost mechanical card-shuffling which the earlier work suggested. Thus we know that in many cases there does not seem to be a random or free assortment of genes or factors among the ripening germ-cells. Many characters have been found to keep together in successive generations instead of assorting freely. It looks as if the genes sometimes hung together in blocks. This is known as linkage and it is correlated with a remarkable process of crossing over, wherein there is an interchange of blocks of genes between a maternal and paternal pair of chromosomes when closely apposed to one another. It seems clear that a gene or factor in the germ-plasm may be associated with more than one effect in the body; that the expression the gene finds in develcpment depends in some measure on the environmental conditions; and 
that a particular character in the body may be the product of many genes. Perhaps we have said enough to indicate that the Mendelian theory admits of more elasticity than it seemed at first to tolerate-an elasticity which the facts of the case appear to demand.

(e) The mode of inheritance called reversionary or atavistic seems to be of very rare occurrence. It is illustrated when a character known to have marked a distant ancestor remains latent for several generations, and then suddenly finds expression again, like a seed that has been lying dormant for years in an uncultivated corner of a garden. It turns out, however, that many of the 'hark-backs' which have been called reversions and regarded as due to the reawakening of a factor which has been latent for generations, admit of a much simpler interpretation. They may be conveniently described as 'reversions,' but they are not really of that nature. For many of them are due to arrested development-to the stoppage of development at too early a stage, perhaps because of some defect in nutrition. Hare-lip in Man seems to be of this nature -not a true reversion.

But many so-called 'reversions' have another explanation, which we owe to the Mendelian school. A strict reversion is due to the reawakening of a character which has lain latent for ages, but what looks like a reversion may be due to a coming-together-again of characters which have been analysed apart in previous generations. When domesticated rabbits of different colours are bred together promiscuously their 
descendants tend to be eventually all grey like the wild rabbit. "Darwin regarded this as a reversion, and it may still be described as reversionary; but it is not due to the reassertion of long latent grey colouring. The return to grey is due, as the Mendelian experiments show, to the recombination of at least eight colour-ingredients ('factors' or 'genes') that go to the make-up of the wild greyness. Man has sifted out all the various colours from the complex coloration of the wild stock, and when the long-separated items are brought together again by unrestricted interbreeding there is, naturally enough, a reconstruction of the original grey colouring" (see the author's Darwinism and Human Life, p. 147).

\section{$\S 6$. Inheritance and Disease}

There is much still to be learned in regard to the inheritance of disease, defects, abnormalities, and the like, but the following propositions are probably justifiable.

(a) The reappearance of a diseased condition, like rheumatism, in a lineage, does not prove that it has been transmitted, or that it is transmissible. In the caves of Dalmatia, Carinthia, and Carniola there is a wan white blind newt called Proteus. It shows no pigment in its skin, and the only spot of colour other than white is where the red blood shines through the delicate gills. It would seem to be a very safe conclusion to say that Proteus is hereditarily pigmentless. And yet if it be exposed to light, it becomes rapidly dark. It is as sensitive as a photographic plate. What 
is a-wanting is not in its inheritance, but in its environment. Similarly, stunted growth in infants, or a succession of rickets generation after generation, may imply defective nurture rather than defective inheritance.

(b) Even when a child is born with symptoms of, or with definite expressions of a disease (a condition to which the term congenital should be applied), it does not follow that the disease was part of the inheritance. For there may be microbic infection before birth, e.g., with the animal organism (Treponema pallidum) that causes syphilis. Similarly, on the other side, there are facts that seem to show that when a mammalian mother has been rendered artificially immune to a disease (by the injection of an antitoxin) she may confer this benefit upon her offspring before birth. But this is an early acquirement on the offspring's part, thanks to its intimate partnership with its mother; it is not strictly part of the inheritance.

(c) An attempt must be made to discriminate between the inheritance of a definite disease and the inheritance of a constitutional proclivity or predisposition towards that disease. Microbic diseases such as tuberculosis cannot be hereditary, being due to specific infection. Yet they seem to run in families. Part of the explanation of this may be the persistence of the same kind of house and habit, and the same abundance of opportunity for infection; but part of the explanation may also be the actual inheritance of a predisposition, e.g. a ready vulnerability of internal surfaces. But the difficulty is to define this predisposition or diathesis, 
and to distinguish it from symptoms of an early infection already accomplished.

(d) The boundary-line between health and disease is not readily drawn, but from the biologist's point of view disease means that certain vital processes (or metabolisms) are occurring out of place, out of time, or out of tune. This disturbance of the wholesome routine may be traced back and back to some disturbance in the organisation and activity of the original germ-cells. Such diseases are called constitutional or innate, and they or predispositions to them may be transmitted from generation to generation in Man's sheltered kingdom. In wild nature they are not allowed to grip. In illustration of such diseased conditions we may mention diabetes (D), epilepsy (R), feeble-mindedness $(\mathrm{R})$, glaucoma $(\mathrm{D})$. These follow the Mendelian rule. They are marked (D) or (R) according as they happen to be dominant or recessive in relation to normality.

(e) There are other diseased conditions, however, which are directly induced by deteriorative peculiarities in surroundings, food, occupation, habits, and the like. Such might well be called modificational diseases, e.g. the conditions brought about by white-lead poisoning, by over-indulgence in alcohol, by working under great atmospheric pressure, and so on. If the disease called beri-beri be due, as experts tell us, to lack of 'vitamines' in the food, e.g. to feeding almost exclusively on polished rice from which the rind has been removed, then it is a good example of a modificational disease. Now the 
important point is, that there is no warrant for belicving that these modificational diseases are transmissible. They may reappear generation after generation if the deteriorative peculiarities in environment and nutrition, habits and occupation persist, but they are not truly heritable. It must also be noted that their secondary effects, on general vigour for instance, may last after the deteriorative conditions have been removed. The child of a drunken father may be hereditarily handicapped in constitution, though he does not inherit any particular modification impressed on the father's body.

While it is very important to realise that modificational diseases do not seem to be transmissible, it must be borne in mind that the liability to be modified sometimes means an innate constitutional weakness, which is, of course, transmissible. In the same way, it seems sometimes to be true that a slight constitutional defect may not become of serious moment unless it be roused through excess in certain kinds of food. This is probably true of gout. These two considerations should be thought over, for they lessen in actual practice the strictness of the biological contrast between innate and acquired, variational and modificational, peculiarities.

(f) A germinal disturbance which results in disharmony in the ordinary routine of health may have diverse outcrops in different members of a family, or in successive generations. It may also change in the time of its outcrop. Thus certain nervous disorders seem to appear earlier and earlier in successive generations, as Dr. F. W. Mott has emphasised in his Law of Anticipa- 
tion. They may appear so early that they disappear, being fatal before birth.

(g) Commoner than the inheritance of disease or tendencies to discase is the inheritance of abnormal peculiarities, such as colour-blindness, night-blindness, deaf-mutism, well-proportioned dwarfness, brachydactylism, polydactylism, hæmophilia, baldness, obesity.

\section{§7. Statistical Study of Heredity}

While the great experimental work of Gregor Mendel lay buried in the records of the Naturalists' Society of Brünn, there was developed in Britain a statistical study of inheritance, especially associated with the names of Sir Francis Galton and Professor Karl Pearson. It was Galton who really began to study the inheritance of particular characters through successive generations, and to measure quantitatively the degrees of hereditary resemblance. Galton was led to the Law of Ancestral Inheritance, according to which the average contributions to each inheritcd faculty are a half from the parents, a quarter from the grandparents, an eighth from the great-grandparents, and so on backwards, in the same diminishing ratio. "The prepotencies or sub-potcncies of particular ancestors, in any given pedigree, are eliminated by a law which deals only with average contributions, and the varying prepotencies of sex in respect to different qualities are also presumably eliminated" (Galton, Natural Inheritance.) The ratio of parcntal, grandparental, great-grandparental, and other avcragc contributions worked out by Pearson is differcnt 
from Galton's; it is $6244, \cdot 1988, \cdot 0630$, etc. . . . But the general idea is the same, that inheritances are not interpretable in terms of the parents only, but are as if the grandparents, great-grandparents, and so on, made contributions diminishing in proportion to their remoteness. The law is statistical, not physiological.

Associated with the law of ancestral inheritance is the law of filial regression, which expresses the tendency that the average of a character in a number of offspring has to approximate to the mean of the stock. If parents differ widely from mediocrity, their children are not likely to differ as widely. As Galton said, "The more bountifully the parent is gifted by nature, the more rare will be his good fortune if he begets a son who is as richly endowed as himself, and still more so if he has a son who is endowed more largely." But "the law is even-handed; it levies an equal succession-tax on the transmission of badness as of goodness. If it discountenances the extravagant hope of a gifted parent that his children will inherit all his powers, it no less discountenances extravagant fears that they will inherit all his weakness and disease."

This is an important idea, that when we consider numbers, not individuals, there is a notable inertia. Society tends to move like a great fraternity. It is not like a class in school where the élite of the class press on eagerly and a long 'tail' is formed. There is a tendency in society to keep up an average, and this is not due to any large extent to the cutting off of the laggards; it is due to 'filial regression.' 
Professor Karl Pearson gives a vivid concrete illustration in his Grammar of Science:- "The father with a great excess of the character contributes sons with an excess, but a less excess of it; the father with a great defect of the character contributes sons with a defect, but less of it." If we take a group of fathers 6 feet in height the mean height of their sons will be $70^{\prime \prime} 8$; if we take a group of fathers of 5 feet six inches the mean height of their sons will be $68^{\prime \prime} 3$.

Regression is a technical term which has nothing to do with retrogression or with reversion; it refers to a movement towards the mean of the stock, whether the movement be in the direction of progress or the reverse. The reason for the regression is tersely stated by Pearson:- "A man is not only the product of his father, but of all his past ancestry, and unless very careful selection has taken place, the mean of that ancestry is probably not far from that of the general population. In the tenth generation a man has (theoretically) 1,024 tenth great-grandparents. He is eventually the product of a population of this size, and their mean can hardly differ from that of the general population. It is the heavy weight of this mediocre ancestry that causes the son of an exceptional father to regress towards the general population mean; it is the balance of this sturdy commonplaceness which enables the son of a degenerate father to escape the whole burden of the parental ill."

These statistical conclusions must be pondered over. (a) They are average generalisations for bodies of people, 
not physiological conclusions relating to individuals. But of course they sum up a multitude of individual physiological facts.

(b) They do not apply to lineages where there has been close and consistent selection, e.g. in the range of permissible marriages.

(c) They certainly do not apply to the inheritance of Mendelian unit-characters. Not that there is any opposition between Galtonian and Mendelian laws of inheritance; they are not antithetic, but complementary, approaching the problem from different sides.

(d) It is difficult to believe that the laws are quite sound as laws of inheritance, since they do not seem to have taken sufficient account of the important fact that resemblances between relations are often in part due to similar nurture, and are not wholly due to similar hereditary nature.

To the statisticians or biometricians we owe a demonstration of the heritability of subtle constitutional qualities like fecundity and longevity, and evidence that clearly defined mental and moral qualities may be handed on to, and distributed among, the offspring, just in the same way as bodily characters. In this comnection too we must recognise the assimilative potency of similar nurture, a subject to which we must return in the next chapter.

\section{Looking Forward}

The history of domestication and cultivation shows that great results may be achieved when Nature and 
Man work into one another's hands. When Nature supplies the raw material in the form of heritable variations and mutations, and Man supplies the sieve, whether by bringing similar desirable forms together or by eliminating undesirable variants whenever they show face, great results may ensue. We see this in cereals and potatoes, cattle and poultry, and in a score of other cases.

As we have already noticed in the first chapter, Mendel put a clue-an Ariadne thread-into the hands of breeders and cultivators. It is becoming increasingly clear that Mendelism can enable a breeder or cultivator to reach his desired end more surely, more rapidly, and more economically. His new knowledge shows him how desirable qualities of the unit-character type can be grafted on to a stock, and how undesirable qualities can be slipped off. Desirable qualities are continually welling forth from life's inexhaustible fountain of change. Mendelism has shown the breeder and cultivator how to utilise these more effectively. The greatest difficulty is with ourselves. In the eighth chapter we shall briefly discuss the question, What is practicable in the way of human eugenics in the stricter sense-the improvement of the human breed? 


\section{CHAPTER IV \\ THE INFLUENCES OF NURTURE}

$\S 1$. Nature and Nurture.-§2. Nurture and Development.$\S 3$. Individually Acquired Modifications and Their Transmissibility. - $\$$. Nurture of the Higher Faculties.- $\$ 5$. The Other Side of Heredity.

\section{§1. Nature and Nurture}

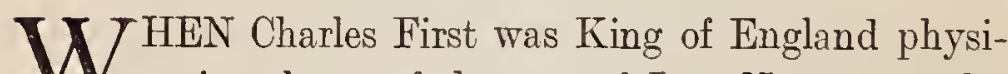
cians knew of the case of Jean Nongaret, who suffered from night-blindness, or inability to see in faint light. For more than two and a half centuries the Nongaret family-history has been kept-re know of 2,000 individuals in ten generations-and the nightblindness peculiarity has cropped up generation after generation. Though no normal nember of the lineage has ever been the vehicle of handing on the defect, the night-blindness has persisted through the abnormal members. It may be absent from an individual, but it does not disappear from the lineage.

Similarly, most of us know of some peculiarity, such as a curious shock of hair, persisting for several generations, or of a baby who is an almost grotesque caricature of his grandfather. In cases like the last the 
eye usually catches two or three salient features of marked resemblance, and these divert attention from the differences. There are characters, such as peculiarities of stature and disposition, which seem to blend and average out, but the lasting-on of peculiarities is one of the sure facts of heredity. Thus after studying man's natural inheritance for a while there grows upon us a feeling of its inexorableness. What is bred in the bone and imbued in the blood has great staying power. We see sturdy wholesomeness; we see, on the other hand, that the iniquities of the fathers reappear in their children to the third and fourth generation or longer.

But as we dwell longer with the facts that cloud of fatalism lifts a little. We begin to realise that, for the individual at least, there is a potent life-moulding factor in 'Nurture'-that is to say, in the influence of surroundings, food, exercise, occupation, education, company, habits, and so forth. Man is in great part born; he is also in great part made. Circumstances count.

John Knox the Reformer and John Lyly the Euphuist both make use of the convenient verbal contrast between inborn or inherited 'nature' and extrinsic or imprinted 'nurture,' and Shakespeare in the Tempest makes Prospero speak of Caliban as "a devil, a born devil, on whose nature nurture will never stick." The usage was made scientific by Sir Francis Galton. By 'nature' in the technical sense is meant all that the living creature in the germ is or has to start with in virtue of its organic continuity with preceding generations. By 'nurture' is meant all the environmental and functional influences 
that affect development: in Man's case, home, school, town, country, cosmic surroundings, food and drink, work and play, exercise and rest, companions and teachers, examples and traditions. It rises from fundamental influences, such as those of food and fresh air, to the supreme influences of the social heritage.

\section{§2. Nurture and Development}

Our first proposition is that the fullness of development depends in part on the adequacy of the nurture. A niggardly nurture may mean an imperfect unfolding of the hereditary nature; a rich nurture may mean its fine blossoming. The constituents of our inheritance are like buds. It does not seem as if we can in any way add to or subtract from their number, but to some extent nurture determines whether a bud of a bad quality will remain sleeping or unfold its loathsomeness, whether a bud of good quality will open out in a half-hearted way or with vigour. The inheritance is the seed-corn; nurture is the soil and the sunshine, the wind and the rain and the morning dew. Nurture cannot change bad seed into good, nor conversely, but it may determine whether the crops yield thirty-fold or a hundred-fold. No amount of nurture can make the Ethiopian change his skin or the leopard his spots, but nurture can work miracles in field and garden, in school and college. Nurture cannot make a silk purse out of a sow's ear, but it often determines whether a man becomesa good citizen or a waster. One of the leading experimenter's, Professor T. H. Morgan, writes : "It is a common 


\section{THE INFLUENCES OF NURTURE}

place that the environment is essential for the development of any trait, and that traits may differ according to the environment in which they develop."

\section{Discussion}

It is unfortunate that an antithesis should be made between 'Nature' and 'Nurture,' since it is plain that the two are complementary, not opposed. There can be no development at all without a minimum of nurture : no amount of nurture can make a bad inheritance good.

As a reaction from a period during which over-sanguine expectations were entertained as to the ameliorative effects of improved environment and function, there has been a modern tendency to an undue depreciation of the potency of nurture. This is due to three sets of facts.

(a) In the first place it is impossible not to be impressed by the extraordinary tenacity of some hereditary characters which persist for generations, no matter how the nurture is changed. A peculiar variety of Greater Celandine (Chelidonium majus), with cut-up leaves, appeared suddenly in an apothecary's garden at Heidelberg in the sixteenth century, and has bred true ever since in all sorts of surroundings.

(b) In the second place, while we are not at present discussing the transmissibility of individually acquired modifications, but the influence of peculiarities of nurture on the individual development, the general scepticism as to the transmission of modifications has prob- 
ably tended to a depreciation of the importance of nurture in general.

(c) In the third place, when an appeal is made to general facts so as to get away from the fallacy of arguing from individual instances which happen to impress us, the evidence warns us against attaching too much importance to nurture-effects. The statistical evidence furnished by Professor Karl Pearson and his investigators at the Galton Laboratory leads them to conclude that the results of changes in 'nurture' are of relatively small importance compared with the results of intrinsic variations in hereditary 'nature' (including physique, mentality, and habits) of the parents. We must confess that it seems to us extraordinarily difficult in Man's case to discriminate what is due to the inheritance (granting in addition an average share of the appropriate nurture that is indispensable if there is to be development at all) from what is due to peculiarities of nurture (granting again an average normal inheritance to work upon). We are assured, however, that "the degree of dependence of the child on the characters of its parentage is ten times as intense as its degree of dependence on the character of its home or uprearing." "It is five to ten times as profitable for a child to be born of parents of sound physique and of brisk, orderly mentality as for a child to be born and nurtured in a good physical environment."

Let us consider the problem from a general biological point of view. There are undoubtedly many cases in which the developing organism is remarkably indifferent 
to its nurture, provided always that there be a modicum of air, moisture, food, warmth, and the other indispensables. It is a striking fact that the ovum of a rabbit can develop for two days outside of the body altogether, and the experimental embryologists have shown us that many developing germs can readjust themselves and develop normally after strange disarranging tricks have been played with them. There are some delicate creatures, such as the larvæ of sea-urchins, which are difficult to rear till one knows the secret, which are readily injured by even slight nurtural changes; on the other hand, many other developing creatures can within limits adjust themselves to, and develop normally in quite peculiar conditions of life.

If we take a broad view of development and think of full-fledged behaviour, the same is true. If the newlaid eggs of, say, the Blackheaded Gull be taken from the nest and kept in an incubator in the laboratory until they hatch, and if the young birds be reared in confinement, we get, as every one knows, normal, wellendowed creatures, which will migrate months afterwards when their kinsfolk flying overhead pull the trigger of an inborn predisposition. The whole nurture of these young birds was peculiar, but it did not seem to make much difference. There is evidence, we believe, that some birds which have not known freedom are somewhat handicapped when liberated, not knowing their way about. But the clear fact seems to be that for many creatures changes of nurture need not be of great importance as long as the essential conditions of development 
are not interfered with. The full inheritance may not be expressed, but a large proportion of it is realised as usual. What, then, is the importance of nurture?

Admitting all this and more, we return to our proposition that the fullness of the development depends in part on the adequacy of the nurture. It is a subject for inquiry in each particular case whether a deficiency in development is due to defective 'nature' or to defective 'nurture.' In any environment, Man will develop two sets of teeth, yet the development of the teeth will in part depend on the nutrition. Very suggestive arecertain experiments made by Gudernatch on tadpoles (Amer. Journ. Anat., XV, 1914, pp. 431-478, 2 pls.). Tadpoles fed on minced thyroid showed the usual division of labour and complexity of parts, but they remained small. They became eerie dwarfs, showing differentiation without growth. But tadpoles fed on minced thymus and spleen grew big without growing complex. They showed growth without differentiation. They remained big tadpoles - children that could not grow up. Another diagrammatic illustration concerns the red Chinese primrose (Primula sinensis rubra), so familiar in greenhouses. Reared at $15^{\circ}-20^{\circ} \mathrm{C}$. it has red flowers ; reared at $30^{\circ}-35^{\circ} \mathrm{C}$., with moisture and shade, the same plants have pure white flowers. The development, so far as colour goes, depends on the nurture. The white Chinese primrose (Primula sinensis alba) bears only white flowers whatever be the temperature (see T. H. Morgan and others: The Mechanism of Mendelian Hcredity, New York, 1915, p. 38). 
A character known to be a part of the inheritance may remain entirely unexpressed in the individual development because certain environmental conditions are lacking, yet the heritable character may be handed on all the same. Let us consider the parable of the Fruitfly (Drosophita ampelophila) as we find it in Professor T. H. Morgan's book already quoted. There is a race of these flies with a peculiar abnormality, and in ordinary conditions the members of this abnormal race produce others like themselves. But if the eggs of these flies are reared in a very dry place the insects are all normal, and one might be tempted to think that the vice had vanished. But if the offspring of these apparently normal flies are reared in a moist place, the abnormality is again displayed. The point of the parable is missed if it be thought that the wetness produces the abnormality afresh. That is not the state of affairs. The hereditary factor for the abnormality is there all the time, but it finds expression in moist environment only.

Another illustration from the Fruit-fly may be useful. There is a divergent (or mutant) stock that produces supernumerary legs, in a considerable percentage in winter, few or none in summer. Miss Hoge has found that when the flies are kept in an ice-chest at a temperature of about $10^{\circ} \mathrm{C}$. there is a high percentage of individuals with extra legs.

In a hot climate there would be little or no evidence that the peculiarity in question was part of the inheritance, This shows that the expression of the inheritance as regards a particular character sometimes depends on nurture. 
While some developing organisms are callously indifferent to changes in the environment, there are others which respond sensitively, sometimes in a startling way, to external changes, even when they do not seem to be very drastic. Thus Professor Jacques Loeb has shown (Biolog. Bull., XXIX, 1915, p. 50) that it is very easy to produce a percentage of minnow-embryos (Fundulus) with defective eyes, by the simple expedient of adding a minute quantity of potassium cyanide to the water, or by exposing the newly fertilised eggs to low temperature. That is to say, relatively slight environmental changes may set a-going vital processes which alter the constitution of the developing embryo in a very precise way. A leap is taken in the direction of blindness.

For the same fish (Fundulus), it has been shown by Stockard (Journ. Exper. Zool., Feb., 1909) that the addition of a very minute quantity of magnesium salt to the water induces in a large number of embryos the development of a single Cyclopean eye instead of the normal two eyes.

We must also recall the experiments of Professor D. T. MacDougal, who injected solutions of sugar and salts of calcium, potassium, and zinc into the developing ovaries of one of the Evening Primroses with the result that a small percentage of the seeds developed into notably atypical plants, which bred true to the third generation. The chemical substances introduced were not of a very out-of-the-way sort; they were not very different from those which might occur in the course of nature in the sap of the plant. Among the changes 
induced there were not only decreases and increases in what was already present; there were some distinct novelties which maintained their distinctiveness when crossed with the parental strains. It is probable that the injections into the ovaries acted as variational stimuli on the germ-cells (see lecture on "The Direct Influence of Environment," in Fifty Years of Darwinism, 1919).

Facts like those cited should be borne in mind in connection with Man and ordinary placental mammals where the unborn offspring lives in intimate partnership (or symbiosis) with its mother. Slight changes produced in the blood of the mother by peculiarities of nurture may affect the development of the offspring. It is very important to realise the difficulty of distinguishing between what is due to inherited nature (and average normal nurture) and what is due to some peculiarity in ante-natal nurture.

Here we may consider the parable of the Planarian worms (Planaria), very simple 'living films,' often seen gliding about by means of microscopic lashes (cilia) on the pond-weeds. When they are allowed no choice of food, but restricted to the uncongenial flesh of freshwater mussels, they cease to thrive. Their vital processes, Professor Child tells us, are slowed down, and their resistance-powers to deleterious influences are lessened. They become old, and, what is more remarkable, if the diet be continued for several generations, they begin to be born old. Now one does not dream of arguing from worm to man, but there is a suggestion here of the danger of too much porridge at the one extreme 
and too much partridge at the other. In any case we submit that the facts warn us against being in a hurry to depart from the common-sense belief that for the individual, at least, peculiarities of nurture may count for much.

\section{§ 3. Individually ACquired Modification and Their Transmissibility}

On some parts of the east coast of Scotland the trees are all lopsided; the main stem bends landwards and almost all the branches stretch their arms away from the sea. This is the result of the strong east wind, and it is a simple example of a modification. If we look at the white Water Buttercup (Ranunculus aquatilis) on a quiet stretch of a stream we see that most of the leaves are lying on the surface and are simply lobed; but on another stretch where there is a rapid flow the leaves are all submerged and cut up into green threads. This is another example of a modification, an individually acquired character due to a peculiarity in nurture, and it is historically interesting in being one of the examples Lamarck gave of the direct action of the environment.

It should be noticed, however, that we do not know to what degree a predisposition to assume filiform leaves is now part of the hereditary constitution of the water buttercup. A more clear-cut case would be one in which a water plant not previously known to exhibit cut-up leaves developed these in a swift stream.

If a part of our skin is persistently subjected to local pressure, it often gives rise to a protective thickening 


\section{THE INFLUENCES OF NURTURE}

of the epidermis, a callosity, an honourable mark of hard work. The schoolboy sometimes has one on his thumb during the season of playing marbles. It is a positive functional modification, a direct reaction to a peculiarity in function. Yet a wart may arise that simulates a callosity, but cannot be referred to any cause operating from without.

A Russian naturalist, Ogneff, shut up some goldfish in total darkness for three years, taking care to give them plenty of food and plenty of room. At the end of the three years they were quite blind; the rods and cones (the percipient elements) of the rotina had disappeared. This was a negative modification, directly connected with the absence of light and the cessation of vision. A certain amount of functioning seems to be necessary if a normally active structure is to retain its position, its architectural stability.

A Japanese investigator subjected white rats to hard exercise for 90 to 180 days, which is comparable to a period of 7 to 14 years in man, for the length of life in the white rat is about three years. What was the result? There was an increase in the weight of the heart, kidneys, and liver, on an average to about 20 per cent. This is an illustration of a modifying influence affecting several parts of the body in a similar way.

It has been shown (by Semper and de Varigny) that the young of the fresh-water snails (Lymnceus) will develop into dwarfs in an aquarium where aëration is abundant, and food likewise, where indeed everything 
is satisfactory except that the surface does not give the animals sufficient room for exercise. This is surely a parable for our instruction.

The French have a wise proverb, "By force of striking one becomes a blacksmith" (C'est à force de forger qu'on devient forgeron); and this is equally true of the powerful wrist of the violinist. The results of physical exercises show that the size and strength of a muscle may be greatly increased by persistent exercise. It seems that the muscle-fibres grow thicker and stronger; we believe we are right in saying that they do not become more numerous.

To a certain extent the colour of some birds, e.g. canaries, can be altered by particular kinds of food. In gulls and poultry the character of the food-canal may change considerably in the individual bird according to the nature of the food. The fattening of geese is a somewhat passive nutritional modification. Mr. Beebe's exceedingly interesting experiments have shown that some birds, such as the bobolink, may be dieted so that they keep their breeding plumage all the year and will sing their spring song in midwinter.

Extreme tanning or browning of the skin as the result of many years of exposure to a tropical sun is a modification that may persist for many years after the traveller has returned to the temperate home country. It is hardly correct to include the blanching of the bankedup celery as a modification, for it does not last after the peculiar conditions of darkness are removed. Some caterpillars subjected to cold develop into dark-coloured 
butterflies; others are able to adjust their coloration or that of their pupæ to the brown, green, or gold colour of the box in which they are kept.

Defnition.-Such, then, are the changes which are called "bodily modifications" or "individually acquired characters." It is advisable to drop the technical term "acquired characters" altogether, for it always gives rise to misunderstanding. It is not open to the argumentative to re-define " acquired characters" or "somatic modifications" to suit their convenience or convictions. The term has been historically defined in the course of prolonged discussion.

Modifications may be defined as structural changes in the body of the organism, directly induced in the individual lifetime by peculiarities in function, nutrition, or environment, which transcend the limits of organic elasticity and thus persist after the inducing conditions have ceased to operate. More briefly, modifications are persistent, individually acquired, direct results of peculiarities of nurture. Modifications, being wrought upon the creature from without, are to be contrasted with variations or mutations which arise from within ; they are impressions in contrast to expressions ; they are exogenous or extrinsic. In a word, they are dints, not outcomes.

It may be convenient, though too much should not be made of it, to distinguish among modifications $(a)$ those due to peculiarities of use and disuse, (b) those due to peculiarities of food, and $(c)$ those due to peculiarities in surroundings. Thus there are $(a)$ functional, 
nutritional, and $(c)$ environmental modifications. It is usual to include the food as one of the environmental influences, but to the ordinary layman this often seems quaint.

Frequent Misunderstandings.-As every thoughtful inquirer has to make up his mind in regard to the importance of modifications or 'nurture-effects' for the individual and for the race, a few explanations may be of use to obviate misunderstandings which are of tedious recurrence.

(a) A temporary change which does not persist after the inducing conditions have ceased to operate may be called an 'adjustment' or 'accommodation,' and usefully distinguished from a modification, which lasts. It is not pretended, however, that any hard and fast line can be drawn.

(b) A modification is a 'nurture-effect,' but that is not precise enough, since normal development always means an interaction between the hereditary nature and the appropriate nurture. A modification is a structural change directly due to a peculiarity or change in nurture.

(c) In continuation of what has just been said, it should be noted that the list of modifications in the strict sense should include only the direct new results of peculiarities of nurture. A change in nurture often serves as the liberating stimulus of a character or quality which remains unexpressed in the ordinary environment. For many organisms liave, as we have seell, alternative possibilities in their constitution, the expression of the one or the other depending on the available nurture. 


\section{THE INFLUENCES OF NURTURE}

Thus the red Chinese primrose has red or white flowers according to the temperature; we have not here to do with modification, but with alternatives of hereditary expression. A true modification is something more or less novel, a directly impressed dint. Yet this word ' dint' must not be taken in any wooden way, for the organism is not like passive clay in the potter's hands. Even the environmentally produced modifications are the result of reactions on the organism's part. To tell the truth, none of our words and frameworks ever fit the living creature perfectly, for it is quite legitimate, though we doubt if it is useful, for the critic of the contrast between modifications and variations (what is impressed and what is expressed) to say that no structural response can be got from the organism save what it was by hereditary nature capable of giving.

(d) It tends to clearness if a distinction is drawn between modifications and their secondary consequences. The body is a unity; part is bound to part; if one member suffer, other members may suffer with it. But it is useful to distinguish the original modification from correlated changes that may follow in its train.

The Question of Transmission.-It is certain that modifications may mean much for the individual. They may even save its life. But can they be handed on ? The question is whether a modification can affect the germ-cells of the organism in such a definite way that the offspring, not subjected to the nurtural peculiarity that modified the parent, will through inheritance exhibit 
the modification that the parent acquired, or even an approximation towards it. There are not many questions more important than this. Herbert Spencer wrote : "A right answer to the question whether acquired characters are or are not inherited underlies right beliefs, not only in Biology and Psychology, but also in Education, Ethics, and Politics." With unwonted rashness he also said: "Either there has been inheritanee of acquired characters, or there has been no evolution."

Now it is certain that the transmission of individually acquired modifications to any readily observable degree is not a common occurrence. It is possible that it occurs rarely; it is possible that it occurs in a degree so minute that the entailnent is not readily observed. The subject has been much discussed for nearly half a century, and a few very careful experiments have been made, yet it cannot be said that the evidence adduced in support of the affirmative position is convincing. Many, if not most, biologists remain unconvinced, not through any unwillingness to recognise the possibility, as Darwin did, but because the evidence is unsatisfactory. There is no reason to close the question dogmatically with an absolutely negative answer, but it does not seem to us that the evidence in support of the affimative or Lamarckian position-that modifications may be transmitted in some representative degree-is at present convincing.

Indirect Arguments in Favour of an Acceptance of the Lamarckian Vierw.-In the absence, so far as we know, of clear-cut evidence showing the transmissibility 
of individually acquired modifications let us consider indirect arguments.

(1) How can there be progressive evolution at all, it is asked, if acquired characters or structural modifications due to peculiarities of nurture are not accumulated by transmission? The answer is that progressive evolution probably depends on a sifting and singling of the continuous crop of germinal variations or mutations. About 1818 the record speed of the trotting horse was 3 minutes to the mile, in 1814 it was $2 \mathrm{~min} .34$ secs., in $18482 \mathrm{~min}$. 30 secs., in $18682 \mathrm{~min}$. 20 secs., in $18792 \mathrm{~min}$. 16 secs., in $18882 \mathrm{~min} .11 \frac{1}{2}$ secs., and (when our information stops) $2 \mathrm{~min}$. 10 secs. The question is whether the progressive gain in speed was in any way due to exercising, or wholly due to breeding from the constitutionally swiftest variants.

(2) It is easy to interpret a giraffe's long neck as the cumulative hereditary result of hundreds of thousands of years' stretching at branches, and a cave-animal's blindness as due to thousands of years of darkness and disuse. Herbert Spencer interpreted his small hands as the result of the minutely manipulative work in which his father and grandfather were engaged. But interpretation is not proof. (3) A common fallacy is to start with a peculiarity which is not proved to be a modification. The argument runs as follows:- Short-sightedness is due to straining young eyes over small print; shortsightedness is transmitted; therefore modifications are transmitted. But it has not been proved that shortsightedness is a modification. It occurs in people who 
do not read or strain their eyes; it occurs in horses ; it is probably due to a germinal variation. It seems that a change impressed on a unicellular organism may be handed on, but the distinction between 'body' and 'germ-cells' has not been established at this low level.

(4) Reappearance in successive generations does not prove transmission, unless the possibility of the modification being hammered on afresh be excluded. (5) What is exhibited at birth in a mammalian offspring or at separation in a flowering plant's seed is not necessarily part of the inheritance, it may have been impressed on the offspring by the mother, through the medium of the blood or the sap. The secondary or indirect results of a maternal modification may thus affect the unborn mammal or the unliberated seed, since both live in close union with the parent. (6) Poisoning of the whole system of the parent may cause deterioration of the germ-cells, and yet not result in the transmission of any particular modification. (7) Sheep transported to a colder country may show after some months a change in the character and length of the wool ; their progeny may have even thicker and longer fleece. Is this not proof enough of the transmission of a modification? The answer must be "Certainly not." For the second generation were subjected to the peculiar nurture from birth, their parents only from the date of transportation. If there were measurable increase in the third generation as compared with the second, and if no selection was in process, there would be evidence worth considering. But we do not know of its being forthcoming. 
Human occupations often produce modifications. Are these not handed on at all? There is very little hint of any such thing. Overwork on a mother's part may prejudice her child; this is admitted by all. But an arrest of development or a general debility induced by defective nutrition is very different from the transmission of a particular individually acquired modification. In connection with occupations it must be kept in view that the son often follows his father, and may soon have the occupational modification impressed upon him. Moreover, particular constitutional types may gravitate towards particular occupations, and of the inheritance of particular kinds of constitution there is no manner of doubt.

Habitual drunkenness on the part of a parent or of the parents may produce modifications, and may be followed by dire results in the offspring. Is this not evidence enough of the transmission of modifications? Certainly not to those who wish to think clearly. There is some evidence that thorough poisoning of the body may cause deterioration of the germ-cells of either parent; (2) the intemperate habits of the parent may be the expression of an inherited lack of control, and it is this lack that is transmitted to the offspring, where it may find the same or some other expression; (3) drunkenness on the mother's part may mean serious enfeebling of the general vigour of the child during the period of ante-natal partnership; (4) some children get alcohol as part of their food from the days of suckling onwards. The question is not easy. A belief in the transmission 
of modifications was perhaps expressed in the old Hebraic proverb: "The fathers have eaten sour grapes, and the children's teeth are set on edge "- - a proverb which the prophet Ezekiel with great solemnity said was not to be used any more in Israel (Ezek. xviii. 2). Now, if "setting on edge" was a structural modification, and if the children's teeth were "set on edge" because of what had happened to their fathers in direct consequence of eating sour grapes, there would have been a presumption in favour of a belief in the transmission of this acquired character. It would still be necessary, however, to be very careful in our conclusion,- to inquire, for instance, whether the children had not been in the vineyard too. If, as Romanes said, the children were born with wry necks, we should perhaps have to deal with an indirect result of the parental indiscretion, and not with any direct representation in the inheritance of that particular modification which was produced in the parents as the direct result of eating sour grapes.

To come down to very concrete cases, peculiarities like rickets, enlarged heart, eye-strain, are modifications, dints or imprints due to peculiarities of environment, nutrition, use and disuse, and the trend of the evidence is certainly towards the conclusion that they will not be transmitted.

Parable of the Peach Trees.--The French biologist Bordage made careful observations on south European peach trees which had been transported to Reunion in the West Indies. As has been noticed in similar cases, they became evergreen,-it took some of them twenty 


\section{THE INFLUENCES OF NURTURE}

years. The individual constitution was altered; they stopped shedding their leaves in autumn. Now, when seeds of these false-evergreens, modification-evergreens, were sown in certain mountainous districts with a considerable amount of frost, they grew up into evergreen peach trees. This looks at first sight like a demonstration of the transmission of an acquired character. But one has to remember that a seed is a complex thing with a considerable history behind it; it is not a germcell ; it is a young plant. The body of the seed had probably been profoundly influenced by the body of the parent plant before separation took place. So is it in mammals and in Man. It is necessary to distinguish between what is acquired or imprinted before birth and what is in the strict sense part of the inheritance.

There are many structural adaptations that almost inevitably suggest to the impartial inquirer that they have arisen by the cumulative inheritance of the results of use and disuse or of peculiar environmental influence. The camel and the wart-hog have great callous pads which protect the skin on areas subjected to great pressure. We know that callosities sometimes develop on individual animals, as on our own hands, as the direct result of pressure. What more natural than the interpretation of the pads of camel and wart-hog as the result of the hereditary accumulation of modifications? What more natural than to interpret in a similar way the blindness of cave animals or the shape of a snake? To this it may be answered that "what seems natural" is not necessarily valid scientifically. Moreover, many 
hard non-living parts of animals, such as the chitinous tools of insects, are just as suggestive of direct adaptations as the pads of camels, but the interpretation is impossible, since they are not living or individually plastic.

The entailment of individually acquired modifications seems such a ready method of securing progress in evolution, that if it does not occur one would like to know why. The answer is not far to seek. If individually acquired advantageous gains could be entailed, the same would also apply to individual losses. Were transmission of modification on the credit side of the account, would there not be the same on the debit side? Had there been any way of entailing modification gains, but not modification losses, it would surely have been found out long ago. There seems to be no way. Why are modifications not transmitted? Actually, because of the absence of any arrangement, so far as we know, for securing that modifications can affect the germ-cells in a manner so specific that the offspring exhibit the same modification, or some approximation towards it. It has been suggested by Cunningham, Bergson, Dendy, and MacBride that a modification may liberate a specific hormone which affects the germ-cells representatively; and the same idea was in Darwin's mind in his theory of gemmules liberated from the various parts of the body and travelling to the germ-cells. But it must be firmly pointed out that these are unverified speculative interpretations of the possible accomplishment of what we do not know to be a fact. From the point of view 
of racial welfare, modifications are not entailed because an advantageous constitution is thus saved from being damaged by dints and buffetings incident on the chequered life of the individual body.

If it be said that it is incredible that individual experience counts for nought in evolution, the answer must be that is not asserted. The individual experience affords the opportunity for playing the cards which germinal variability puts in the organism's hands, the opportunity for testing the survival value of new departures whose origin is from within.

\section{§4. Nurture of the Higher Faculties}

As we have seen, Man's natural inheritance includes on the mental and moral side (1) a common stock of intellectual and emotional capacities (shared in some measure by all mankind, but varying greatly in intensity or potential), (2) a common stock of fundamental instinctive predispositions and springs of conduct, and (3) a number of individual traits or idiosyncrasies.

Now, while the respiratory movements of the newborn child are set a-going almost automatically by a change in the physico-chemical character of the blood, and are continued almost automatically throughout life, so finely adjusted according to need that they are rarely at fault in healthy people, it is surely very different with the higher mental and moral capacities. They are not like so many musical boxes in our brain that may be set a-going with a touch and then left alone. They are more like seeds which require to be 
watered and sunned. They require, as every one knows, careful and subtle nurture if they are to develop aright. To an extent to which the development of the body offers no analogy, the development of the mind is a social product. As we look round among our fellows, we see many whose widely recognised ability was marked in childhood; there is no getting away from the fact that a fine brain was part of their natural inheritance. But it is not less certain that men of no special excellence of cerebral endowment may by fullness of nurture attain to a high degree of mental efficiency, and that there are others whose fine sword is allowed to rust in its scabbard. The poet, the painter, the musician, the mathematician of high excellence is born not made, but there is in the majority of civilised men a small bud at least corresponding to the fine flower of genius, and a certain poetical, artistic, musical, and mathematical capacity is within reach of most. It may be an exaggeration to say that we are as much made as born; it is certain that more can be made of us than we usually believe.

Future generations will probably wonder at our treatment of, let us say, the rovers. They can no more help being rovers than one can help having red hair. What has to be done is to make the best of them-in boy scouts to begin with, perhaps, as explorers, King's messengers, missionaries, and the like later on. To try to make one an elder of the Church is to court disaster.

From 89 family histories not selected Dr. Davenport has given substantial backing of fact to his interesting thesis that there are in our natural inheritance two unit 
factors-one which he calls excitability, its absence spelling placidity, the other which he calls cheerfulness, its absence spelling depression. With rare exceptions the offspring of two excitable parents are excitable; out of 133 such offspring, only 6 were well-balanced, quiet, douce, placid, sensible people, like you and me. The excitable types correspond to the old 'nervous' types: active, energetic, irritable, excitable, ambitious, given to planning, optimistic, talkative, and jolly. An extreme of this is the old 'choleric' type: overactive, fussy, shifting from one thing to another, usually hilarious, passionate, even violent.

Similarly the man without the cheerful factor corresponds to the old 'phlegmatic': he is quiet, serious, conservative, and a little pessimistic. If this goes too far it becomes the old 'melancholic'-unresponsive, taking things lying down, weak, given to worry, and even to tears. His life is rather a burden to him, and certainly to other people. It often looks as if a dichotomy ran through our whole population-between the quickly reacting, with low arterial tension, and the slowly reacting, with high arterial tension, which again may have to do with the secretion of adrenalin by the suprarenal bodies. We know the dichotomy between the enthusiast and the reflective, the romantic and the classic, the radical and the conservative, the feebly inhibited and the strongly inhibited, the Bohemian and the conventional, the tender-minded and the tough-minded, the idealist and the matter-of-fact man, the free-willist and the fatalist. As Dr. Davenport says, the two contrasted. 
types are to be seen in all sorts of garbs:- "In business, the bold, energetic, dashing promoter and the solid, conservative, thrifty merchant; in law, the emotional jury lawyer and the learned judge; in medicine, the skilful operator in difficult cases and the skilled diagnostician and consultant; in divinity, the magnetic evangelist and the profound theologian or exegetist ; in war, a dashing Sheridan and a solid, quiet Grant."

Dr. Davenport thinks it probable that there are in the germ quite definite determinants whose presence or absence settles our dominant temperament whether excitable or placid, cheerful or depressed. The amendment that we propose is that, human life being a very complex thing, the probability is that the settled temperaments of most of us, though based on definite hereditary determinants, are complicated resultants of many factors bodily as well as mental, social as well as individual, environmental and occupational as well as constitutional-made as well as born, for we build them up in the way we relate ourselves to nurture and opportunities, just as we build up our characters. We are architects of our own fortunes. Our mind is an instrument which we and social influences construct together. Mental Disturbances.- This is the appropriate place for a reference to what some authorities have told us concerning nervous or mental disturbances. After a long experience of the insane, Sir Thomas Clouston came to the conclusion that what was continued in the inheritance of the mentally affected was usually a general proclivity or weakness, e.g. in the power of control, 
and not any particular disease, such as some form of insanity.

It is certain that what was in the parent a weakness or tiredness of the brain (general neurasthenia) may take some other form in the offspring, possibly under provocation a more virulent form, and that it may be shifted from one period of life to another. Dr. F. W. Mott has given interesting cases of what he calls "the law of anticipation"-the tendency that the nervous disturbance sometimes shows to be shunted earlier and earlier in its expression.

As every one knows there is a rapidly growing conviction that those who have a marked family predisposition to serious mental instability should not have children. The individual and racial risks are too great. What constitutes "a marked family predisposition to serious mental instability" must be decided by the wise family physician (or by the board of experts who will perhaps grant marriage certificates in the future). But this much is clear, that a common-sense distinction should be drawn between a weak-mindedness and uncontrolledness which is manifested from birth onwards and is plainly bred in the bone, and a nervous breakdown which occurred in a catastrophe, such as an earthquake, or under a terrible strain, such as that of the trenches. The former will be very heritable, the latter probably not.

But what we have learned in regard to the importance of nurture leads us further, and we venture to quote from a recent report by a distinguished authority in 
this dreadful field. Dr. Easterbrook writes: "It cannot be too strongly emphasised that no one becomes insane without previously being or becoming 'nervous.' ... It does not follow that every nervous individual will become insane. . . O Only a small proportion do so. ... Those who have an unstable nervous system should recognise it as such, their weak point of defence and resistance, and regulate their lives accordingly."

A nervous disposition may be inherited and then transmitted, but it may also be acquired and then not transmitted. Faulty habits of mind and body which lead to the nervous disposition-which is the dangerzone of insanity-are often remediable, especially in early years. Just as sleeplessness may warn a man that he is overworking or overpoisoning himself, or that some organ of the body is insidiously going out of gear, so the acquired nervousness may be a useful warning of the possibility of worse. Insanity is often summed up as due to unstable inheritance shaken by stress, but it would be truer, Dr. Easterbrook says, to refer insanity to nervous disposition and stress. And the point for us in this simple discourse is just this, that while the nervous disposition is sometimes inborn or inherited, it is sometimes acquired or induced. In the former case, it cannot be got rid of, but it can be quieted or provoked according to the wisdom or folly of nurture. In the latter case, it can be un-made if taken in time, or redirected into safety by appropriate discipline. Best of all, it may be avoided altogether.

Criminals.-It would be absurd to try to discuss in 


\section{THE INFLUENCES OF NURTURE}

a few lines a vast subject like criminology-a large section of social pathology-but we venture to invite attention to the thesis to which so many careful investigations point, that there are more crimes than criminals. That is to say, crime is more frequently the result of external influences-especially economic and political conditions-than the expression of a definitely criminal nature. In support of this thesis we may refer, for instance, to the learned work of Dr. W. A. Bonger, Criminality and Economic Conditions, the conclusion of which is that the preponderant, if not the decisive, cause of criminality is to be found in economic conditions. If this conclusion be true, it follows that there is need for further changes-much has been done-in our treatment of criminals. There is much reason to doubt whether our present system of punishing certain kinds of crime, such as theft and public drunkenness, has any beneficial effect on either prisoner or on society. The punishment tends to distract attention from the social causes of the crime and tends to make the criminal. That, at any rate, is one side of the case, in which there is much truth.

On the other side there is the position of criminologists like Lombroso and Ferri, who have emphasised the reality of the criminal type. It is the contrast between 'nature 'and 'nurture' again, and the truth lies between the two extreme positions-that which lays all the blame on environment and that which lays all the blame on the individual. Criticism has seriously damaged the validity of Lombroso's thoroughly criminal type with 
all sorts of stigmata, but his conception was an exaggeration of one side of the truth. Human beings are sometimes born in a very imperfectly finished state of development-for infants, that is ; others are singularly deficient in generous impulse, imagination, power of attention, and power of control-defects which spell weak will when added up; it looks as if others were born with a double dose of sex. It is quite easy to understand how a constitutional disharmony in the supra-renal bodies might predispose an individual to crimes of violence, just as a constitutional disharmony in the thyroid gland might predispose a child to idiocy.

It is of great practical importance to realise that predispositions to certain crimes, like predispositions to certain diseases, may form part of the individual inheritance; and that, while they cannot be got rid of, their development in the individual may be greatly affected by 'nurture.' A roving disposition in the inheritance may easily afford the starting-point for a criminal career, especially if the first or second 'roving' is branded as a crime. On the other hand, a well-thoughtout system of nurture may use the roving disposition to the positive advantage of society. Many so-called criminals are only anachronisms. It is not proposed that they should be exempted from social selection; what is desired is that our treatment of them should be intelligent.

At this point it is useful to refer to the story of the Jukes, as told by Mr. Dugdale in 1877 and brought up to date in 1918 by Dr. Estabrook. "Into an 
isolated region, now within two hours' railroad journey of New York, there drifted nearly a century and a half ago a number of persons whose constitution did not fit them for participation in a highly organised society. There were, of course, various degrees of inadequacy; and the retired, well-wooded, and well-watered valley [one recalls Mr. H. G. Wells's wonderful picture of 'the country of the blind '] gave many of the immigrants a chance to pull themselves together. It was a change of nurture, and some profited by it; but perhaps the conditions were too easy. Among the immigrants who did not profit by the change were some uncontrolled types who had been 'assisted out' of Europe, with a strong hereditary bias towards evil. From such came the Jukes. Here are some of them: Max, the hunter and the fisher, the jolly, alcoholic ne'er-do-well; Lem, the stealer of sheep; Lawrence, the licentious, free with his 'gun'; Margaret and Delia, the wantons; and Bell, who had three children by various negroes." Dr. Davenport, who writes the preface to Dr. Estabrook's investigation of the later history of the Jukes, points out that inbreeding of originally bad stock made matters worse, for defects were brought in from both sides. Some outbreeding with good stock yielded progeny who were able to hold a good position in organised society.

Mr. Dugdale was a quiet reticent Englishman resident in New York, who had an unusually lively faith in political education, and was keenly interested in social reform. On an official visit to jails in County ' $Z$ ' in 
the Stage of New York, he was struck by finding prisoners under four family names who were blood relations in some degree. He set to work to discover the hereditary relations and the nurture of these unfortunate people, and was able to study 709 persons, 540 being Juke blood, and 169 of ' $\mathrm{X}$ ' blood who had married into the Juke family. He found that there had been 140 criminals and offenders, 60 habitual thieves, and so on, the degenerate lot of them costing the State in three-quarters of a century (beginning with 1800) over a million dollars. Mr. Dugdale was a careful thinker, and what his book, published in 1877, really showed was that given a bad hereditary nature and a bad environmental nurture, there will be a multiplication of criminality, harlotry, and pauperism.

It should be noted, if it is not too obvious, that the name Juke was fictitious, and that the names of places were not given, so that the publication of The Jukes did not bring about a result like that which follows giving a dog a bad name. Not that this factor of social branding can ever be eliminated. The chance discovery (in 1811) of Mr. Dugdale's original manuscript made it possible for Dr. Estabrook to bring the dismal story of the Jukes down to 1915; and the sequel is not less instructive than the book itself.

Starting with five Juke sisters, the investigator has found out a good deal about 2,094 people, of whom 1,258 were living in 1915. To about a half of the total the somewhat vague term "feeble-minded" is applied; the history of the other half seems to have 
varied greatly-as our own does-according to the social nurture. Let us take a few particulars. In 1915 there were 43 male Jukes, between the ages of 15 and 18, anti-social and doing poorly, 2 criminal, 1 so obviously mentally defective as to bc noticeable to the general community, 19 industrious. In 1915 the number of males over 19 and of females over 15 was 705 ; of these 305,43 per cent., were described as inimical to the general welfare of the community, including 41 criminal, 103 mentally deficient, 83 intemperate. But 152 were industrious and 65 were classed as good citizens. Of these good citizens, we are told that "the bad traits which have held down their brothers and sisters have become lost, and they are fountain-heads of new families of socially-good strain." It will be an interesting exercise to think out what is meant biologically by a peculiarity being "lost."

Some of Dr. Estabrook's general conclusions are interesting :-in radically defective stock cousin-mating results in defective offspring; there is a clear hereditary factor in licentiousness; all the criminals in the lineage were also weak-minded; one in four Jukes is improved socially by Children's Institutions; the ne'er-do-well in new surroundings often finds another like himself, but improved social environment counts for much in the individual's development, success in life, and chance of marrying into a better family. But this only applies to those who are hereditarily able to respond to the improved nurture, who are not beyond the pale of the desirable. 
The five sisters were represented in 1915 by 600 feeble-minded and epileptic Jukes, of whom only three were in custodial care. This piece of statistics suggests the necessity of doing something to stop the multiplication of Jukes--who are not confined to America.

Limits to the Potency of Nurture.-So far, the outcome of this chapter is a reasoned appreciation of the life-moulding potency of nurture, especially as regards the individual. But there are certain saving-clauses to be borne in mind. (1) Strong natures often thrive well on hard nurture, just as oppression often stimulates love of freedom. There is much to be said against making things too easy for the mediocre. On the other hand, there is reason to fear that a good many individualities of first-class ability are still wasted for lack of appropriate nurture. It is certain that many quite sound organisms slip down the ladder of evolution more because of deficiency in nurture than through deficiency in nature.

(2) Good nurture sometimes makes an individual look better than he is; and there is an unfortunate risk of veneering rotten wood. The 'unfortunate risk' is lest good stock be tainted by the introduction of what is unsound in reality, though sound in appearance. It may be remarked, however, that it is absurd to get into the way of talking as if society was made up of 'clean' and ' unclean,' like the fauna of the Pentateuch, or of desirables and undesirables, saved and damned. "We are not all the finest Parian," as George Eliot said. Furthermore, family histories are 
not buried in obscurity, and a degree of unsoundness which can escape the attention of parental eyes quickened by love, the experience of the family physician, and the everyday tests of work and play, is not likely to be so very unsound. Apart from marriage certificates, which will probably come, what is commonsense for? What has been wrong in the past has often been that obvious unsoundness was winked at.

(3) Deteriorative nurture sometimes makes people look worse than they are ; and there is an unfortunate risk of confusing dints due to the blows and buffetings of outrageous fortune with outcrops from within. The social consequences of giving a dog a bad name are familiar, and it is to be feared, for instance, that there are more criminals made than there are born. As it is said in the Gospels: it is what cometh from within that defiles a man.

\section{§5. The Other Side of Heredity}

The past lives on in the present, that is what is meant by heredity. There is an inexorableness in the transmission, or one should rather say, the persistence, of all sorts of inborn or constitutional characteristics. Sometimes it is a trivial feature like a shock of white hair; sometimes it is a deadly vice of blood; sonetimes it is all bodily, leaving the spirit unblemished, as in many cripples; sometimes it is a blot on the brain that affects the character now in this way and again in that, but always perniciously. There is no gainsaying the fatalistic impression, and since heredity is just a 
term for the relation of organic continuity between successive generations, there can be no other side to it. But there is no harm in using the phrase " the other side of heredity" to indicate that the fatalistic impression of determinateness is not the whole truth. There is another side to the inevitable reappearance of an evil past, another side to the inexorable transmission of defects, another side to the terribly discouraging hereditary handicapping, another side to the undeniable lien that our ancestry has over us. We must drie our weird, but' we need not surrender the captaincy of our soul.

(1) Perhaps it is unwise to seek much satisfaction in uncertainties that surround inheritance, which lead some people to "risk it," as they say. For the uncertainties are disappearing. Yet we may be pardoned for recalling a really beautiful expression of the unpredictability of heredity from Thomas Fuller's Scripture Observations:-" Lord, I find the genealogy of my Saviour strangely checkered with four remarkable changes in four immediate generations.

"1. Roboam begat Abia; that is a bad father begat a bad son.

"2. Abia begat Asa; that is a bad father a good son.

"3. Asa begat Josaphat; that is a good father a good son.

"4. Josaphat begat Joram; that is a good father a bad son.

"I see, Lord, from hence, that my father's piety cannot be entailed; it is bad news for me. But I also see, that actual impiety is not always hereditary; that is good news for my son." 
(2) Perhaps one is a little apt to forget that the hereditary relation is even-handed. It is for better as well as for worse. It secures the entailment of all manner of wholesome human qualities. Nay more, when we take a broad view, it is more than even-handed, for there is more likelihood of the hereditary entailment of the stable, the harmonious, and the integrative. The dice are loaded in our favour.

(3) There is a continual variability or creativeness which affords fresh raw material for progress. The mould is always being broken, and the image cast over again. But this metaphor is too static; it is better science to say that the little child is always leading the race. Against the fact of persistent hereditary resemblance has to be set the fact of variability.

(4) We do not really know how novelties take origin. We have no recipe for the production of organic movements in the direction of heritable vigour or intelligence, beauty or goodness. But the speculation is worth considering whether beneficial changes of nurture may not evoke beneficial variations in the germ-cells. We know that individual children often take big strides after they have had a change to a new environmenta new world of liberating stimuli. Is it ridiculous to suppose that this may be true of the implicit potential organisms we call germ-cells? As Professor E. B. Wilson, one of the wisest of living biologists, has said, "In the present defective state of our knowledge we may well grant that there may be many a thing between germcell and body that is not dreamed of in our biological 
philosophy." In the opinion of Professor Bateson, than whom nonc has more right to be listened to, it is a reasonable view that environmental change may lead to abnormal divisions in the ripening germ-cells, and that these abnormal cell-divisions are the starting-points of new varieties. Broadening this, me may suggest that changes in nurture may have an unsuspected importance as the liberating stimuli of germinal variations.

(5) The quality of nurture, which is largely in Man's own hands, determines the degree to which the buds of good qualities in our inheritance may be made to unfold, and the buds of bad qualities may be kept more or less dormant. We do not know-when we are young, at any rate-all that is in our inheritance; it is commonsense to give it every chance, with as varied a nurture as we can. This is one of the reasons for embarking on adventure, when there is opportunity, before our voyaging is narrowed down to a stated course. As long as we are young at least-we discover ourselves gradually-we do not know all that is in our inheritance ; the common-sense advice is not to take too many chances, not to play with fire, and to let sleeping dogs lie, if we can.

(6) For the individual there is great plasticity as the rcsult of changes in environment and function. Man is very modifiable and educable. And though the resulting modifications do not seem to be transmissible as such, they can be reimpressed, if desirable, on generation after generation. In her interesting study, Environment and Efficiency (1912), Miss Mary Horner Thomson 
tells of her study of 265 children, mostly of " the lowest class" (Class A, fourth below the poverty level!), who had been sent to institutions and trained. She found that 192 (72 per cent.) turned out well; that 44 (16 per cent.) were doubtful; and that only 29 (less than 11 per cent.) were unsatisfactory, and of these 13 were defectives. One would like to know, of course, that the turning-out-well lasted, and one would like to have a hundred similar sets of figures. But the suggestion is that nurture means much to the individual.

Professor Punnett probably expresses the views of most biologists when he says: "Hygiene and education are influences which can in some measure check the operation of one factor [(what in the germ-cell is causally related to a character in the adult)] or encourage the operation of another. But that they can add a factor for a good quality, or take away a factor for an evil one is utterly opposed to all that is known of the facts of heredity." But there are modifications that hygiene and education can imprint on the organism, and the very fact that these are not hereditarily entailed should lead us to an increased appreciation of their importance. Desirable modifications can be impressed on each successive crop and undesirable modifications evaded. It should also be borne in mind, though it is rather a speculation than a fact, that desirable modifications hammered on generation after generation may serve as a protective screen for an inborn variation evolving from within in the same direction.

And apart from particular modifications, this also 
should be realised, that thoroughly bad nurture may arrest the development of the general constitution, reducing vigour and reacting porver. This may be cumulative if the bad nurture persists, though not perhaps hereditary in the strict sense. Contrariwise, a notable improvement in good nurture may raise the whole pitch of the individual offspring's life, with the result that the individual makes more of his opportunities, and in turn secures still better nurture for his children.

(7) There is another consideration that is of the utmost importance and in no way speculative. What is particularly characteristic of Man is his external registration of the gains of evolution. His extraorganismal organisation-so far away from the anthill or beehive-includes fresh air, pure water, sound food, pleasant houses, leisure, and so on up to traditions and institutions, literature and art. All this is part of our nurture, and the chances of a promiseful new departure developing and persisting must depend considerably on the reception it meets with in the externally systematised nurture. The evolution of 'nurture' must accompany the evolution of 'nature' if progress is to be secure. In our social heritage, which is as supreme as our natural inheritance is fundamental, there are ever-widening opportunities for transcending the trammels of protoplasm. Wherefore, let us lift up our hearts. 


\section{$x$}

\section{CHAPTER V \\ THE BIOLOGY OF HEALTH}

$\S 1$. The Meaning of Health.-- $\$ 2$. The Body as Engine-and More.- $-\S 3$. The Nervous System.-- 4 . The Regulative System.-- 5. What is Disease?

\section{$\S 1$ The Meaning of Health}

W $\mathrm{E}$ need not delay over definitions of health, for every one knows in a general way what the priceless gift means. It is much more than the absence of disease, it implies a positive quality of versatile vigour; and that depends on the harmonious working of the chief parts of the body. It need not mean great strength, a powerful dray-horse is often far from healthy, but it always implies a pleasurable efficiency. It is the condition which a man describes when he says he is feeling "very fit," when he is able for vigorous and enduring self-expression. He feels " a man for a' that," not, as Samuel Butler said, a mere appanage of his wife or some other near relative.

But we have to widen this idea of internal fitness by recognising that the ideal of health includes fitness to the external conditions of life in so far as these are of a kind that make for the conservation and enrich- 
ment of life. The healthy man must be able to adjust himself to circumstances without losing his foothold; he must be able to respond to stormy as well as sunny days; he must have a fair measure of resisting power to the invasions of disease-germs and to other deteriorative influences.

Yet health, we must admit, is a relative quality, and our attainment of it is not usually more than approximate. (1) One reason for this is that many of us start with some hereditary handicap, sometimes trivial, sometimes serious. All that we can do is to recognise and understand this handicap, and to establish by wholesome surroundings and habits a set of counteractives. (2) But there is a larger reason-namely, that Man's bodily organisation does not in its evolution keep pace with his habits and surroundings. Thus it is that some old-established parts of our structures, which have done duty admirably for ages, do not suit quite so well in the artificial conditions of modern life. They lag behind and give rise to what are called bodily 'disharmonies.'

For an understanding of bodily disharmonies we owe much to the insight of the Russian biologist, Metchnikoff (d. 1916), though he tended, like many other discoverers, to overstrain his bow. The reduction of the snout region and the enlargement of the forehead became possible among our arboreal ancestors by the emancipation of the arm from being an organ of support for the body, as it is in quadrupeds, and by the promotion of the hand-the free hand--to the office of testing things, 
grasping things, and lifting some of them to the mouth. But one of the far-off consequences was a crowding of the teeth in the jaw, and this, accentuated in modern man, has given rise to many problems of dentistry, and to a considerable amount of handicapping disharmony among otherwise healthy men, women, and children.

To take another illustration, Man is heir to some thirty feet of food-canal, with a naked-eye surface of 7 to 8 square feet. Part of the canal seems to be of much more trouble than it is worth. In early days, Man had to eat a good deal of bulky and crude food, which meant a considerable amount of undigested residue, which accumulated in the large intestine. This was all very well in early days. In modern times, however, among civilised people, Man has been able to procure much better food-with much less useless stuff about it, not that we can safely dispense with hardness of texture and a measure of bulk. And besides getting better food, Man now tends to eat more sparingly than in days gone by. Moreover, for the most part, he no longer eats when he can, but has regular meals served with more or less punctuality. Now these changes of habit are robbing the large intestine of an appreciable part of its utility, and it is a not infrequent seat of disease as well as a source of poisoning.

(3) But besides hereditary weaknesses and disharmonies there are other reasons why Man's health is apt to be only approximate. Perhaps these may be 
summed up by saying that Man's instincts are very generalised and that his restless intelligence prompts him to experiment with himself and to 'chance things.' He has very little of a resting instinct; he has relatively little clear awareness of what is good for him; he does not understand the significance of pain and sleeplessness as danger-signals; he is so safe in his stronghold of wits that he runs risks for the sake of immediate pleasure. In a way quite unique among organisms he uses artificial means to stimulate his energies or to dull the sense of fatigue, and however useful or pleasant these means may be, no one can pretend that they do not involve some risk. By ambition, zeal, or dire necessity, man is often forced to overwork himself, and then he often seeks " the shortest way out," for alcoholism is often the nemesis of an attempt to evade occupational fatigue. In the very imperfectly organised social systems of to-day it is often difficult for an ordinary citizen to secure a mode of life that allows enough open air, exercise, and change. And so Man falls from the norm of health.

\section{§2. The Body as Engine}

An animal is much more than an engine, for it is self-stoking, self-regulating, self-adjusting, self-repairing; it can register experiences and profit by them; it is more or less aware of what it is doing, and often plans and purposes; it can give rise or help to give rise to other creatures like itself. We have elsewhere (The System of Animate Nature, Gifford Lectures, 1920) tried 
to do justice to the deep differences between an animal and $\mathbf{a}$ whirlpool in the river, or between an animal and $\mathbf{a}$ machine (which is the embodiment of a human idea), and we hold firmly to the belief that a philosophical justification can be given for the common-sense belief that one enters a new world when one passes from the domain of things- the inorganic-to the realm of organisms, the obviously animate. But for purposes of investigation it is often very useful to treat the body as if it were an engine, and for the purposes of study it is also very useful to think of it in this way.

Many books have been written about the structure of our body, but perhaps the most illuminating plain account is that given by Professor Arthur Keith under the title The Engines of the Human Body (1920). His idea was to compare the structure of the living body to that of an engine, and to follow the comparison till it broke down, as break down it did. An engine is a mechanical contrivance for changing matter and energy from one form to another in order to do work; and our body is a living contrivance which does this and more besides. For we cannot forget that we think and feel.

If we ascend a hill road on a motor-cycle, we get to the top by mechanical work, the power or energy being supplied by the internal-combustion engine which makes the wheels go round. If we ascend a hill road on foot, we get to the top by mechanical work, the power or energy being supplied by our muscles which move those levers we call our limbs. But the metal engine works by pushing the crank-pin; it has a rigid cylinder and a 
rigid piston. Whereas the flesh engines or muscles work by pulling, and as they work they change their shape; and their piston-rods are flexible, we call them sinews or tendons. A muscle is a 'pull' engine; a motor-cycle is a 'push' engine.

Walking, when you come to think of it, is a very wonderful performance, and we cannot be surprised that it took us a good long time to learn. Nor do we all walk as well as we should. When we are walking at the rate of four miles an hour, only half a second elapses from the moment the heel of the foot is raised until the limb completes its swing forward and the foot is planted firmly on the ground again. Yet in that half-second fifty-four muscles or flesh-engines have been started and stopped, speeded up and slowed down, and that not once or twice but many times. Another very interesting thing is this, that when cur right leg swings forward, the whole weight of our body is balanced on the slippery ball-shaped head of the left thigh bone which works in the socket of the hip-joint. It is difficult to balance a weight on a slippery ball-andsocket joint; it would not be possible were it not that about fifteen muscles surrounding the hip-joint are set in action and work together, acting against each other, and yet in harmony with each other. But the balancing feat is helped by many other muscles in our momentarily stationary left leg, some at the knee, some at the ankle, and some at the arch of the foot. And next half-sccond all this will be happening in our right leg. Nor is this all, for as we walk we keep our body erect; 
our backbone does not sway unduly forwards or backwards, to one side or to the other. But our backbone is made up of many vertebræ, and to these 144 muscles are attached which give our body what we call poise. Indeed, there are about 300 muscles concerned when we walk. As Professor Keith says, "With every step-every half-second-some three hundred engines have been started, regulated, and stopped, and each has done its allotted task in helping the body forward." Were we not right in saying that walking is really a quite wonderful achievement?

When we draw our lower arm towards our upper arm, e.g. in lifting a teacup to our lips, we use a big muscle called the biceps, which we can feel working if we grasp our right arm just above the elbow with the fingers of our left hand. As the forearm draws nearer the upper arm, we feel the biceps muscle contracting; it becomes shorter and broader and harder under our fingers. The muscle is fixed above to the shoulderblade; it is fixed below by means of its piston-cord or tendon (mainly) to the radius bone of the forearm. When it contracts it lifts up the forearm and bends the clbow. Now this biceps-muscle is a huge collection of muscle-fibres-half a million in the arm of a workingman-each of which is a sort of microscopic enginecylinder. In the motor-cycle the space inside the cylinder is lengthened when an effective stroke is made; we are dealing with a 'push' engine. In the musclefibre, the cylinder itself becomes shorter and wider; we are dealing with a 'pull 'engine. In the motor-cycle 


\section{THE CONTROL OF LIFE}

the energy is supplied by the explosive combustion or oxidation of the petrol. In the muscle, the affair is more complicated, for the using up of the oxygen is not in the contraction itself, it is in the process which instantaneously restores the muscle-fibre to a state that makes another contraction possible. In fact, no one yet knows the secret of the muscle-engine.

But if we say cautiously that the muscles are peculiar engines, living engines, we may usefully continue to compare them to the internal-combustion engines of the motor-cycle. They are engines of great merit; they work so smoothly, with so little noise ; they always have their 'steam up,' ready to start working at a moment's notice; some of them never stop working all through life, while others are able to take a rest. They work in pairs, opposed to one another, and when one muscle goes into action a message travels into the nervous system and orders come back so that the opponent muscle yields just to the right extent. They say that the best engine man has yet made does not turn more than 20 per cent. of the energy of the fuel into effective work, whereas our muscles can turn about 25 per cent. of their fuel or food into effective work. Then the muscles are self-stoking, self-repairing engines, requiring no looking after from us, making no demands save one-that they be exercised.

The motor-cycle works obviously by wheels, which are very complicated levers; our movements are brought about by more ordinary levers-the bones. Students of mechanics know well that there are three kinds or 
orders of levers, and these are all illustrated in our body - the first order in the movement of the skull on the backbone; the second order in the foot ; the third order in the forearm and hand when the elbow is the fulcrum. Where one bone works on another there are cartilagebuilding cells that make good the wear of the joint surface-an impossibility in a metal engine; and when these cells have worked themselves out they are dissolved to form a lubricant. Thus our joints are kept from wearing away; thus our joints are kept supple. Like the engine, the body has its lubricating arrangements.

But the muscle-engines require to have fuel brought to them, and the living levers require to be kept in good order ; so we see the use of the heart as the pump of the body. It drives round the body a combustion-mixture (oxygen and blood-sugar) which is comparable to the oxygen and petrol which is brought into the motorcycle's internal-combustion engine. In both cases the waste products have to be swept away. The piston of the motor-cycle is made to do the pumping as well as the actual work; in our body the pumping apparatus (the heart) and the locomotor apparatus (the muscles) are quite separate from one another.

The motor-cycle would not work if it could not draw in fresh air and drive out foul air ; and the arrangement for this is comparable to the pair of bellows which we call our chest. Our windpipe is an air-pipe; our nose is a nozzle; the engines that work the bellows are carefully built into the sides and front and floor of the chest, 
The bodily engine is able, as we have seen, to get more work out of its fuel or food than any engine of man's constructing, and this depends (1) on the internal workshops or laboratories which prepare the food so that the engines make the most of it ; (2) on the regulations that keep up in birds and mammals a constant body-temperature (between $98^{\circ}$ and $99^{\circ}$ Fahrenheit in man); and (3) on the thorough arrangements for preventing the accumulation of any form of waste. We are fearfully and wonderfully made.

There is a sort of timing or regulating system in a motor-cycle, a series of revolving toothed wheels set so as to be turned by the crankshaft at fixed rates, but the regulation of the living body is so different that Professor Keith wisely drops the comparison. Our body, he says, is more like an army. There are millions of millions of microscopic living units or cells, many with considerable independence, yet all working with considerable perfection into one another's hands and so that a unified harmonious result follows. The brain and spinal cord correspond to General Head Quarters; the nerves form a living telegraphic system; and there is an altogether marvellous postal system by which "key-missives" are despatched throughout the body. These "key-missives" (chemical messengers or hormones) which are sent from ductless glands, like the thyroid gland, throughout the body are compared by Professor Keith to "ultra-microscopic Yale keys sent out to search for the locks of letter-boxes which they fit and can enter." Some kinds of key will fit 
only one kind of lock, and the lock seems to have a positive attraction for the appropriate key. Again we must say: We are fearfully and wonderfully made.

It is very useful to compare our body to an engine, but the comparison breaks down. In particular, the regulation of the living body is something that we cannot explain in terms of anything else. If the body is an engine, it is a self-stoking, self-repairing, self-regulating engine ; it can profit by experience; it can behave as a self-willed agent; it can work along with others; it may give rise to another engine like itself, as parents to their children. But, above all, the living body is a Mind-body.

The general idea to be grasped is that the body is a material system for transforming the energy of food into the energy of motion, whether that be the movement of limbs in locomotion or the beating of the heart. The furnace, the boiler, the piston are all, as it were, condensed in the muscular system. To keep the fire burning there must be a supply of fuel, which is prepared in our food-canal and liver. To keep the fire burning there must be air, and the lungs are the ventilating structures. To keep the fire burning there must also be a removal of the ashes, and this is effected by the lymph and by the blood which sweep the waste-products to filters like the kidneys. There must also be arrangements for regulating the supply of fuel, the draught, the speed, and so on. Anticipating a little, we may say that the obvious conditions of the continued efficiency of the bodily engine are plenty of varied exercise, plenty 
of food, sufficient rest, and adequate removal of wasteproducts.

\section{§3. The Nervous System}

As Sir Michael Foster said, there are two masteractivities in the body, and all the rest are ancillary or sustentative. One of the master-activities we have already dealt with very briefly-the contractility resident in the muscular system. The other master-activity is the irritability resident in the nervous system. This implies feeling and controlling, in its higher reaches, thinking and purposing. It is the nervous systemespecially the brain-that starts, regulates, and controls the motor apparatus represented by the muscles. In some ways the nervous system is like a storage-battery, contributing the initial spark that sets the combustion a-going. In other ways it is the intermediary between the rest of the engine and the outer world, so that suitable responses are made to what happens outside. It is also the intermediary between the various parts of the body, so that they work into one another's hands harmoniously. The learned word for this function is integrative-making many members a whole (see C. S. Sherrington's Integrative Action of the Nervous System).

An understanding of the general nature of the nervous system is indispensable if we are to understand health even a little bit; so we must linger over some fundamental facts.

(A) Our nervous system consists of (1) the braina world in itself with many nerve-centres integrated 


\section{THE BIOLOGY OF HEALTH}

into unity; (2) the spinal cord-a complicated tract of pathways apparently innumerable and of subordinate centres; (3) the nerves which issue from the brain and the spinal cord, some consisting of fibres which carry messages only inwards (sensory or afferent), some consisting of fibres which carry messages only outwards (motor or efferent), and some consisting of fibres of both kinds; (4) the sympathetic system-a series of small nerve-centres, connected with the brain and spinal cord, which have to do with the control of bloodvessels, food-canal, heart, and so on. The sensory nerves carry messages from superficial sense-organs or sensecells, and from sensory nerve-endings on internal organs. The motor or efferent nerves carry commands to muscles stimulating them to contract, and to glands stimulating them to secrete. There are also efferent nerves that command inaction, inhibiting rather than stimulating.

$(B)$ The nervous system consists of millions of microscopically minute elements-nucleated cell-bodieswhich receive, shunt, store, and combine messages received from the outside world and from the recesses of the body, and which also send out orders to the muscles and glands and other parts. The messages that come in and go out are carried, in some way that we do not understand, by nerve-fibres, which are very delicate outgrowths of the cell-bodies. The cell-body and its fibres taken together form a nerve-cell or nerve-unit, or neuron. The cell-bodies (often called the ganglion cells) are like the telephones of a telephonic system, and a certain set of them form the 'central.' The nerve-fibres 
are like the wires, and one set of wires (called sensory or afferent) carry messages to a cell-body or telephone, while another set (called motor or efferent) carry messages from a cell-body or telephone. The comparison is a useful one, but it must not be pressed far. Thus the 'Central' Office in a telephonic system may connect one telephone with another for purposes of intercommunication, but it is not supposed to store and combine messages as our brain does.

Besides $(a)$ the sensory neurons which carry messages inwards, and receive, store, shunt, or otherwise deal with them, and (b) the motor neurons which issue and carry orders, there are (c) many neurons which link the other two kinds together within the central nervous system. These are called connecting, communicating, or internuncial cells, and they actually form the bulk of the central nervous system. In some of them intelligence is at home.

Besides the neurons there are in the nervous system supporting cells (the neuroglia) and blood-vessels, and these weigh much more than the nerve-elements alone. It is interesting to notice in passing a quite unique thing about the nervous system, and that is the extraordinary length of some of the nerve-fibres, which, as we have seen, are outgrowths of nerve-cells. In Man, for instance, some of the fibres that issue from the spinal cord in the small of the back and reach to the toes are far more than a yard long, and they must be longer still in a giraffe.

(C) A great part of our nervous activity consists of 
what are called reflexes. Our finger touches something hot or sharp and we draw it away without knowing or willing. That is a simple reflex action; what is it that happens? An external stimulus acting on the nerveendings in our finger-tips is followed by a message which travels by sensory nerve-fibres up our arm to cells in the ganglia on the dorsal roots of the spinal nerves; the signal is passed on from these receiving elements into the spinal cord and stimulates internuncial cells; from these the message is passed on in the cord to the motor nerve-cells that give out orders; a command is sent viâ motor nerve-fibres to the muscles, and effective action results,-all in a shorter time than we take to say "Jack Robinson."

These reflexes occur independently of our will; they take place in virtue of certain structural connections which are established in the nervous system in the course of development. A sensitive nerve-ending is linked to a receptive neuron, this to an internuncial cell, this to a motor neuron, and this to a muscle. The linkages are established as part of our inheritance, and though people differ in the rapidity of their reflexes, there is a common stock shared by all mankind. The example we took was a very simple reflex; every one is familiar with many that are more complex, such as coughing, sneezing, sucking, swallowing, shivering. It would take us a long time to learn to sneeze, but the infant sneezes without a lesson. Some biologists would say that its body unconsciously remembers how to sneeze; what is certain is that an inborn organisation has made 
the process of sneezing easy and in certain conditions irresistible. Reflexes, the capacity for which is inborn, must not be carelessly mixed up with reactions which have become very rapid and facile in the course of long practice, e.g. in cricket, tennis, and bicycling. This facility, properly called habitual, is of course individually acquired, and is the outcome of a process of learning which is anything but facile to begin with.

Very important are the internal reflexes that only physiologists know much about. These are responses that organs of the body make to messages from other parts of the body, or to changes in the composition of the blood. When we are excited by good news and the heart beats with unusual vigour, there is an automatic enlargement of the blood-vessels so that there is a free outlet for the blood.

$(D)$ In some way that we do not understand, our personality is more bound up with our nervous system than with the rest of our body. Our quickness or slowness, alertness or dullness, cheerfulness or gloominess, reliability or fecklessness, good-will or selfishness, are wrapped up-in our ordinary life inextricablywith our very wonderful nervous system. Some people believe that our inmost self uses the nervous system as a musician uses a piano, and compare the disorder of mind illustrated in the delirium of fever, or the decay of mental vigour in the aged to disturbances or wear and tear in the instrument. Others think that the inner life of consciousness-feeling, thinking, and willing -is one aspect of our mysterious living, and that the 
physico-chemical bustle that goes on in the nervous system is the other aspect of the same reality. The two aspects are inseparable, like the concave and the convex surfaces of a dome ; but no metaphor is of any use, the relation is quite unique.

This is one of the oldest of riddles, and Tennyson made "The Ancient Sage" say :-

Thou canst not prove that thou art body alone, Nor canst thou prove that thou art spirit alone, Nor canst thou prove that thou art both in one:

For nothing worthy proving can be proven, Nor yet disproven.

Yet three things seem to us to be quite certain: (1) Our nervous system is a scientific actuality that can be measured and weighed; it is complex beyond our power of conception, if only because of the millions of living units which it includes; it is the seat of an extraordinary activity which baffles our imagination. No theoretical view can stand that is subversive of the fundamental reality of our nervous system. (2) Even more real, however, if there are degrees of reality, is our inner life of consciousness, our stream of thoughts and ftelings, desires and purposes. It is our supreme reality, for it includes all others, and no theoretical view can stand that is subversive of this reality. (3) But the third certainty is that organism and personality, body and mind, nervous metabolism and consciousness, are in the experience of everyday life interdependent. If it is a relation, there is nothing to which we can 
compare it; if it is a unity, it is equally unique. We are mind-bodies or body-minds; sometimes we feel more of the one, sometimes more of the other.

We are born with ready-made structural arrangements which make a number of reflex actions at once possible. We have the power of adding to reflexes a certain number of habitual accomplishments, and we differ notably among ourselves in our readiness to acquire dexterity. We are also born with a limited number of old-established instinctive predispositions, which express themselves in impulses along certain lines of behaviour. As to higher activities, we cannot say much more than this, that our inheritance includes a marvellous cerebral organisation of a certain pattern, which puts into our hands a number of aptitudes rather than ready-made accomplishments. We have to learn most things, and we are above all creatures educable. Using the abundant material supplied by the sensory elements, we build up an intellectual framework. Perhaps it is better to say, that endowed with a certain cerebral surface-relief, we soon become the possessors of a characteristic stream of inner life-a stream of thought and feeling and other mentai activities. As our experience grows, what may be called the stream-system becomes more complicated. The system, which has the analogues of banks and pools, tributaries and overflow beds, quiet reaches and rapids, is conditioned by the flow of the stream, but, in turn, conditions it. Eddies are always forming in the stream, and some we call memories. There is stagnancy of thought, and there are floods of feeling that erode new 
beds. But soon our metaphor breaks down, for we cannot apply it to our customary experimenting with ideas or to the controlling power that we have over our behaviour. We are able to do 'in our head' what we do objectively in experimenting in the laboratory.

The complexity of elements and activities in our nervous system is quite unimaginable. Thus there are in the convoluted part of our fore-brain (the cerebral cortex) five or six times as many nerve-cells as there are human beings in the world, and the complexity of interrelations is past all telling. There is a rush of multitudinous orders always issuing from the brain, and there is also a torrent of impressions-from eye, ear, nose, tongue, finger-tips, skin, and the deep internal organs-that flows into our central nervous system, keeping us awake and conscious. All this means wear and tear, and the formation of subtle waste-products, even the production of heat. We have only to think of the complexity to realise the importance of sleep and rest. We understand also the value of a sleep in which the signals from eye and ear have stopped. It may be a gift to be able to sleep anywhere, but the better sleep is that in quiet and darkness. It is also well that besides the signals from eye and ear, those from the food-canal should have stopped.

Living is in some ways an extraordinarily tough kind of activity; the way our intricate, finely adjusted nervous system stands treatment which we should never dream of giving even to our watch, speaks volumes 
for its tenacity. But it does not always stand it so well as we think.

From Professor G. H. Parker's luminous lectures on Biology and Social Problems, which every one interested in either half of the title should read, we venture to take a few figures, and to these we should append a moral. Sensations and memories, intellectual experiments and volitions have their seat in the cortex of the fore-brain, a wrinkled or convoluted field, which, if smoothed out, would cover a little over a foot and a half square. This convoluted cortex weighs about 658 grammes, rather under a pound and a half, but most of this is due to blood-vessels and supporting tissue. The nerve elements taken by themselves are said to weigh only about 13 grammes, rather under half an ounce. In a man weighing 150 pounds, the cerebral cortex would be only about $1 / 5000$ th of the whole, yet this rules all the rest of the body. It is a little less than a cubic inch of material altogether, yet it may shake the whole world. It is indescribably complex, and includes not far from 9,200 million cells, between five and six times the 1,700 millions of human beings believed to inhabit the earth. The moral is: Take care of it!

Another very important fact concerning our nervous system is that the number of the nerve-cells is not added to after birth. In most parts of the body there is renewal of worn-out cells, but not in the central nervous system. Many tissues in the body are made afresh far oftener than once in seven years, as popular estimate puts it, but nerve-cells are not replaced, The 
cells of the skin, of the lining of the food-canal, of the glands, and of the blood get worn-out and others take their place. We are said to have about 25 trillions of red blood corpuscles, occupying 3,300 square yards if spread out on a surface. These cells are continually, as it were, wearing out, and being replaced by fresh units, but we never get a new nerve-cell after birth. The moral is plain, that over-fatigue is more serious for nerve-cells than for other cells, and an injury to a cluster of them may be very serious indeed.

\section{§4. The Regulative System}

We have seen that the muscles correspond to the motor parts of the bodily engine; that the nervous system is the storage battery, the sparking apparatus, the steering gear, and the observant driver besides; that the fuel is the food which the stomach prepares and the liver stores; that the air for combustion is supplied by the lungs; that the blood distributes oxygen, digested food, and lubricant substances, and collects carbon dioxide and nitrogenous waste-products; and that the latter are filtered out by the kidneys. We must now consider the regulative system.

Paul the Apostle had a very vivid conception of the correlation or harmonious working together of parts. "There are many members and one body. The eye cannot say to the hand 'I have no need of you,' nor again the head to the fcet 'I have no need of you.' Quite the contrary. Yes, God has tempered the body together, with a special dignity for the inferior parts, 
so that there may be no disunion in the body, but that the various members should have a common concern for one another" (1 Cor. xii.; Moffatt's Translation).

Discoveries, still in rapid progress, in regard to certain apparently 'inferior parts,' the organs of internal secretion, have profoundly changed our whole scientific picture of the internal economy of the body. A few illustrations must be given.

One of the most important digestive organs in the body is the pancreas or stomach-sweetbread. It pours into the beginning of the intestine a large quantity of digestive ferments, which attack all the different kinds of food-the starchy, the fatty, and the proteid. For a long time it has been known that this secretion of ferments was most copious after meals, and this was usually attributed to orders coming through the nervous system, commanding the pancreas to secrete abundantly at the appropriate time. But Professors Bayliss and Starling showed (about 1905) that a substance called secretin is made by cells in the wall of the intestine under certain conditions of food, is carried away by the blood, and on reaching the pancreas provokes secretion. The secretin is a specific messenger, carried by the blood, which provokes an answer when it reaches the appropriate place. Such chemical messengers or internal secretions were called by Professor Starling "hormones."

The thyroid gland near Adam's apple furnishes to the blood an internal secretion which is essential to 
the continued health of body and mind. Deficient thyroid gland results in children who are dwarfish and lumpish and dull, of defective intelligence. In adult life thyroid deficiency may bring on sluggishness, a decline of intelligence, and a disease called myxœdema. It has been one of the triumphs of medical art to cure or ameliorate these conditions by giving the patients injections of thyroid-extract or by feeding them on sheep's thyroid. This recalls the old prescriptions that the coward should eat of the heart of a lion, and the simple of the liver of a fox.

Thirdly we may mention the adrenal bodies which lie at the anterior margin of the kidney, and produce from their central portion a substance called adrenalin, which is distributed by the blood. When an animal is enraged or in great fear, the secretion of adrenalin increases, blood passes from the abdomen to lungs, heart, nervous system and limbs, the heart beats more vigorously, the amount of sugar (a muscle food) in the blood increases, the blood acquires a greater power of quickly clotting, and the muscles' power of rapid recovery from fatigue is heightened-all a most marvellous pre-adaptation to physical struggle.

Returning now to our engine-with its motor, storage, battery, ventilator, and so on, we see that there are intricate arrangements which supplement the nervous system in securing the smooth working together of parts. The thyroid, for instance, has a good deal to do with the control of speed-with the control of the rate of combustion; and the adrenals seem to play a con- 
tinuous rôle in the neutralisation of acid waste products.

\section{§5. What is Disease?}

It is told of one of the great French chemists, Chevreul, that when he was interviewed in his hundredth year and asked: "Have you always had a good digestion?" he answered out of the fullness of his vigour: "I really cannot say, for I have never noticed." This is quite ideal ; it indicated a great harmony of internal processes. The antipathy which unsophisticated people have to learning about the works of the living engine, is in a way quite sound. For we really should not know anything directly about organs like the stomach and liver-hard-working structures quite unobtrusive when well used. The body is a great laboratory in which upbuildings and down-breakings, combustions and fermentations, dissolvings and filterings go on in crowded order. They are all summed up in the word metabolism, which means change. We may speak of them as vital processes. And the idea we must grasp is that health spells harmony of vital processes, while disease means metabolism out of place, out of time, and out of tune. What is disease in one animal may be normal in another. What would be ominous at one time of life may be natural at another.

Disease is a disturbance of the body's wholesome routine, and there is progress simply in realising this. Our forefathers thought of disease as a mysterious 
potency, stalking out from the unknown, and seizing a man by the throat. There may be a truth in thinking of disease as a visitation or a judgment, but a great part of the value of the truth is lost if we do not understand that disease is often an inevitable consequence of our carelessness, or ignorance, or sluggishness, or foolhardiness. When the disciples asked Christ about the man blind from his birth, "For whose sin-for his own or for his parents'-was he born blind?" they were not thinking about heredity or about the transmission of acquired characters, or about blindness due to infection before birth, they were thinking of the blindness as a judgment imposed from without. That idea of disease must be given up.

Perhaps we get to some clearness by distinguishing three kinds of diseases, considered in a large biological way. These are constitutional, microbic, and modificational. Constitutional diseases are due to some deficiency or exaggeration or perversion in the hereditary organisation, and as the deficiency or exaggeration or perversion is likely to be continued from generation to generation, it is generally said that these constitutional diseases are hereditary. It is probably more accurate to say that what persists is not exactly the disease, but the predisposition to the disease. As the predisposition, like every other item in our inheritance, requires suitable nurture if it is to be fully expressed, there is some hope-and an increasing one--of letting the sleeping bud sleep. The possibility is not great, however, if the nurture which predisposition to the 
disease requires, if it is to express itself, is just the average nurture of everyday life. It is probable that gout, albuminuria, and some forms of diabetes and nervous instability are examples of constitutional disease. The biological tactics are to try by counteractive nurture to save the body from having to fight a battle with two fronts-which is seldom hopeful.

The second class of diseases may be called microbic. These diseases are due to the invasion of the body by injurious organisms-usually of microscopic size. Some of the microbes incline to the plant-like mode of life, and most of these are called bacteria. Thus bubonic plague (the Black Death), cholera, tuberculosis, tetanus, typhoid fever, and many other diseases are due to bacteria. Other microbes incline to the animal mode of life or are undoubted animals. Thus sleeping-sickness, malaria, and syphilis are due to microscopic animals or Protozoa. Some larger animal parasites sometimes cause very serious human diseases. Thus about every third native of Lower Egypt suffers from a very serious disease called Bilharziasis, which is due to a worm allied to the liverfluke of sheep. One of the great life-savers of the period of the Great War was Dr. Leiper, who discovered the life-history of the Bilharzia-worm, and has shown how its invasion of the human body may be frustrated. In connection with these microbic and parasitic diseases, we must understand that conquering them depends in many cases on discovering the lifehistory of the intruder. A remarkable fact which has 
made mastery at first more difficult, and eventually easier, is that many of these pests require to spend part of their life in one host and part of their life in another. Thus, the malaria microbe spends part of its life in the mosquito, the sleeping-sickness microbe spends part of its life in the tsetse fly. Apart from cases where a human parasite must pass part of its life within another host, there are many cases where insects or the like act as 'carriers' or distributers. Thus, the house-fly is a great distributer of typhoid.

When microbes enter the body, what do they do? They make and liberate poisons which are often very prejudicial to the tissues. By their activity they may also break down membranes and cause structural injuries or lesions. They may multiply so enormously that they block up passages, and there are other ways in which they work mischief. Luckily we have two great counteractives-we have a bodyguard of wandering amoboid cells or Phagocytes-really a particular kind of white blood corpuscle-which engulf and digest microbes, and there are several destructive substances or antitoxins in the fluid of the blood which counteract the poisons of the intruders. In various artificial ways it is possible to increase the protective efficiency of both these natural defences of the body.

In the third place, besides constitutional and microbic diseases there are modificational diseases which are due to peculiarities in nurture. Lead poisoning and rickets in children are two well-known examples. All who work in the gold-mines at Johannesburg get 
their lungs infiltrated with the fine dust. When the staple food is rice, the disease of beri-beri sets in if the rice be eaten without its outer coat. There are many diseases directly induced by deteriorative peculiarities in occupations and surroundings.

It follows from our previous studies, that modification-diseases are not transmissible, though indirect effects may influence the child prejudicially through the mother; that microbic diseases are not transmissible, though a susceptibility to them may be, and though very early-ante-natal-infection may bring about a semblance of hereditability. The diseases that are heritable are constitutional diseases, and in many cases what is entailed is not so much the disease as a tendency or predisposition in that direction.

We can give but a sketchy answer to a question which the inquisitive layman often asks: What exactly happens when a disease sets in and upsets the finely established harmony of health? Three things that happen may be noted. (1) A common thing is the overfatigue of a particular structure. The heart is a muscular organ, about the size of our closed fist, which 70-80 times a minute throws $3 \frac{1}{3}$ ounces of blood into the aortic tube against considerable pressure. When it is in good condition and has much to do, it draws upon its reserves and becomes stronger, but this has its limits. In certain conditions it may get overworked beyond its great recuperative power. When it is too strained to do its work well, the circulation is less active, and all the body suffers. 
The brain-cells of a hive-bee at the end of a long day show structural changes as the result of fatigue. Food and rest stave off the inevitable consequences for days, but soon the cell becomes irrecoverably fatigued. With all its getting, the bee gets not wisdom, but foolishness. So with ourselves, a using up of vital material which is not compensated for by the renewal which comes in repose and sleep, results in neurasthenia. The brain is fagged; impressions are dull; we don't take in what we read; doors banged as they never banged before and our shoe-lace is always breaking; things go all wrong; we hear what we were not meant to hear; we don't sleep well ; every one is against useven the cocks crowing in the morning are in the conspiracy. That is the beginning of fatigue disease, The moral is, nip it in the bud.

Fatigue is often due to over-eating, over-drinking, over-smoking, and the like, but there is a real industrial fatigue which follows from over-strain. It is certain that beyond an uncertain limit this fatigue lessens the quality of the work, makes the body less resistant to disease, and suggests the use of injurious ways of getting rid of the oppression of over-tiredness. It is in the interests of employers and workmen alike to find out the limits of safety for the organism's health, the limits consonant with good citizenship, and the limits admitting of the best workmanship. Where the work cannot but be hard, the alleviations of good air, plenty of light, convenient meals, and lightsome change must be tried and are being tried. (See Lord 
Henry Bentinck, Industrial Fatigue. King, 1918, 6d.) The biological importance of change is recognised in 'week-ends' and holidays, and in many other familiar ways. We need to recognise it more, for it staves off ageing. Railways and other means of rapid locomotion have made it possible for many humble people to live at a considerable distance from their work, and have in the opportunities of change that they multiplied atoned for occasional disfigurements. That the opportunities are often abused may be said of every new door that is opened.

(2) It seems well established that worry and anxiety and fear contribute greatly to break-down. This operates in several ways, partly through over-fatiguing some particular area of the brain where is situated that particular eddy which is the centre of our brooding. But in another way. The worry and fear have fatigue effects in various parts of the body which influence the blood (increasing its hydrogenion-concentration), increasing its acidity. If this goes on increasing beyond the neutralising power of adrenals and liver, then there is a break-down. The moral is, "Be aisy, and if you can't be aisy, be as aisy as you can." Continuity is bad for us. Changes are lightsome. There is a great deal to be said for keeping the Sabbath.

(3) One of the commonest things to happen is poisoning, which throws part of the system out of gear. The poisoning may be due to intruding microbes; to bad food; to stimulants and narcotics; and very 
often to the waste-products of food which has been unused or imperfectly used within the body, or to other waste-products which are in a more direct way the ashes of the living fire.

No Disease in Wild Nature.-This seems the place to notice a fact which should make us think and act; that there is almost no disease among wild animals. Wild animals grow old, but they are never senile. Wild animals have many parasites, but with most of these they have established live-and-let-live relations. Epidemics due to microbes sometimes occur, but almost always because man has interfered, e.g. by taking animals to new surroundings where they encounter microbes which they are not adapted to resist, or by killing off the natural eliminators of the weakly, or by permitting over-crowding, or by infecting soil and water. What, then, of salmon disease, fowl cholera, grouse disease, swine fever, and so on through a dreary list? These occur in more or less artificial, humanly contrived conditions; and the same is probably true of plant diseases. It is not asserted that variations in the direction of weakness and abnormality and disturbed vital processes may not occur among wild animals, but they seem to be rare and they are sifted out before they take grip. Disease in wild nature is a contradiction in terms. Why, then, is it that Man has diseases always with him? Because many human activities and surroundings are so artifcial and injurious, because modern Man has poor resting instincts and feeding instincts (Man does not 
even scrutinise his food as a monkey does), because Man has all sorts of ways of evading Nature's sifting of the weakened and of circumventing consequences; because social sentiment protects the weakly and diseased, which is right, and sometimes allows them to multiply, which is all wrong. Indoor life, crowded workshop life, crowded home life, urban life-all favour disease, but their evil influences can be largely counteracted.

We have already referred to the great strides which have been made in modern times towards the mastery of disease.; Man has control of smallpox, diphtheria, bubonic plague, typhoid fever, syphilis, and some other diseases. Every one knows that smallpox and typhus are now rare diseases in Great Britain; so it will be with other microbic diseases. Modificational diseases can also be brought under control. Thus, one man of energy and insight, Sir Thomas Oliver, has enormously reduced the miseries of lead-poisoning. The constitutional diseases will last longest, but it is likely that their expression can be increasingly curbed by careful dieting and the like. Public opinion will probably create an enlightened prejudice against allowing the more serious constitutional proclivities, like epilepsy, to spread.

Danger Ahead.-Involved in the achievement of conquering disease, however, there lurks a dangerthe danger of forgetting causes when we evade consequences. To get injected with an antitoxin that makes one immune to a disease is great gain, espe- 
cially when the disease is fortuitous and not dependent on oneself at all, like typhoid, for instance. But this sort of thing will not be gain unless man also forges ahead with improvements in surroundings, occupations, and 'habits,' removing the unwholesome factors which more or less directly engender disease. Biological progress must always be three-sided:organism, function, environment; people, work, place ; the creature itself, its doings, and its not-doings.

Positive Health.--Talking is easier than acting, but one may express what one at any rate sees clearly, that the hopefulness of counteractive and curative measures will be greatly increased if it can be associated with a positive raising of the standard of human healthfulness. This is an obvious but fundamentally important idea, to which we shall return. Just as peace is not merely the cessation of war, but a positive ideal, so health is not merely the absence of disease, but a positive ideal. It means a reaching forward towards a life of greater fitness and fullness and freedom.

Mind on Body.-Where the metaphor of the engine leads us farthest astray is that it leaves the mind out. The ideal is a healthy body at the service of a healthy mind. Let us take an illustration of the influence of mind on body.

The famous physiologist of Petrograd, Professor Ivan Petrorich Pavlov, was the first to demonstrate the influence of the emotions on the health of the body. Good circulation and good digestion make for cheerfulness, but the converse is also true. As was said 
long ago, "He that is of a merry heart hath a continual feast," and "A merry heart is the life of the flesh." The researches of Pavlov, Cannon, Carlson, and Crile have shown that pleasant emotions favour the secretion of the digestive juices, the rhythmic movements of the food-canal, and the absorption of the aliment. Contrariwise, unpleasant emotional disturbance and worry of all sorts hinder digestion. Good news, psychical if anything is, may set in motion a series of vital processes, complex beyond the ken of the wisest. What is true of digestion is true of the circulation. Wordsworth was a better physiologist than he knew when he spoke of his heart leaping up at the sight of the rainbow and filling with pleasure and dancing at the recollection of the daffodils by the lakeside. There are facts which point to the conclusion that a gladsome mind increases the efficiency of the nervous systen. Good tidings will invigorate the flagging energies of a band of explorers; an unexpected visit will change a wearied homesick child, as if by magic, into a dancing gladsome elf; a religious joy enables men and women to transcend the limits of our frail humanity. How it operates is not very clear, but emotion has its physical accompaniment in motions visible and invisible throughout the body. Somehow the oil of joy, as the Scriptures call it, makes the limbs more supple and the face to shine.

It goes without saying that forced cheerfulness is a horror, but the persistent will to be glad, if worthily satis- 
fied with some of the real joys of life, may soon become a habit. Those who find good reason for rejoicing-in the sunshine and stars, in the flowers and birds, in works of art and the faces of their friends -wish for no reward, but they will get it all the same. In Conclusion.-Even an introductory study of the Biology of Health brings into prominence two ideas -(1) that, shelter and bolster ourselves as we may, survival of nationalities among mankind must ultimately in part depend on being genuinely healthybodied and healthy-minded; and (2) that the effect upon our health is a touchstone of behaviour which we can use within certain fields with some subtlety, with great security, and with much profit both to ourselves and other people. 


\section{CHAPTER VI \\ THE INDIVIDUAL LIFE CYCLE}

$\S 1$. Different Forms of Life-curve.- $§ 2$. The Ante-natal Life.$\S 3$. Infancy and Its Fragility.- $\$ 4$. The Individual's Recapitulation of Racial Evolution.- $\$$ 5. Childhood: Its Playing and Schooling.- $\$ 6$. Adolescence: Its Adventures and Dangers. - $\$$ 7. Falling in Love-or, rather, Rising.§ 8. Married Life and Parental Affection.--\$ 9. The Difficult Age. $-\S 10$. The Problem of Growing Old, the Art of Remaining Young.

\section{§1. Different Forms of Life-curve}

NE man differs from another in details of structure and temperament, but also in the rate of the vital processes. In blood-stream and in thoughtstream there are great differences in the rate of flow. It is a well-known biological theory that the fundamental difference between the sexes is a difference in the rate of certain kinds of chemical routine or metabolism.

One of the characteristic features of life is cyclical development. In all ordinary creatures life is a very delicate kind of activity to begin with-a flickering flame easily blown out by a gust. But the creature 


\section{THE INDIVIDUAL LIFE CYCLE}

develops and grows, it shows increasing complexity and division of labour (differentiation) and increasing control and harmony (integration); it secures its foothold and gains grip; in short, there is an ascending curve of gradually increasing strength. Then comes a period of mature efficiency, with which reproductivity is usually associated. The creature is at its prime. Sooner or later, however, it begins to relax a little, to weaken, and to grow old. It passes on to the downgrade which ends in death.

The general fact, then, is a gradual curve upwards from the weakness of early youth to the full strength, and then a gradual curve downwards to the weakness of old age. "And so, from hour to hour, we ripe and ripe, and then, from hour to hour, we rot and rot, and thereby hangs a tale." But just as some animals have a long youth and some a long prime, so in Man the precise shape of the life-curve varies greatly with the individual, and is, in some measure, in his own hands. There are averages, of course, but there is no precise length of years to be reckoned to youth, or to maturity, or to senescence. We have to think of the threads of our life as consisting in part of nonextensible stretches and in part of elastic stretches. The latter, e.g. the stretch of cerebral variability, may be lengthened out or shortened down. Our nature consists of a great many of these threads, and we may stretch out the youth of some of them while we cannot do this for others. In spite of ourselves, sometimes, certain threads in our composition grow old prema- 
turely, losing all their elasticity. One of Professor Child's very curious experiments with Planarian worms shows that these creatures may be born old if their parents and grandparents are restricted to unsuitable food. So, though we do not know precisely how, some children are born old. Similarly it is said of the victims of lead-poisoning that young men often look middle-aged.

On the other hand, there are many rejuvenescent types in whom certain threads remain young even when the tale of years is a very long one. Montaigne wrote of his father: "I have seene him, when hee was past threescore years of old, mocke at all our sports, and out-countenance our youthfull pastimes, with a heavy furr'd gowne about him leap into his saddle; to make the pommada round about a table upon his thumb; and seldom to ascend any staires without skipping three or foure steps at once." He at any rate might have been appropriately called "old boy."

Illustrations.-A few examples may be given of the way in which life-histories differ-by altering the 'time' of the different stretches of the life-curve, elongating one part and compressing another, lengthening here and telescoping there. Mayflies often have two or three years of sub-aquatic juvenile life, and only two or three days of adult aërial life. The lampreys are young for four or five years, and fully formed for some years, but they die abruptly after spawning, as eels seem also to do. The strange Peripatus 
-intermediate in some respects between worms and insects-may carry its young ones before birth for a whole year, for they must be born ready to fend for themselves. Among wild horses the foal must be able to run beside its mother soon after birth, so the ante-natal embryonic period is drawn out to eleven months. In the opossum the gestation is sometimes telescoped down to a fortnight, for the mother carries her baby after birth in a skin pocket or attached to her tail. In bats, which are highly specialised mammals, the ante-natal period is again very short, for the young one hangs on to its mother for a long time by toes and thumbs and mouth, and has many a giddy journey through the air before it is able to use its own wings. In birds the juvenile period is often very short-mound-birds can actually fly the day they are hatched-for it is a precarious time. In mammals the tendency is the other way, to lengthen out the youthful period into a playing time, when this can be done with safety. There are many interesting facts of this sort, but all that we need here is an illustration of the suggestive idea that one chapter in the life-cycle may be lengthened out and another telescoped down. We know in part how this can be done, namely, by variations in the rhythm of the regulatory system-the organs of internal secretion. It may also be effected in mankind by enlightened adjustments of function and responsibility, and there can be little doubt that true civilisation implies a lengthening out of the youthful period. This is per- 
haps more marked in women than in men. A welcome fact is the lengthening of life that is going on in our midst; thus the span of life in England seems to have increased by about a third since 1865. Still more welcome is a lengthening of youth and of full strength. But we must look for even more-the improvement of the health-rate and the raising of the standard of health.

\section{§ 2. The Ante-Natal Life}

The first chapter in the life-cycle is that before birth - the ante-natal life. It is the time of early development, when the egg-cell divides and differentiates to form an embryo, when this pinhead-like germ grows -at first with amazing rapidity-into a creature thousands of times bigger and millions of millions of times heavier than itself. It is the time when out of seeming simplicity there is coined and minted obvious complexity, when out of invisible intricacy there arises a visible manifoldness. It is the time to which the Psalmist reverently refers (Ps. cxxxix. 15-16) :-_" Thine eyes did see my substance yet being unperfect; and in thy book all my members were written, which in continuance. were fashioned, when as yet there was none of them."

From a general biological point of view three ideas stand out clearly. (a) One of the evolutionists before Darwin was Robert Chambers, anonymous author of The Vestiges of Creation, and, along with his brother, founder of the well-known publishing house of Cham- 


\section{THE INDIVIDUAL LIFE CYCLE}

bers. Now Robert Chambers had many shrewd ideas, and one was that the lengthening out of the antenatal period in mammals had to do with the evolution of fine brains, as in horse and elephant. It afforded in man's case nine months during which his extraordinarily complex nervous organisation (with its 9,200 millions of nerve-cells in the cerebral cortex alone) could develop more or less sheltered from the great booming, buzzing confusion of the world, from the torrent of impressions that keeps us awake and conscious. We must remember that it is during the antenatal life that we get all our equipment of nerve-cells, and though there are illustrious examples of children born at seven months or so who grew up to a brilliant career (e.g. the philosopher Hobbes), perhaps it is safe to say that for the average the child who bides its time is best. One half of the untimely children die in a few hours, days, or months.

(b) The second thing is that if we are to keep our ideas clear, we must realise that 'nurture' is playing upon the developing human organism for all these months before birth, and that it is not always easy to be sure whether a peculiarity seen in the newly born is a modification induced by some peculiarity in the maternal nurture, or is an inborn variation arising from some new arrangements before or during the fertilisation of the egg-cell. In the first case it is not likely to pass on to the grandchildren; in the second case it has every chance of so doing. The deteriorative effects of ante-natal alcohol absorption are well 
known; so also of ante-natal infection with microbic disease, such as syphilis.

(c) The third thing is that the relation between the unborn child and its mother is extraordinarily subtle. No one should dogmatise concerning "the mysterious wireless telegraphy of ante-natal life," to use Dr. J. W. Ballantyne's apt phrase. On the whole, the child gets the best of it, there being, for instance, very effective arrangements for safeguarding it from many of the disturbances that may upset the mother. But there is good reason for believing that the mother is by no means without her physiological reward.

According to a modern view, well represented by Professor Bar of Paris (Leçons de pathologie obstétricale, 1907), the intricate placental union between the unborn child and the mother secures a harmonious partnership-a literal 'symbiosis,' a term used in biology for an intimate internal mutually beneficial partnership, like that between Radiolarians and their companion Algæ, or between certain Fungi and Algæ to form Lichens. The point is that the child is not so much a parasite on its mother as a paying guest. In the great majority of cases the state of pregnancy is a state of health, but it is health under a great strain, and the mutually beneficial symbiosis may readily sink into a parasitism prejudicial to the mother's vigour. To quote a great authority, Dr. J. W. Ballantyne of Edinburgh, who accepts the idea of symbiosis with some provisos, "mother and unborn infant are not antagonistic in this great matter of reproduc- 
tion, but are working together for the benefit of both, the mother putting forth energy and giving nourishment, but the child so acting upon her as to enable her to do so without exhaustion or loss" (Brit. Med. Journ., Feb. 14, 1914, p. 349). There is evidence that the child may help the mother to make the most of her food and may act as a bracing tonic. It is very interesting to find Herbert Spencer, a bachelor philosopher, remarking that "parenthood produces a mental exaltation not otherwise producible"; there is now definite physiological evidence that the unborn child may activate the tissues and organs of its mother to greater vitality. The probability is that the future will see a facilitating of the patience of maternity, a removal of dangers and a reduction of irksomeness-an amelioration which may lessen the evasion of motherhood on the part of types of fine physical and intellectual quality.

\section{§ 3. Infancy and Its Fragility}

The second chapter is that of infancy-helpless, fragile, in certain aspects adorable, infancy. Three biological notes are very plain. (a) The prolonged infancy characteristic of mankind has almost certainly been a factor in the evolution of human gentleness and sympathy. Opinions may differ as to the importance of the arboreal apprenticeship served by man's pre-human ancestry, which meant a reduction of the offspring to one at a time (see Wood Jones, Arboreal Man, 1916), and the habit on the part of both parents of carrying the baby about among the branches-a 
prolonged physical attachment leading presumably to something better; but there is no doubt as to the validity of the general thesis of Fiske and others that the prolonged infancy characteristic of the human race had been an important factor in the Ascent of Man. It made for tenderness, kindness, family affection.

(b) Man is the most illustrious example of the 'bigbrain' type of organism, with relatively few instincts but great educability, and his prolonged infancy must be recognised, like the playing period, as a time in which the young creature learns to find its way about, supplementing or replacing instincts by intelligent control.

(c) The third note is the sadly familiar one of high infantile mortality. For infancy is unarked by fragility and there is much wastage. In spite of remarkable improvements along many lines, e.g. maternal instruction, better housing, milk inspection, segregation of infectious cases, and so on, the British nation's deathrate for infants under twelve months stood a few years ago at 100 per 1,000 , and in overcrowded areas this may rise to nearly 160 . This is not only a reproach to humanity, but a national wastage on a scandalous scale.

Social sentiment being what it is, we are bound to seek to save all we can, and in many countries a praiseworthy a mount of systematised and voluntary service is devoted to lessening infantile mortality. Perhaps some of this tends to allow ignoble parents to evade the extreme consequences of their neglect of the children, but as far as the children are concerned it is for the 
most part to the good. It cannot be maintained without grotesqueness that the efforts to reduce infantile mortality should be abandoned because they imply an interference with natural selection. This position is grotesque not only because Man has been interfering with natural selection ever since civilisation began, not only because natural selection cannot be trusted to work in the right direction when the conditions of its operation are of Man's making, but mainly because a great part of the mortality is not discriminating at all and is quite avoidable. In a huge number of cases it is merely thinning, not sifting, that goes on. Moreover, while there is a right place for preaching repentance and 'less coddling,' it is not in regard to infants. And finally the advocates of the policy of 'Thorough' would do well to remember, for instance, how much the modern world owes to one who is said to have been about the miserablest infant ever seen - Isaac Newton to wit.

\section{§4. The Individual's Recapitulation of Racial} EVOLUTION

Many forms of life show in the early stages of their life-history, and especially in the building-up of their organs, a tendency to repeat in condensed form what we believe to have been great steps in the evolution of the race to which they belong. This is called recapitulation. As Professor Milnes Marshall put it, the creature may be said to climb up its own genealogical tree. The individual development tends to be a con- 
densed recapitulation of the racial evolution. This is an important and luminous idea, but it requires to be used very carefully.

In the first chapter in man's life-cycle, there is certainly much that may be described as recapitulation of racial evolution, such as the almost evanescent development of the old-fashioned dorsal axis, the notochord, which is speedily replaced by its substitute the backbone. But it is obvious that the child we know does not work through the history of human acquisitions, e.g. in learning to speak. That is happily unnecessary, for while many strides in the evolution of aptitudes are enregistered internally in the hereditary constitution, many others are enregistered externally in man's permanent products. Part of the business of education is to shorten the recapitulation such as it is by supplying children with a thought-out succession of appropriate liberating stimuli which enable the inborn hereditary organisation to make in a few years advances which meant for the race the patience of ages. A liberating stimulus means in the domain of things a spark to a barrel of gunpowder, which leads to self-destruction, the releasing of a spring which sets the gramophone unwinding. Among living creatures it means the entrance of the sperm-cell that sets the egg-cell developing, the rise of temperature and the insoaking of moisture that prompt a seed to germinate, the touch of a twig that sets a tendril twining, the diffusion of an internal secretion that calls a dormant structure into activity. For children a liberating stimulus means all sorts of 


\section{THE INDIVIDUAL LIFE CYCLE}

things, a crust for the cutting teeth, paper and chalks for the child-artist, a doll for the child-mother, a gardenplot for one, a mechano for another, a problem for Jack and a poem for Jill, and so on without end. Perhaps the biologist may be permitted to say that the liberating stimuli supplied in school should avoid three extremes. They should not be too grown-up, tor that means unnatural coercion. They should not be too sophisticated and modern, for then they lose reality, missing the primal interests. They should not be too primitive, for we cannot go back to the simple life; we live in conditions to which our engrained predispositions and our instincts are far from being altogether well fitted.

The zoological evidence of recapitulation refers chiefly to embryonic development-to the making of organs, and it seems incontestable that the young creature often proceeds from stage to stage in a strange circuitous fashion, which we cannot explain except on the theory that because of its enregistered inheritance, due to many steps taken in many successive ages, it has to follow the trail blazed out by distant ancestors. Though it is nonsense to speak of a fish-like stage in the development of man, even man has gill-clefts like a dogfish. None of them is of any use for breathing, and only one is of any use at all, the one that becomes what is called the Eustachian tube. Yet they are telltale recapitulations of a very distant aquatic ancestry. The recapitulation can only be general, for great steps that may have taken the race hundreds of thousands of years are condensed in the individual into a few days. Moreover, 
evolution has not occurred (as far as we understand) by adding on additional pieces as wings might be added to a house; there is unification at the beginning of each new life. And again it must be recognised that each kind of creature is specific, itself and no other. A frog has at one stage in its tadpole life a two-chambered fish-like heart, a fish-like type of circulation, and oldfashioned gills like the external gills of some ancient fishes, but it is an amphibian all the same from beginning to end. The recapitulation doctrine requires careful handling.

But we are not here interested in embryos, is there recapitulation in juvenile life? The answer must be cautious. Our inheritance is made up of ancestral contributions, including a few very ancient instinctive predispositions-of self-preservation, nutrition, sex, and the herd-instinct-but the non-human elements in these instincts have been gradually sifted out. And the instinctive under-current has to operate in most cases through an upper current of consciously controlled life. Yet, those who give an attentive ear may still catch reverberating in the recesses of their being the echoes of a very distant past.

\section{§5. Childhood: Its Playing and Schooling}

What comes out of the egg of a snake is a miniature snake, which usually goes about its business forthwith. But in many mammals there is, after the chapter spent in darkness and the period of infantile de- 


\section{THE INDIVIDUAL LIFE CYCLE}

pendence on the mother, a long childhood. It is familiar in kittens, lambs, kids, foals, and so on. What is the biological significance of childhood? It is the time of self-expression, of character-forming, of finding oneself, of substituting experiment for instinctive prompting, and not least of play. We shall take the last first.

To Groos in particular we owe the idea that animals continue young in order that they may play, for play is of fundamental importance in life. There are many play-instincts among higher animals-sham fights and sham hunts, races and follow-my-leader, gambols and 'daring do'; and playing is justified not only as a safety-valve for overflowing energy and spirits, and as the motor expression of emotions, but also as affording elbowroom for idiosyncrasies and originalities before criticism is too stringent, and most of all as a not too responsible 'prentice time for educating aptitudes which are essential in after-life, replacing or modifying instinctive promptings by the registered results of experiment. Man's brain has relatively few instincts, but it is eminently educable; and in play there is a chance for learning and testing, roving and adventuring before consequences are too serious. Play is the young form of work; and it gives elbowroom for selfexpression. Instead of being a trivial and dispensable activity, play is of profound biological and psychological importance. In general it may be said that those who play best will afterwards work best, live best, and love best.

It goes without saying that the biological and psy- 
chological utility of play is to remain in the background of our minds, for the essence of play is that it has no conscious end beyond itself. It is next door to art. But it is very important that the joy of pleasurable activity should possess young minds, and become a need, so that in grown-up life a man shall insist that his days shall be a pleasure to him.

But childhood is the time of schooling as well as of playing, and we venture to contribute to the discussion of this pre-eminently interesting subject a few considerations from the biologist's point of view. We do this in full awareness that education is one of those problems the solution of which every man with ideas believes himself to possess.

(1) A fundamental fact-so obvious that it tends to be ignored-is that the child is a developing creature. It is continuing what went on in the womb and at the mother's breast; it is not merely growing, it is developing. That is to say, it is becoming more complex (e.g. in the inter-relations of its nerve-cells, whose numbers however do not increase after birth); and it is becoming more of a controlled unity. In other words, besides growing, it is exhibiting self-differentiation and self-integration. Now, a developing organism requires, of course, food and air, but it also requires a succession of liberating stimuli. So it is pre-eminently with the human child, pre-eminently because so many steps in Man's evolution are registered outside himself in the social heritage. It is in this external social heritage that we must look for 
many of the keys wherewith to open doors through which the child's mind may go out and in. Another set of liberating stimuli is to be found in art, and another set in Nature. What the child needs is not so much meals of information, though these are well enough in their way, but thrills of delight, discoveries that open up new worlds, adventures that reveal new powers. For really fine gains like 'a love of the country,' the indirect æsthetic approach is surest.

(2) One of the profound facts of biology, not as yet fully understood, is the formative rôle of function. Development, especially after the early stages, is no passive unfolding, it is an active process. The young creature traffics with circumstance and in this way comes to its own. It is true, indeed, that the embryo chick has tiny lungs formed long before the twenty-first day on which the creature gets its first mouthful of air; this internal capitalisation or organisation of past achievements is the central mystery of heredity; but the subsequent open-air development of the lungs of the chicken depends on its breathing. It seems, moreover, that a certain amount of active functioning is necessary to keep complicated structure up to the level previously attained. The unused hill-road, the unused trench, disappears, and a structure shut off from the bustle of metabolism is apt to go back on itself, to unweave its web, to show de-differentiation. On such facts rests our second biological principle of education, that the best learning is that in which the pupil has an active share-and is not merely a passive recipient. 
Vivendo discimus.-By living we learn to use body and mind, sense and soul aright.

(3) Another biological idea of obvious relevancy in regard to education is the unity of the organism. We are mind-bodies or body-minds, and education fails of its mark if it is not the development of the healthy mind in the healthy body. To the physiologist it is so plain that the child is a motor organism, surging to move, to do things, to translate thought into action, to relieve emotion by emotion, that he wonders how he survived the long school-hour, the frequent repression of even vocal cord movement, the straining of attention to or beyond the limit of 'fatigue-stupefaction.' But it is not only the motor capacities that must be championed as having rights alongside of the intellectual; there is the training of the senses in precision and alertness-often an enjoyable as well as a valuable discipline; there is the training of the emotions-from the thrills of the simple beauty-feast of shells and flowers, or of the simple song, up to the appreciation of picture and music, from a simple admiration of the hero or heroine of the great stories to an ennoblement of the whole being with courage or pity when the imagination is fired by reading or hearing in fit language of the historical realisation of some great ideal; there is the discipline of enduring hardness; and there is the supremely educative moment-which some Boy Scouts find-when knowledge and imagination, sense and sympathy are combined in the accomplishment of something that requires to be done. We suppose that this has been said 
many thousands of times, but it remains in great part an unrealised ideal. Moreover, there is rarely any recognition of the fact that, the organism being a unity (we do not thoroughly understand how), the child's finding of himself or herself along any one line-even if it be only swimming, or planing, or sewing, or drawing, or cooking, or golfing-with reasonable efficiency reacts through the whole being with encouragement and stimulus. One has heard an adolescent confess: "Yes, I should like to go back to the school for a day, just to let the teacher know what I can do."

A profoundly important fact about childhood is that living creatures are much more in the grip of "nurture' when they are young than later on. Children are impressionable and modifiable extraordinarilyoften by influences which neither we nor they know much about. "There was a child went forth every day and what that child saw became part of him for a day or for a year or for stretching cycles of years." Some of these modifications require careful watching. It is our duty to notice recent work which shows that in very young children there are often dim experiences more or less connected with sex, and that care should be taken to avoid exaggerating these by careless caressing and exuberant fondling, or by thoughtless ways of soothing, or by the common assumption that what a child does not understand has no effect on it. In normal cases, happily, the very early deviations pass into oblivion, and until puberty approaches there is a joyous period of latent sex. 
During this time the child continues consciously what the infant began unconsciously-garnering its mother's love. During very early childhood the parents are in the place of God to their children, and to many, happily, the mother always remains in a peculiar way sacred.

\section{§6. Adolescence: Its Adventures and Dangers}

Adolescence is a long stretch on the ascending curve of development, when childish things are put away, when juvenile characteristics are for the most part slipped off as a crab slips off its shard, when adult characters are gradually put on, when the life begins to take definite shape, when the limit of growth comes within sight, and when sex-impulses, at first mere passing whispers, compel a hearing to their mingled voices. Male adolescence in North Temperate countries usually lies between fifteen and twenty, female adolescence bctween fourteen and nineteen.

From our biological standpoint, we would notice four things about adolescence. (1) There is a reacceleration of growth toward adolescence, and this growing preoccupies the youth-organically, not consciously -and is apt to induce slackness and limpness. It is surely a time for plenty of rest and plenty of play.

(2) The adolescent creature is rearranging itself. It becomes more complex, from its teeth to its nervepaths; it likewise becomes more subtly knit together. There are new complexities and new controls, new ambitions, new ideas. The readjustments are accom- 
panied by the pains and risks associated with all progress, by 'growing pains' and instabilities, with promise as well as portent, with portent as well as promise. All this must be allowed for.

(3) It is in adolescence that the new departures and original acquisitions of youth have to run the gauntlet of criticism and selection, which is often very cruel. It is well when natural selection sifts out the unstable, and when social selection sifts out the lazy, but there is a lamentable amount of rough-handed nipping of fine buds.

(4) The sex becomes mature-sometimes setting in suddenly and violently like a storm, sometimes gradually and gently like the coming of spring. The tissues of internal secretion associated with the reproductive organs begin in a new way to send their mysterious messengers or hormones through the body, subtly affecting the brain and the blood, impressionability and controlling power. Healthy work and play and wide interests furnish some safeguard, but one must not forget the mental side which is as supreme as hormones are fundamental. Happiest are those who have garrisoned their hearts with nobility, for out of the heart are the issues of life.

Towards the close of adolescence the voices of sex call more clamantly, varying in tone with the individual temperament. There is a clash between the imperious demands of the sex-instinct and the opposing forces-ethical, religious, and practical-which refuse satisfaction. There are three common results, 
or, often, there is a mingling of three.

(1) There may be indulgence which is apt to mean damaged health -mental as well as bodily. It often has punishment out of proportion to the offence. (2) There may be a morbid repression, which takes the form of finding fictitious substitutes for the activities which should naturally accompany or follow normal sex-arousal. This 'substitute gratification' is apt to lead to mental troubles called 'anxiety-neuroses.' (3) But thirdly, the outcome may be a strengthened control, an enriched life, and a love which, when it finds its mate, will not die. Things often go badly wrong in adolescence, as every one knows, and tragedy results, often without there being any terrible wickedness when all is said and done. The frequent misery is leading many to ask for more definite sex-instruction in adolescence at least. As Mr. H. G. Wells says, "The cardinal thing in life sneaks in to us darkly and shamefully like a thief in the night." We should let in more daylight, more sunlight. Many will agree with Samuel Butler that muddle is largely our enemy, and that there has been far too much reserve. "Get at," he said, "the best opinion of our best medical men, and let us have it out." There should be added, however, the best opinion of our best biologists, psychologists, and moralists.

One knows only a small number of cases, and it is dangerous to generalise, but there is perhaps a tendency to exaggerate-especially as regards girls-the part that sex-calls play in the conscious life of adolescence. Perhaps, furthermore, there is a tendency to make a 
scapegoat of sex, and to interpret as disharmonies what are really due to a poverty of nature, a dearth of sound human interests, and an absence of real responsibilities.

§ 7. Falding in Love-or, Rather, Rising

The natural climax of adolescence is a genuine falling in love-not a passing fancy, nor a sudden impulse of the flesh-but a reaching out of the whole being,--impulsively rather than deliberately, intuitively rather than rationally. It normally includes (1) an instinctive organic attraction, (2) an æsthetic attraction to qualities of voice, eyes, gesture, manner, and dress, and (3) a sentimental psychical attraction of personality for personality. Love is an affair of body, sense, and mind. Those who have given special attention to the subject declare that the least successful fallings in love are those which are the outcome of a too specialised attraction, too purely physical, too purely æsthetic, too purely intellectual. The lasting basis is manifold, not simple. It has been well said that "There is gold and clay, sunlight and savagery in every love-story." But if the root of the matter be there-and the profounder tendernesses in which self is half forgotten, then even if the turtle-doving seems silly let us not greet it with a superior smile, and even if the captivation seems mad let us not ban it. As Meredith says, "Love is a madness, but with heaven's wisdom in it-a spark. Even when it is driving us on the breakers, call it love; and be not unworthy of it, hold to it." 


\section{§8. Married Life and Parental Affection}

The attainment of mature strength and a foothold in life is normally followed by marriage. To postpone this till prosperity has been gained and youth lost is a mistaken policy.

"How to be happy though married" is a favourite subject of good-humoured jest, but it is no laughing matter. (1) One of the authorities on the subjectMr. Heape-points out that man and woman are so different that they must eventually become opposed in what he calls sex-antagonism. We adhere to the thesis of The Evolution of Sex (Geddes and Thomson, 1889), that there is a deep and pervasive constitutional difference between the sexes, but there is nothing in this contrast to necessitate eventual antagonism. It may as reasonably be regarded as an organic condition of attaining in married life to increased appreciation and happiness. The three sails of a happy marriage voyage are organic fondness, intellectual sympathy, and some capacity for actual working-together. Many voyages are made with one sail and many with two, but the most prosperous voyages are made with three. A normal affectionate married life, with some fundamental agreements, which need not be political, and with some reasonable working-together (and mutual appreciation of that, it must be added), does not as a matter of fact lead to diametrical opposition of the partners, but very generally to a loving comradeship-one of the fine things of life. Marriage without some working or playing 
together courts disaster, and is terribly patriarchal in outlook. Marriage without fondness often makes shipwreck, for love is a unity with bodily and spiritual expressions inextricably intertwined. Marriage with too much physical fondness may also make shipwreck. Bernard Shaw states an ugly truth for men when he says "marriage is popular because it combines the maximum of temptation with the maximum of opportunity."

The normal love of civilised men and women happily married is like a tree with deep roots, going far down into animal nature-roots that may be safely pruned, but never wholly cut--but with lofty branches that rise into the sunlight and bear always the homely and sometimes the rare fruits of the spirit. It is a pity when love does not rise off the ground.

There is no doubt that we may look to hygiene and education and the like, and to social changes as well, for the removal of extrinsic hindrances-in housing, for instance-to married happiness; but some of our grandfathers and grandmothers were probably happier and better in their but and ben than many who live in mansions. We greatly err if we think change of circumstances will necessarily save our souls. But we must try to secure the evolutionary circumstances all the same.

The maternal instinct is of supreme survival-value, and it has influenced the rest of the nature in the direction of other-regarding sympathies. In the family life in which it has expressed itself there has been established a garden for the individual cultivation of these 
virtues. The kindly instinct which mothering expresses, which is very strong in many who are not mothers, is not a strictly sex-linked character; it passes in inheritance to sons as well as to daughters, though the seeds often find the masculine soil rather stony ground. There is no allusion here to the occurrence of sex-intergrades, which cannot be regarded as quite normal; as Sancho Panza the wise said, we like men to be men and women to be women, equally able in their own ways, which, happily, are not quite the same ways. But experimental work in regard to lower creatures shows that an excellence primarily gained by one sex may become in a measure the property of the other also, unless it happens to be sex-linked, or is handicapped in its expression by the general constitution of the opposite sex.

Fathers have doubtless also made their contribution to the common human treasure of good-will. But if women have perhaps contributed most along the line of maternal virtues, men have probably contributed most along the line of the qualities of lovers. And the counterpart of men's excellencies as lovers may become part of the inheritance of daughters as well as sons. No one knows enough to gauge the rôle that the qualities of the lover have played in the evolution of the human mind, but let us get away from thinking of it in an easy-going or little-minded way. Darwin showed in lis Descent of Man how much might be traceable to preferential mating and its sifting; and he did not exhaust the inquiry. The finding and winning 
of a mate has been in infra-human evolution an agelong stimulus against slackness; it has made for adventure, for prowess, for alertness. It has been an organic spur for millions of years; can we suppose it is to cease to be potent in mankind, because for the time being we have too much allowed things to get into the saddle? Permanent monogamy seems an ideal-in many cases a happy reality-worth keeping as intact as possible. It has had a chequered history, but in most conditions it has proved itself the best arrangement for the realisation of mutual affection on the one hand, and for the welfare of the family on the other hand. Monogamy commends itself ethically, and likewise socially-it is the best method of rearing the next generation.

We have said above "as intact as possible," for we recognise the need for some changes; it may be necessary to change some of the marriage laws, for instance. To many it seems regrettable that in some countries a marriage cannot be dissolved for insanity, or for crime, or for cruelty, or for desertion, or for adultery by both parties. It may be said that if the bodily tie becomes intolerable separation may be possible, though divorce is not. But separation is a luxury beyond the means of many. In his recent book on what he calls social reconstruction Mr. Bertrand Russell proposes to permit divorce by mutual consent. In this he is surely arguing from his own fine nature and forgetting the frailties of the average man. He says: "Lifelong monogamy is best when it is success- 
ful, but the increasing complexity of our needs makes it increasingly often a failure for which divorce is the best preventive." "Mutual liberty, which is now demanded, is making the old form of marriage impossible." Man is rather imperfectly monogamous, perhaps, but it is difficult to accept this philosopher's conclusion that monogamy becomes "sooner or later retrospective, a tomb of dead joys, not a well-spring of new life." A truer note was struck by the French philosopher, Comte: "For two beings so complex and so diverse as man and woman, the whole of life is not too long for them to know one another well and love one another worthily."

\section{§9. The Difricult AGE}

There is much to admire in the bird's life-cycle, where sex activity is definitely seasonal and sharply punctuated. One of the peculiarities and dangers of man's case is the practical absence of seasonal punctuation.

It is rare to find instances of wild animals outliving their full vigour or their effective reproductivity. Metaphorically speaking, Nature does not tolerate the usedup. Literally, those races survive whose life-cycle is most successfully punctuated towards survival, the others have got sifted out.

The average duration of human life-about fortyis much the same all over the world and in all conditions, and it is probable that the cessation of women's reproductivity about that time, and the normal waning of sex-impulses in both sexes somewhat, later, have 
reference to an old-established span of life. It is not for us to discuss the great constitutional changesnotably in the regulative system-associated with the normal waning of sex about fifty or so ; but two things are important biologically, the one is the danger of artificially fanning the embers of a naturally dying fire, and the other is the value of having at a dangerous age a many-sided-indeed inexhaustible--interest in life. As the parable tells us, it is dangerous to leave empty the room from which the unclean spirit has departed.

\section{§ 10. The Problem of Growing Old, the Art of Remaining Young}

One may die a more or less violent, accidental or extrinsic death, as happens apparently to most wild animals; one may be poisoned by an invasion of microbes-and when they come from a neighbour's drains, one must die feeling rather ill-used; one may poison oneself with over-eating, over-drinking, or over-anxiety; one may in rare cases wear oneself out with overwork alone. In one or other of these four ways one may avoid the long slope of senescence. But growing old is part of the normal cycle, though one cannot believe that senility is. Prolonged senility never occurs among wild animals, and rapid senility is rare; even senescence is not very common. This is a parable.

We cannot draw any hard and fast line between senescence and senility, any more than between tiredness and neurasthenia, but in senility the disintegrative processes have gone so far that the unity of the 
organism has been lost. Every one knows the marvellous picture of old age which we owe to the author of Ecclesiastes:- " The mind and senses begin to be darkened, the winter of life approaches with its clouds and storms; the arms-the protecturs of the bodily house-tremble, the strong legs bow, the grinders cease because they are few, the apples of the eyes are darkened, the jaws munch with only a dull sound; the old man is nervously weak and startled even by a bird chirping; he is afraid of even hillocks, his falling hair is white as the strewn almond blossoms, he drags himself along with difficulty, he has no more appetite, he seeks only for his home of rest, which he finds when the silver cord is loosed or the golden bowl broken."

Physiologically regarded, the process of ageing is manifold. The bones become lighter and less resistant, some of them break easily; the muscles become weaker and stiffer-hence the stoop; the nervous system becomes slower and less forceful, the heart less vigorous; the arteries are less elastic ; the parts begin to fail to answer to one another's call, " and then, from hour to hour, we rot and rot."

Many answers have been given to the question What compels a creature to grow old? It is said that we wear out parts of the body such as the nervous system which cannot be renewed, such as the hard-worked heart, liver, and kidneys. But why should there not have been more perfect recuperation? It is said that we accumulate poisonous waste-products, so that the 
fire of life is smothered in its own ashes. But why should there not have been more perfectsifting? Itis said that the regulative system-made up of the organs of internal secretion-loses its activity. But why? It seems as if these were rather symptoms than causes of old age ; we can conceive of ways in which they might be evaded. There must be some more radical imperfection. That is disclosed when we ask whether it is really the case that all living creatures must and do grow old and die. The answer is in the negative. Most of the simplest organisms are continually making good their wear and tear, and seem to be exempt in natural conditions from natural death. There is good reason to believe that even some of the simple multicellular animals, like fresh-water polyps and Planarian worms, are able to stave off natural death indefinitely. Natural death is due to a mounting up of physiological debts-part of the bill is paid in every meal and in every night's rest, but the book is never cleared and in spite of holidays which knock off big arrears there is always a growing balance against us. Let us not press the metaphor too far; it is to ourselves we are in debt. Now the very interesting thing is this, that among the lower animals especially, but in all to some extent, there are processes of rejuvenescence which counteract the processes of senescence. In the single-celled animals the two balance; in some simple creatures just mentioned they also balance. Why should this not occur higher up the scale? The probable reason is this, that in a complicated creature there has to be a more or less per- 
manent framework within which the vital processes of metabolism occur. This framework is built up of relatively inactive constituents, and it is difficult to keep these young. The vital current deposits materials in its flow, and the bed begins to slow the stream. Every now and then there may be a flood and a fresh erosion -a fortnight's walking tour-but there are limits to this. It is the laboratory apparatus that gets exhausted, rather than the materials or the chemist within. Professor Child, our greatest authority on the subject, says: "For his high degree of individuation man pays the penalty of individual death, and the conditions and processes in the human organism which lead to death in the end are the conditions and processes which make man what he is." Perhaps we may say that natural death was the price paid for having a body at all, and that senescence is the tax on a body worth having.

We have sympathy with those who wave aside our biological theories of senescence and rejuvenescence and demand a recipe for remaining young. That is the really interesting aspect of the problem.

Now the greatest authority on this subject was Metchnikoff, who died in 1916, and not so very old either. His conclusion, well grounded in fact, was that if man lived a more careful and more temperate life, and had a more enlightened understanding of the limitations and disharmonies of his constitution, he would no longer, as Buffon said, die of disappointment, but would everywhere attain a hundred years. The two poisonings that age us most, he said, are those of alco- 


\section{THE INDIVIDUAL LIFE CYCLE}

holism and syphilis. He quoted with approval the saying of one of the founders of modern physiology (Pflüger):- "Avoid the things that are harmful and be moderate in all things" - - theoretically simple advice. Metchnikoff was an untiring advocate of buttermilk and that sort of thing; and that is well; for the character of our old age depends on the character of our physiological bad debts. But Metchnikoff's teaching must be supplemented by more positive encouragement of rejuvenescence. Better than buttermilk is a cruse of the oil of joy. Preventive measures are very desirable, but we need more positive rejuvenescence; we need more changes, new interests, fresh experiences, some adventures, more beauty, more joy. Thus we increase our chance of being young when we die. 


\section{CHAPTER VII \\ POPULATION PROBLEMS}

$\S 1$. The Need for Caution.- $\S 2$. The Biological Alternatives as regards Population: the Spawning Solution and Economised Reproduction.- $§ 3$. Spencer's Generalisation as to Individuation and Genesis.- $\$ 4$. Rise and Fall in Population.- $\$ 5$. The Persistent Increase in the Population of the Globe.- $\$$ 6. Causes of the Falling Birth-rate.$\S 7$. Good and Evil in the Decline of the Birth-rate.

\section{§1. The Need for Caution}

7 HE problems raised by the rise and fall in the 1 population of a country demand an unusual degree of caution and critical judgment. There is no security in predicting all that may be involved in a deliberate control of the birth-rate, and we have not anything like the full facts before us in regard to what actually happens in our midst. Therefore we should walk warily and be content for a while to balance provisional findings and to look out for guiding principles.

It must be admitted that there are facts and facts. When we pass from relatively simple things, like stars and stones, to complex living creatures and to still more complex human societies, it becomes increasingly 
difficult to get our facts clear-cut and complete. A falling stone near the earth's surface has an acceleration of about 32 feet per second. That is a clear-cut complete fact. But when we say that nesting terns can find their way home over an unknown area from a distance of a thousand miles, the fact is less clearcut and less complete. Half-a-dozen questions rise at once, what percentage find their way, how long do they take, do they fly in a straight line or tentatively hither and thither, and so on. And when we say that the crude birth-rate in Ireland in 1901 was 22.7 per 1,000 of the population, and that of Scotland 29.5, we are stating a fact so incomplete that it is positively misleading. We have to know, for instance, the relative numbers of child-bearing women in that year in the two countries. We have to know how many married couples emigrated from Ireland in 1901 before their first child was born. The more complex the phenomena, the more difficult is it to get clear-cut complete facts.

§ 2. Biological Alternatives as regards Population: the Spawning Solution and Economised REPRODUCTION

To understand population problems it is first of all necessary to get the biological foundations clear. Living creatures are encompassed by difficulties and limitations. To these they answer back in many different ways, using armour, weapons, capacities of concealment, circumventions, changes of habit and habitat 
-in short, all manner of shifts and devices. They use their fitnesses and they frequently strike out little improvements in these. This answering back to the environing difficulties and limitations constitutes the struggle for existence, especially when there is something novel and individual in the answer. The struggle for existence is a technical and metaphorical term; it need not be sanguinary; it sometimes leads to the sifting out of the relatively fitter to given conditions. The great law of life is that species survive in virtue of qualities of relative fitness. Fittest does not mean strongest, cleverest, gentlest-it means best adapted to the given conditions. The tapeworm is as fit for its inglorious life of ease in the food-canal of a dog as the lark at heaven's gate. Some animals survive because they are strong, others because they are clever, others because they have found a safe habitat (such as a cave), others because they are so quick, others because they have a garment of invisibility. But all succeed because they have certain qualities of fitness. Professor Punnett calculates that if in a population of 10,000 wild animals in a district there were 10 of a new and promising variety, which had a 5 per cent. selection advantage over the original forms, the latter would almost completely disappear in less than a hundred generations, and of course there might be sevcral generations, as in rats and rabbits, in a year. So if the sifting is consistent and persistent a change may come about in a comparatively short time. A dark variety of the Pepper Moth (Amphidasys betu- 
laria) has in a few years gained a majority over the typical form in some parts of England; a dark variety of Rice-bird (Oryzivora) is superseding the typical form in the West Indies. We know of a number of these changes occurring at present in wild nature, and we know what is done by analogous methods in domestication and cultivation.

But besides strength, quickness, cleverness, armour, weapons, inconspicuousness, and so on, there is another quality that has a great deal to do with survival, and that is fertility. Variants with valuable life-saving qualities will become the dominant type of the species more rapidly if they are also more prolific than their neighbours. Other things equal, low birth-rate may be a serious handicap. The success of a strain or species, in short, depends in part on its relative fertility.

So, as every one knows, a great many animals are prodigiously fertile. A cod has several millions of eggs; if these all developed into codlings and these into codfish there would soon be no more fishing, and that would be the end of the world. There is a starfish, called Luidici-and not a very common onewhich has 200 million eggs. Huxley calculated that if the descendants of a single green-fly all survived and multiplied, they would, at the end of summer, weigh down the population of China. An oyster may have 60 million eggs, and the average American yield is 16 millions. If all the progeny of one oyster survived and multiplied, its great-great-grandchildren would number 66 with 33 noughts after it, and the heap of 
shells would be eight times the size of our Earth. "Which is absurd," as Euclid used to say-when (according to Samuel Butler) he was tired of arguing.

This great fertility is an obviously effective solution of the problem of survival-the spawning solution. It is not without its good points, for it may enable the creature-say, fish or frog-to concentrate the business of multiplication into a short period of the year. It may also enable the creature to dispense with the embarrassment of parental care. With a family of a million, there is considerable margin for accidents, and nursing is gratuitous.

There are disadvantages, however, to the spawning solution. We need not refer to what is often called the enormous wastage of young life, for it is difficult to explain what wastage means in the case of an animal like the herring, and it is certainly not wastage in relation to the broad economy of nature, which is to such a large extent a chain of incarnations. What does seem a disadvantage, however, is the exhaustion of the parent, notably of the mother, when large numbers are produced at once. Butterflies usually die after egg-laying; so do marine lampreys after spawning; and the same is probably true of eels. Death is often the nemesis of launching new lives.

The other line of solution is economised reproduction in both sexes, and this is associated with parental care-with giving the offspring a really good start. The young creature must be launched well equipped, and this takes time and energy. The offspring must 
be few and widely spaced. The reduction of the number is more than compensated for by the correlated reduction of the infantile mortality. Quality wins against quantity. The flower of the grass with one seed exceedingly well equipped and well advanced when set adrift is far more successful than the flower of the orchid with hundreds of seeds which are liberated poorly equipped and as it were prematurely.

Another good example is the old-fashioned relic called Peripatus, which brings forth its young-miniatures of itself-after a very long ante-natal life. The fact that they are so highly developed at birth is surely in adaptation to their precarious existence, without armour and weapons, in this rough-and-tumble world.

Thus in many different corners and at many different levels in the animal kingdom we find mating (which often means prolonged partnership), and parental care, and, it may be, the beginning of family life. Time and again animals have turned from the facile solution of spawning to economised reproduction which secures survival by giving the offspring a good sendoff on the journey of life. What has actually happened has been that, in certain conditions of life, survival has been with those types that varied in the direction of reduced reproductivity and at the same time in the direction of better equipment of the young or on the line of parental care.

In their reproductive relations, as in so many other ways, wild birds command our admiration. Their sex- 
instincts, so intense in their expression, are sharply punctuated, being asleep for most of the year; the mother is not encumbered by having to carry the unborn young; the egg-laying is physiologically inexpensive; the males often share in nest-making and nurturing; there is sometimes prolonged monogamous partnership and what at any rate mimics human affection; the care of the eggs and of the young is so successful that the greatly economised reproduction works well; the young are in some cases able to look after themselves soon after hatching.

The three lowest Mammals (the duckmole and the spiny ant-eaters) lay eggs; the Marsupials, like opossum and kangaroo, have but a short gestation, and only one of them is known to have a true placenta, binding the unborn young to the mother's womb. The true placenta, which mediates in the intimate antenatal partnership, is confined to the ordinary mammals, like carnivores, ungulates, rodents, insectivores, monkeys, and man, and it permits, in a new way, of a high degree of development being reached before the young are born. In elephants the ante-natal life or period of gestation actually lasts for more than a year.

The typically mammalian method of motherhood may cost the mother a good deal, but she often gets something back in increased health, and it is probably on the whole less costly than the spawning method. It has the advantage of giving the offspring a fine sendoff with a big educable brain. It is probable that the long partnership between mother and offspring before 
birth has helped in the evolution of gentleness, patience, and affection. Other things equal, the more maternal mother will have more children, thereby diffusing her kindly gregarious temperament. But she will also tend to give them more careful and successful nurture. Thus, in two ways there will be a selection of the more domesticated or more mammalian types. This has probably meant much in man's evolution.

Compared with fishes and amphibians, birds and mammals are on the tack of economised reproductivity and enhanced parental care. Compared with a Blue Tit or a Common Wren, often with 8 eggs, the Guillemot with only 1 shows the same economy; it stakes everything on one egg for the year, and yet it holds its own well. Compared with rats and mice, highly evolved mammals like bats and monkeys show great reproductive economy, for they usually bring forth only one offspring at a time. The important general fact is that Man, however variable his fertility in different races and in different sections of the community, is on the evolutionary tack of economised reproductivity and high parental care. It is an important truth that everything became in some measure new when Man became Man, but it is likewise of importance to understand that Man has simply developed or elaborated a mode of evolution that is as old as many of the hills. 


\section{§3. Spencer's Generalisation as to Individuation AND GENEsis}

Herbert Spencer, after a prolonged argument, reached the conclusion that genesis decreases as individuation increases; the two are in inverse ratio. Individuation means complexity, fullness and freedom of life. The tapeworm with its degenerate body and drifting life of ease has its millions of embryos; the golden eagle with its complex body and controlled life has two eaglets at a time. It must be noted, however, that what Spencer really showed was that the inverse ratio between individuation and genesis is an evolutionary result, a fact of observation; he did not prove that high individuation directly lessens fertility. Perhaps it does, but that has not been proved. The fact is that we know very little regarding the physiology of fertility. Statements as to the infertility of men of great ability (illustrating inborn individuation), or as to infertility being the result of changes in the physical and mental education of girls (illustrating acquired individuation), are to be regarded with great scepticism. We know that high nutrition of ewes before breeding season greatly increases the number of twins, but we dare not say that luxurious living in Man either increases or decreases fertility.

What the evidence from the animal kingdom shows is this, that when birds, for instance, evolved big brains and strong parental instincts, it became possible for them to survive with much smaller families. We must 
rid our minds of all thoughts of prevision on the part of bird-parents, or of any providence that favoured variations in the direction of racial welfare. What probably happened was this. Those types that varied in the direction of better brains and increased parental care, and at the same time in the direction of economised reproductivity, were naturally in certain conditions of existence the surviving types, and directed the course of racial evolution. Did reduced reproductivity prompt parental care; or did the reduction of the family and its worries make better brains possible? We do not know. It is probable that two more or less independent lines of variation - the organism is a unity-worked into one another's hands.

It is very interesting to press the question whether increased civilisation may not directly lessen fertility. But we cannot give a convincing answer. It is easy to ask for the children of the great men of the worldAristotle, St. Paul, Descartes, Newton, Hume, Leibnitz, Kant, Kelvin, and so on; but it is not difficult to compile a good list of famous fathers-Darwins, Herschels, Bernouillis, Jussieus, Hookers. Sir Walter Scott was a seventh son; John Wesley was one of nineteen; Tennyson one of seven. The strongly individuated Brahmins and Rajputs of high caste are said to show no dwindling fertility.

What is one to make of the fact that the average size of the family among college-trained gentlefolk in the States is under two? What is one to make of the large number of childless marriages among profes- 
sional classes in Britain? The question is whether there is a constitutional decrease of fecundity, or whether what is observed is in the main an indirect result. For it is probable that a reduction of fertility among the highly individuated may be in part due to the frequency of marriages that are not love-marriages, to the frequency of late marriages, to selfish or timid non-maternity, to deliberate evasion of parentage, and even to overstrain in early efforts after self-realisation. It is also to be remembered that, up to a certain point, improved conditions of life tend to lessen multiplication indirectly, for new interests divert the animal nature and better housing lessens the provocations to sensuality.

While there is no doubt as to the occurrence of types constitutionally sterile, or relatively infertile, or with strongly inhibited sex impulses, little is known as to their relative frequency; and apparent infertility among the highly individuated can be in great part accounted for as an indirect result. There is very little evidence that heightened individuation brings about lessened reproductivity as a physiological consequence in the individual.

\section{§4. Rise and Fall iN Population}

Even in ancient times fluctuations of population were well known. Over and over again the following sequence occurred. In a limited area the increasing population began to overtake the means of subsistence. To relieve the pressure recourse was had to all sorts 
of expedients-exposing the children, infanticide, abortion, emigration, war, and so on. The Trojan War was definitely regarded as a timely solution of the problem of "a world too full of people." Moreover, epidemics and famine often halved the number of eaters; irrigation, improved cultivation, and the like occasionally increased the food-supply. In Greece an equilibrium was attained about the time of Aristotle and Alexander the Great. But as Professor J. L. Myres points out, industrial slavery, indifference to parenthood, addiction to club-life brought a most gifted race to an end. Dean Inge suggests that another factor was hopelessness about a future life, but that does not seem to have affected the Chinese. Of more importance probably, as a factor in decline, was the failure to give the women and the children opportunities for systematic education, and the short-sighted acquiescence in the breaking up of home-life. These things are a parable for our instruction.

Industrial Age.-For a long time before the eighteenth century there seems to have been in Britain a slow increase of numbers or even a populationequilibrium (as now in China), save for short periods after wars and plagues. Births made up for deaths. There were more births than deaths in the country, which God made; and there were more deaths than births in the towns, which man made; so that town and country between them kept a balance. The apologists for Providence in those days used to refer to this wonderful adjustment of births and deaths. 
But in the course of the eighteenth century the preestablished harmony was dissolved in discord. The population began to go up by lcaps and bounds. Between 1750 and 1800 the population of England and Wales rose from $6,500,000$ to 9 millions. This was associated with the sombre onset of the industrial age with its factories and machinery. The expansion reached its climax about the middle of the Victorian period. It is one of the most stupendous facts in human biology that the population of Europe, about 187 millions in 1800, was 266 millions in 1850, and 400 millions in 1900. In the nineteenth century the population of England and Wales was more than trebled (in 1801, 8,893,000; in 1901, 32,528,000. For Scotland the corresponding figures are $1,608,000$ and $4,472,000)$. From one case we may learn all. What conditioned this extraordinarily rapid increase in the population? Some arc inclined to emphasise a single factor--the economic factor-that big families 'payed '-.'payed' workers and employers alike. But we are bound to recognise at least three other factors. (1) In the early industrialism there were great waves of material prosperity, - plenty of work, big wages, falling prices. Now a sudden glut of material prosperity tends to slacken men's grip and restraint. This tends to raise the birth-rate. The most widespread prosperity was in the middle of the grcat Victorian period, when the birth-rate reached its maximum of 36.3 per thousand.

(2) But, as Havelock Ellis says, "The magnificence of this cpoch was built over circles of Hell to which the 
imagination of Dante never attained." And when people lose heart and are reckless excessive birth-rate may follow, just as from the opposite causes. We read in Exodus i.: "But the more they afflicted them, the more they multiplied and grew."

(3) Another reason for the rapid increase of the population was that in the latter part of the period there began to be notable advances in preventive medicine and hygiene. Man was entering into his kingdom -in controlling the death-rate. One must remember the very important fact that since 1865 the duration of life in England and Wales has risen about a third.

(4) Having admitted the reality of other factors, we are now free scientifically to recognise the vast importance of economic conditions. There is no doubt, surely, that the unprecedented multiplication had to do with the fact that children were sent out in tender years-one recalls the pictures in Wells' Clayhanger - to the factories and mines to increase their parents' incomes; and that the employers said Amen. Those who have gone deeply into Natural History say that foxes quite approve of large families among rabbits.

The Over-population Cry.-A generation ago those who lived in large towns in Britain were familiar with Population meetings. The cry was that the world would soon be "too full of people,"-the words used in Greece two thousand years before. Much reference was made to Malthus, who advised his generation to 
avoid the terrible positive checks to over-populationnamely, famine, disease, infanticide, and war, by practising the prudential check of postponing marriage and by practising moral restraint after marriage. He did not realise the possibilities of increasing the food-supply or the possibilities of more or less artificial birth-control. The most practicable piece of advice he gave amounted to "Marry late," and most biologists are agreed that this advice was very unsound biologically.

There was considerable misunderstanding of Darwinism. For it was said: Let us not interfere with Nature's sifting; leave things alone and all will come right. In spite of Darwin's express warning, it was assumed that famine, disease, infanticide, and war may be trusted to sift in the right direction. There were also more excusable misunderstandings of Herbert Spencer's doctrine, and the "old woman who lived in a shoe, and had so many children that she did not know what to do" was told that she should have been more individuated. Finally, from James Mill to begin with, there were whispers of various means which might be employed after marriage to keep down the family.

Looking backwards, we see some sense in all the suggestions. Prudence within limits is good, though it is a pity when it kills the spirit of adventure or leads to unwholesome repression; over-coddling is bad, but mere thinning of a dense population can mean little more than wastage; education and pitching the life high must always make for progress, but it is not 
known that they directly affect fertility; and a control of births seems to many to be in line with other steps which man has taken profitably in directing his own evolution.

But what happened? The tide turned, in 1877 in England, as men were arguing how to stem its advance. The birth-rate per thousand of the population was 32 about 1850 ; it rose a little (helped by more thorough registration) to its maximum 36.3 in 1876 , the year of the Bradlaugh-Besant trial; it has steadily fallen to about 24 per thousand. This movement of decreasing birth-rate, in which France led the way, is now common to all the more highly civilised nations. The decline, corrected with reference to the number of wives under forty-five, has during the last thirty years or so been most marked in New South Wales, then in Victoria, Belgium, Saxony, New Zealand. There has also been a considerable decline in France, Germany, England, and Denmark. There is little evidence of any in Russia and the Balkans. Apart from a few interesting exceptions, it may be said that among English-speaking people there has been a decrease of about one-third in the last forty years. But it must always be kept in mind that this has to be brought into correlation with changes in the death-rate and in the marriage-rate.

While we cannot enter into details regarding the decline of the birth-rate, we must call attention to a few general facts. The decline is most marked in areas where the highest standard of living prevails and vice 
verse. In illustration of this Dr. C. Killick Millard, in his effective address on "Population and Birth Control " (1917), contrasts Hampstead, a typical middleand upper-class residential district, with Shoreditch, a poor working-class district. In 1881, the birth-rates of these two districts were approximately equal, viz., 30 and 31 respectively. "In 1914, Hampstead's birthrate had fallen to $14 \cdot 8$, whilst that of Shoreditch remained at the old figure. The same tendency exists in almost every town."

The decrease is much more marked in the upper and middle classes than among the poor, much more marked among skilled workmen than among unskilled. In a table of comparative fertility for England, which refers only to women of child-bearing age, the four occupations at the top end are coal-miners (126.4), agricultural labourers (113.4), boilermakers (110.1), farmers $(100 \cdot 5)$. The numbers show proportions to a general population fertility taken as 100 . The four at the lower end of the list are nonconformist ministers (79.8), Church of England clergymen (72), teachers $(70 \cdot 3)$, and doctors $(64 \cdot 7)$.

The smaller the number of rooms the larger is the family, and the death-rate among infants is always highest where the birth-rate is highest. Making some notable exceptions, e.g. for coal-miners, who are physically a fine set of men-Dr. Millard writes: "It appears undeniable that poverty, degradation, ineffciency, ignorance, over-crowding, almost everything, in fact, that in human judgment tends to disqualify 
for parenthood, are just the factors nowadays which too often coexist with large families."

\section{§5. The Persistent Increase of the Population OF THE GLOBE}

There are some careful students of Population Problems who warn us that concern about the present decline of the birth-rate is very short-sighted, since the real cloud in the sky is the persistent increase in the number of the world's inhabitants. We may refer to an able address by a distinguished biologist, Professor E. M. East (Scientific Monthly, June, 1920). At present the population of the globe stands at about 1,700 millions. But it does not stand; it is being added to at the rate of between 14 and 16 millions a year. The white race is increasing much more rapidly than the yellow or the black; China's 300 million population is practically stationary. With the exception of France, few white peoples are increasing at a less rate than 10 per thousand every year. It is true that in most civilised countries there is a steady decrease in the birth-rate, but the effect of this in reducing the population is counteracted by the lowering of the death-rate.

In his Presidential Address to the Agricultural Section of the British Association in 1920, Professor Keeble maintained that as a population increases, so does the intensity of its cultivation; but Professor East finds little satisfaction in this idea. The law of diminishing returns operates widely; it is even now in operation in a comparatively new country like America, thought 
to be supplied with inexhaustible riches. There are limits to the harvest.

Professor East views with concern the persistent increase of the world's population. If the rate of increase actually existent in the United States should continue, within the span of life of the grandchildren of persons now living the States will contain more than a billion inhabitants (meaning a thousand millions). " Long before this eventuality, the struggle for existence in those portions of the world at present more densely populated will be something beyond the imagination of those of us who have lived in a time of plenty."

The cloud grows denser when it is noticed that the birth-rate of the foreign population of the United States, coming largely now from eastern and southern Europe, is so much greater than that of the Anglo-Saxon stock (to which, it is claimed, most of the superior types belong), that within a century the latter will be but a fraction of the whole. Professor East looks forward with hope to a severe restriction of immigration; to the spread of education, which seems to be correlated with a lowering of the birth-rate; to equitable readjustment in many economic customs, for the word 'proletariat' is suggestive enough ; to rational marriageselection, which will tend to an increase of the birthrate in families of high civic value; and, among the rank and file, to a restriction of births commensurate with the family resources and the mother's strength.

While it is impossible to predict what may yet be done in the way of increasing the harvest which man 
gathers at present from land and sea (there are scores of devices waiting to be tried); and while it is impossible to predict what biochemical advances await discovery, it seems common sense to attend to Professor East's warning. For it points towards a policy which is bound to be progressive whatever the future has in store,the policy, namely, of trying to secure a more masterly and therefore more economical exploitation of the resources of Nature, and of trying to evade the cruder forms of the struggle for existence by always preferring quality to quantity. Il faut cultiver son jordin-in more senses than one.

\section{§6. Causes of the Faliing Birth-rate}

No complete answer can as yet be given to the question: What are the causes of the falling birthrate? The problem is in the hands of investigators. The birth-rate depends on many factors, and these are variable. It depends on the age-composition of the community, on the number of wives under forty-five, on the age at marriage, on the duration of marriage, on the loyalty of husband and wife, on the amount of illegitimacy, on the economic conditions which affect control either through continence or through some evasion of parentage, and on some other factors like alcoholism and reproductive diseases. Nutritive factors do not seem of direct importance ; mental development does not seem to have much, if any, direct effect.

Among men who have a ligh standard of taste and restricted means of satisfying this, the marriage-rate 
sinks, the age of marriage rises, the birth-rate declines. There is often an element of selfishness in this, especially when the demands of sex are met outside of matrimony, but it would be quite erroneous to write down the postponement of marriage as necessarily selfish. It would be equally erroneous to sum up a certain type of marriage, at various levels of society from working-man to financier, as having merely an economic basis. All these phenomena are complex resultants. In past times at certain levels the child used to be regarded as a savings-bank from which the parents could draw early; if children are nowadays regarded as investments it is only on the understanding that they cannot yield a rapid return. Consciously or subconsciously the economic consideration lingers, but it has not the force that misery lent it in worst days of unregulated industrialism. A new consideration has arisen. There is a heightened appreciation of the value of human life : the child is more precious. What infuences many parents, who have had a hard fight themselves, is the fear of being responsible for many children-especially girls who will have to face a similar struggle for existence. 'This fcar may indicate timidity, but it is certainly not selfish. Many, again, resent the wearing down of the mother's health with too frequent births; and the predominantly maternal and domestic rôle in which our grandmothers were happy and admirable (and quite as clever as their grandehildren) will not do nowadays. But just as prudence, commendable up to a limit, may pass, on the minus side, into a non-mammalian 
recoil from the trials of maternity and the claims of children, so the commendable determination to make the best of life in the direction of fullness, freedom, and fitness, may pass, on the minus side, into a lust for gratification without responsibilities.

Careful students of the decline of the birth-rate have come to the conclusion that it is not due to decline of fertility, e.g. as the result of the higher education of girls; that it is not more than slightly due to changes in the age of marriage or in the proportion of wives of child-bearing age; but that it is mainly due to intentional restriction of births, to deliberate birthcontrol.

The Registrar-General for England has made the important statement that not more than about 17 per cent. of the decline in the birth-rate can be accounted for as the result of abstinence from marriage or of postponement of marriage, and that nearly 70 per cent. of the decline must be ascribed to voluntary restriction. Dr. Newsholme of the Local Government Board concludes that postponement and avoidance of marriage have had little share in causing the reduced bi:th-rate experienced in Britain and some other countries during the last thirty years. Mr. Sidney Webb made a fow years ago (1911) a voluntary confidential census, and found out of 120 fertile marriages among professional men 107 'limited,' and out of 316 marriages among middle-class people 242 'limited.' Dr. Millard calls attention to a fact believed to have been brought out 
by a recent Birth-rate Commission, "that the mean size of the limited families was larger than that of the unlimited families. This is important, as it shows that it is not so much the small families which are limited, but the families which are getting too large. In other words, it is not that people nowadays do not desire children, but that they do not desire too many." Before full reliance can be placed on such conclusions, it will be necessary to have a larger body of data.

\section{$\S 7$ Good and Evil in the Decline of the BirTH-RATE}

Many wise men to-day regard the decline of the birth-rate with as much alarm as their fathers regarded its continuous rise in the Early Victorian period. Is the modern scare better grounded than its predecessor? The main reason for foreboding is lest the nation lose its place in the sun, its military and ezonomic stability, and dwindle away. The decline of the birth-rate is regarded as the beginning of a facilis descensus leading to ruin.

As we have said before, in reference to the 'Nature and Nurture' controversy, it is vely undesirable to 'take sides' in face of a problem of this sort, especially when we have not the facts fully before us. We have not to choose between two antithetic policies; the problem is really that of a movable adjustment of the birth-rate in adaptation to definite conditions. Every man and wife have to decide for themselves how many children, if any, they ought to have, and a decision to 
limit the family which was wise when circumstances were straitened and prospects gloomy might well be subject to revision some five years afterwards. The control is relative to many conditions, e.g. (a) the likelihood of securing good education and auspicious launching in life, a likelihood which might be great for two but sniall for ten; $(b)$ the health of the mother; $(c)$ the vigour of the children. Similarly with nations, the problem is relative to conditions. When the land is crowded, when openings are few, when unemployment is rife, and distress is at the doors, it might be wise to counsel restriction of families. But when numbers are dwindling or have been terribly reduced, when new opportunities of industry are offered, when new countries are opening out, when there is vigour and mastery, then it might be wise to hearken to the old counsel, "Be fruitful and multiply."

To those, and there are at present (1921) many, who cannot see in the decline of the birth-rate anything but menacing evil, if not ' race-suicide,' we would submit the following considerations:--(1) Much depends on how far the decline goes. If there should begin to be an excess of deaths over births, which has not come about even in France, that would be ominous indeed. But may not a considerable decline in the birth-rate strengthen a nation? May it not make for stability, by raising the health-rate and lessening the strain of domestic anxieties? We can compensate for a falling Birth-rate by lowerimg the Death-rate, and also by raising the Health-rate.

(2) The decline in the birth-rate is now an almost 
general phenomenon in so-called civilised countries, though the rate of decline varies considerably. If the decline extends from nation to nation, as it is doing, it may make little difference in the numerical proportions. The German birth-rate is said to have reached its climax forty years ago, just like that of Britain ; from 1871 to 1880 it was $40 \cdot 7$ per 1,000 population (paralleled in some Welsh mining villages); in 1906 it was down to 34, in 1909 to 31, in 1912 to 28, in fact the birth-rate in Germany is now falling faster than in England. The rate of increase of population in Germany for the five years, 1907 to 1911, was 13 per cent. ; for England and Wales, 11 per cent. ; so that there is no great difference.

(3) It must be remembered that one of the conditions that make a nation a menace to others is a high birthrate accompanied by a low death-rate. France, which may be called, amid all its prowess, an organically pacific country, had not so very long ago a birth-rate higher than that of Germany to-day, and it was then, as has been said, "the most militarist and aggressive of nations, a perpetual menace to Europe." In regard to the 'yellow peril' and the like, it may be noted that birtlcontrol methods are already in use in Japan and India ; and that while some Asiatic races show a prodigious birth-rate of 50 per 1,000 population, 70 per cent. of the children sometimes die.

Differential Decline.-But a second reason for foreboding is found in the fact that the decline is differential ; it affects certain sections of the community more than othcrs. The less desirable-the thriftless, the careless, 
the unreliable-tend to be the most prolific. The more desirable-the thrifty, the educated, the controlled, those who care-tend to be the least prolific. This is very serious, for social progress depends on a steady increase in the proportion of the more fit to the less fit, and the differential decline in the birth-rate seems working in the wrong direction. (We shall leave out the special case of nationalities with a very heterogeneous population-e.g. America with the Negroes, South Africa with the Kaffirs-and keep to the case of the higher birth-rate among the less desirable members of a society.)

The following considerations should be borne in mind:-(a) There is a high death-rate among the thriftless, which counteracts in some measure their high birth-rate. But society will, of course, continue to try to lessen the high death-rate. (b) It is absurd to talk as if all people were equally endowed, but it is also absurd to talk as if the desirable and the undesirable could be distinguished at a glance. Many people who have lost grip and heart were made, not born, undesirable, and there is more wrong with their purse than with their germ-plasm. We do not really know to what degree the differences between the people of Shoreditch with a high birth-rate and the people of Highgate with a low birth-rate are extrinsic (modificational) or intrinsic (variational). It is certain that the production of the fit and of the remarkably able is not a monopoly of any class. It takes a lot of different kinds of men and women to make a world and to keep it a-going. (c) It 
has also to be remembered that all measures implying increased control of life work from the more thoughtful to the less thoughtful.

It cannot be denied, however, that there are facts which warn us to watch with anxious attention the differential decline of the birth-rate. Among the miners of Rhondda Valley, who are said to be vigorous people, the birth-rate is still about 40 per 1,000, twice as much as in a residential suburb of London. The crucial question is how far this disparity of the birth-rate in different sections of the community will go.

In his inquiry into the birth-rate in different districts in London, Dr. Heron was led to the following conclusion:- "In those districts where the professional classes are most numerous, and where many domestic servants are kept, there the married have fewest children. In districts where there is overcrowding, where there is a superabundance of the lowest type of labour, where child-employment is most prevalent, where infant mortality is greatest, where pauperism is general, and pauper lunatics are plentiful, where signs of bad environment like phthisis are prevalent-there the birth-rate is highest."

Few will regard with misgivings the notoriously low birth-rate among millionaires, but what about this sort of fact? In the eighteenth century, Benjamin Franklin declared that the average number of children in a family in North America was 8; at the end of the eighteenth century, it seems to have been about 6 ; 
in some parts of America it is down to $2 \cdot 7$; among college-bred Americans it is less then 2. Less than 2 seems too few. The proportion of births in England per 1,000 married men under fifty-five is represented by the following figures:--Upper and middle class, 119; skilled workmen, 153; unskilled workmen, 213.

We are not arguing here in support of any thesis. We have not the facts fully before us. We merely indicate that there are two sides to the question. It may be that the period after a terrible war is a time for recuperating and not for further reduction of the population. Moreover, not marrying at all, or not marrying till late, or not having a family seems on the average a very regrettable policy, both biologically and ethically. But it is quite another thing to say that the decline of the birth-rate within limits of safety is altogether a bad sign. The following considerations on the other side must be kept in view.

5. The diminished birth-rate may tend to improve the - health of children and mothers. It may tend to substitute quality for quantity. It may make life less anxious, more secure, and with greater possibilities of fineness. Associated with birth-control, it makes earlier marriages more feasible. The control of the birthrate makes for the independence of women and increases their opportunities of self-development. If the decline of the birth-rate proceeds more or less uniformly it will work against war, which is partly due to expansive population, and if war still persists, a restriction of 
numbers will keep it from being still more terrible than now in its wastage of human life.

Havelock Ellis is a notable champion of the view that " the chief cause of the superiority of a highly civilised state over lower stages of civilisation is precisely a greater degree of forethought and self-control in marriage and child-bearing." Birth-control is not 'race-suicide' but race-saving. " The expanding nation has always been a menace to the world and to itself. The arrest of the falling birth-rate would be the arrest of all civilisation and all humanity."

\section{By What Means?}

Many wise men in recent years have said that they are not so much afraid of the decline of the birth-rate as of the methods by which it is effected. In old times infanticide was practised without reproach. In a graveyard at Gela, in Sicily, with a total of 570 burials, there are 233 of exposed infants. Plato and Aristotle countenanced abortion, and this lingers in many English towns by the use of lead preparations now being suppressed. Now, these solutions are surely much more deplorable than modern preventives or contraceptives, which keep a new life from beginning.

In a recent article (Nation, Oct. 2, 1915) Dean Fremantle says that rather than artificial restriction he would see continued the struggles of parents of large families, from which he says, "a large part of the moral greatness of our people has resulted." But the achievement of many parents in rearing large and highly 
successful families was surely due to a moral fibre already present; it was not engendered by the struggle. Moreover, while big families of the right sort are admirable when the parents are sufficient for these things, one doubts if almost anything can be put against the misery and hopelessness to which many good women have been reduced by too rapid succession of births. There is considerable impiety in the saying that whenever the Lord sends a mouth, he will send the food to fill it.

In an open-minded and wise article on the Birthrate in a recent number of the Edinburgh Review, the Dean of St. Paul's points out firmly that the "Comstock" legislation in America against the sale and use of preventives "has done unmixed harm" by terribly increasing the recourse to abortion. Dean Inge's personal opinion is that high-minded married persons should avoid preventives as a last resource in the failure of self-restraint. But one must not expect the supernatural from ordinary mankind. Even great restraint and great conjugal temperance may soon be followed by too many babies. But one agrees at one's best with the Dean, that whatever injures the feeling of honour with which St. Paul bids us regard these intimacies of life, whatever tends to profane or degrade wedded love, is so far an evil. But this is emphatically a matter in which every man and woman must judge for themselves, and must refrain from judging others. In Holland authorised nurses give instruction to working-women and the society behind them has State authority and support. 


\section{What Motives?}

Some thoughtful critics of our modern development have said that what fills them with foreboding in regard to the decline of the birth-rate is not the fact itself, nor the method of birth-control employed, but the motive. It is difficult to discover motives. Most of our motives are a good deal mixed. But one cannot help feeling what was well expressed in a remarkable article in the Scotsman some years ago, "Stand Up, $\mathrm{Ye}$ Dead," that there is a good deal of selfishness and poor-spiritedness behind the empty cradle and the celibate club. As Mr. W. S. Lilly says : it is well that men should wish to warm both their hands before the fire of life, but they need not be so mortally afraid of burning their fingers. Yet it would be a gross error to suppose that the motives behind the control of births are necessarily selfish.

Three notes in conclusion.

(1) We should recognise how little we know about the birth-rate, its changes and its possibilities of harmful and useful control. Our ignorance is immense. But we must not shut our eyes and drift. We must command our course with more knowledge. We must have franker medical advice. We must not be impatient in conclusions, or in conduct. He that believeth in evolution shall not make haste.

(2) We must view the decline of the birth-rate not only personally but in relation to national welfare and stability. Better 40 millions healthy and vigorous and joyous, than 60 millions riddled with bad health, weakness, and depression. But we must also view it inter- 


\section{POPULATION PROBLEMS}

nationally. For there are few of us who wish to give up our place among the nations or to see our race dwindle away to disappearance as did that of ancient Greece.

(3) Lastly we must not look at things too biologically or too materialistically. We are body-and-mind creatures, personalities, and the greatest thing in human life is love. If we jettison this we are sacrificing one of the treasures that make our voyage worth while. If the mode of life and thought we are settling down into tends to materialistic views of marriage and having children, no matter what we secure, we are missing the substance for the shadow. We must not allow the word artificial to be a bogie, but no substitution of mechanical control for moral control can ever be regarded with entire equanimity. If we lose the chivalry and tenderness of lovers, the joyousness of the Springtime of the heart, the adventurousness of early marriage, and the delight of having children while we are young enough to sympathise with them, we are missing the fragrant flowers of life. 


\section{CHAPTER VIII \\ THE KINGDOM OF MAN}

$\S 1$. Cosmosphere, Biosphere, and Sociosphere.- $\$ 2$. Control in the Domain of Things.- $\S 3$. Control in the Realm of Organisms. $-\S 4$. Control of Disease. $-\S 5$. Control of Body and Mind.- $\$$ 6. Social Ideals: Eugenics, Eutechnics, and Eutopias.- $\$ 7$. Selection in Mankind. $-\S 8$. The Dilemma of Civilisation. $-\$ 9$. The Social Heritage.- $§ 10$. Man's Imperium in Imperio.

$\S 1$ Cosmosphere, Biosphere, and Soctosphere

UR world may be thought of as three spheres, one within the other, though all are comprehended in the mind of Man, the measure of the universe. First, there is the domain of things in general-the Cosmosphere :-water, earth and air; dewdrops, stones, and the spacious firmament on high; matter and motion, the ether, and all the energies within the limits of the inorganic. It is the domain of the relatively unorganised, though there is some organisation in crystals and stellar systems, not to speak of man-made machines; but it is begging a question to call it inanimate. The modern discoveries of the internal activities of things show us the inappropriateness of the word 'inert'; all is move- 


\section{THE KINGDOM OF MAN}

ment and flux; there is bustle in the dust; and though it is darkening counsel to speak of the 'life' of crystals, there is a hurry-scurry of particles in the heart of a quartz pebble. What happens every day in the domain of things can be described for practical purposes exhaustively in terms of matter and motion. The laws of the domain are chemical and physical, dynamical and mechanical. The laws that Man has succeeded in formulating must be approaching the truth, i.e. cor. respondence with reality, for they can be used as a safe basis for prediction and preparation. The fates of empires are staked on them,-in a naval battle, for instance.

Secondly, there is the realm of organisms, the sphere of plants and animals-the Biosphere. It is immersed in the domain of things and always interacting therewith. It is more intricate and more elusive than the non-living world, and we have not-probably cannot have-such an expert knowledge of it. No doubt it is possible to give a chemical and physical account of the measurable activities that go on in this animate realm, but to think that this is all is to leave Hamlet out of the play. The outcome of the chemico-physical analysis is not an intelligible re-description of the activities and behaviour of living creatures. Even when we leave ' mind' out of account, living creatures cannot be described adequately or exhaustively in terms of matter and motion. If we are clever enough we can account mechanically for the return of a boomerang to the thrower's hand, but we cannot account mechani- 
cally for the return of the migratory bird to the place of its birth. Moreover, though we can sometimes make a secure biological prediction, in regard to heredity for instance, we cannot trust to living creatures as we can, let us say, to the tides. Animals are often very reliable, but they have wills of their own, and beyond a certain limit " they cannot be lippened to," as Scots folk say. The "indeterminateness" of a dog is much greater than that of a starfish.

Thirdly, there is the Kingdom of Man-the Sociosphere. It is separated off from the realm of organisms, because Man works in societies or societary forms, because Man understands and purposes at a higher level than any animal, and because Man has to an unprecedented degree the power of registering his personal and racial gains outside himself-in books and buildings, in traditions and institutions, and so on. The Kingdom of Man is a realm of ends in a much more conscious way than holds among animals. We often keep an end of a rather subtle sort for years consciously and deliberately before us, and it influences the deeper currents of our conduct.

Bacon's phrase, the Kingdom of Man, is here used, however, to indicate not merely human society and its products, but also that part of Nature (cosmosphere and biosphere) which man subdues to his service or trans. forms for his purposes. Thus, we may think of the Panama Canal, the damming of the Nile, the Mont Cenis tunnel, the planting of a great forest, the domestication of animals, as part of Man's kingdom. For purposes of 
understanding man takes the whole universe for his province, but his kingdom which he would control, in which he would in some measure express himself, has a less ambitious range.

Materialism and Biologism.-The particular classification of the outer world which any one adopts does not perhaps matter much-different schemes appeal to different minds-but it is important to avoid the error of false simplicity. One may get a good deal out of a horse if one treats him as an engine, and he must never be treated in a manner subversive of the reasonable treatment of an engine, by ignoring the law of the conservation of energy, for instance; but one dos not get the best out of a horse if one persists in being materialistic. The best horsemen treat their horses as fellowcreatures ; see, for instance, Roger Pocock's The Horse (Murray, 1917). Similarly, one may get a good deal out of a boy if one treats him just as a young mammal, and he should never be treated in a manner subversive of the reasonable treatment of a mammal, by ignoring sex, for instance; but one will not get the best out of a boy if one confines oneself to the zoological point of view. A biologism is just as dangerous as a materialism.

\section{§2. Control in the Domatn of Things}

As regards the conquest and control of the domain of things, man's aim is to make the most of the physical universe, with the minimum waste of materials and 
energy and life, and with most good to himself, considering "good" and "himself" not too narrowly. "Real gain," said Sir William Ramsay, " real progress consists in learning how better to employ energy-how better to effect its transformation." There are, of course, other gains equally real, but the great chemist we have quoted was speaking from the matter and motion standpoint. It is one of the great facts about our raceto be set against some disappointing features--that every year increases man's mastery of the physical forces. He taps one reservoir after another, and slowly learns economy. He annihilates distance with his deep devices, he makes the ether carry his messages, he coins wealth out of the thin air, he journeys through the sky and beneath the waves of the sea. With science as torch Man has already done great things; and why should we think that he has more than begun to enter into his kingdom? As regards the domain of things, every year adds fresh illustrations to the saying of the poet Herbert, "Man is one world, and hath another to attend him." It is not, however, within our present scupe to follow further what we have illustrated in the first chapter of this book. But there is one caution that the biologist must not leave unsaid. No one can suppose that all Man does in the field of physical operations is equally commendable. Within the physical domain itself there is the criterion that the exploitation should not waste materials or energies; and that criterion has not always been attended to. But from outside the domain comes the criterion that we must ask how the 
physical operations are affecting living creatures and Man himself and society; and that criterion has not always been attended to. Almost ideal is Man's use of a head of water to generate electricity, by which in turn he captures the nitrogen of the atmosphere, with the result of forming fertilisers which increase the produce of the earth, and give us daily bread. On the other hand, the desolation of those areas to which the terrible name "Black Country" is or may be applied, shows that however necessary the iron-works are, the exploitation cannot be called perfect. Irrigation-achievements in a country where the rain previously went to waste -are supremely economical, and, so to speak, greatly to man's credit. But what of gold-mining where every man working underground gradually gets his lungs infiltrated with the fine dust and is doomed to a short life unless he can change? Man must look to the whole cost of his conquests in the domain of things.

\section{§3. Control in the Renlm of Organisms}

As regards the realm of organisms, Man's aim is to get more control of living creatures so as to make his own position more secure, progressive, and enjoyable. So he puts a check on the multiplication of poisonous animals, dangerous animals, destructive animals, disease animals. He offers a farthing a head for poisonous snakes, and the wily Hindoo breeds them in his back yard. He puts a check on multiplication of poisonous plants, troublesome weeds, destructive plants, and disease plants. Contrariwise, he tries to promote the 
increase of animals and plants that are palatable, profitable, and pleasant. He has to do this with scientific caution both in removing and in adding. Let us briefly illustrate some of the practical recommendations which experience has brought into prominence.

Realisation of the Web of Life.-If Man is to succeed in the control of the realm of organisms, he must acquire an increasing knowledge of the old-established, subtly adjusted balance of nature or system of inter-relations, a disturbance of which is often followed by portentous results. The consequences of the careless introduction of animals into a new habitat, where they multiply unchecked, is familiar in connection with the rabbits introduced into Australia and the sparrows introduced into the United States. Contrariwise, the ruthless killing off of birds and beasts of prey has been followed by plagues of voles, and the destruction of white herons has been followed by great losses in the rice-fields of the East. Destroying squirrels may mean an overmultiplication of wood-pigeons, which are extremely destructive to the crops. What is needed at every turn is more science.

Let us take a diagrammatic illustration. There was some years ago a decrease in the yield of fish from certain Australian rivers and estuaries. A hasty inference put the blame on cormorants, which are well known to be greedy fish-eaters. So the edict went forth for a massacre of cormorants, and the edict was obeyed. But the extreme thinning of the cormorants did not 


\section{THE KINGDOM OF MAN}

result in any increase of food-fishes, though it was persisted in for years. Then, at last, when an appeal was made to scientific knowledge, it was discovered that the cormorants fed in great part on the sand-eels and crabs which devoured the fry of the food-fishes.

To destroy rats in Jamaica they imported the mongoose from the Old World, and for a time things went well. But when the mongoose had finished with the rats, it had become many mongooses, and these turned their attention to the poultry. Thence they passed to ground-birds and lizards and snakes. There was no mourning over the loss of snakes, but the lizards and ground-birds were missed. For injurious insects and ticks began to multiply exceedingly, and some people said they would rather have the rats back again and the mongooses safely home. The last part of the story is that the insects and the ticks are making life a burden to the mongooses. It will right itself, but much is always lost in the process.

Wastage and Economy of Exploitation.-It is very interesting to contrast the old ways of hunting and fishing, shepherding and farming with those of to-day; and one fact stands out-that modern methods are or can be made far more economical in immediate result Take in illustration a very ancient and very widespread mode of fishing - still practised in Australia, for instance - that of throwing into the water quantities of certain poisonous plants. The fish are poisoned and float up to the surfacc where they are caught dying or dcad. It is a diagram of wastefulness. Young are killed as 
well as old; a whole lagoon may be cleared out; the supplies obtained are far in excess of demand. What a contrast this wastefulness is to the conservative expedient of tumbling cartloads of bracken into a freshwater loch, with the result that the trout-supply in succeeding years is greatly increased. The bracken, worked on by bacteria, affords food for Infusorians, which are devoured by minute crustaceans, which form the food of the trout, which are in turn reincarnated in man. Most of us will prefer this way of eating bracken to that counselled by some frugal minds who recommend bracken-top asparagus and bracken-root fritters. The indirect way of eating bracken is the more scientific. To economists in the days of Malthus the danger of human population outrunning the means of subsistence was a dark cloud; it would not have seemed so dark if they had known what we know of Man's power of multiplying loaves and fishes, e.g. by rearing more prolific strains of cereals or by artificial stimulation of the resources of the sea. It is not indeed to be supposed that there is not much wastefulness in modern methods of exploitation,-in trawling, for instance,-but the point is that we know more or less clearly when we are wasteful, that we can stop it when we choose, and that we can increase our food-supply enormously whenever we please to put more brains, i.e. more science, into the problem.

It is easy to exhaust mussel-beds unless they are used in a series, giving each a long rest in turn; it is easy to exhaust a field unless there be rotation of crops ; 
it is easy to spoil a countryside unless there are five seedlings planted for every good tree cut down; but this is the mere alphabet of science.

The secret of domesticating animals seems to have been lost, or perhaps the number of domesticable animals is very small ; but there are surely enormous possibilities of new cultivated plants.

\section{§. Control of Disease}

The great steps that Man has taken in the eontrol of things have been very largely due to seientific genius. "If necessity is the mother of invention, euriosity is almost certainly its father" (A. D. Darbishire : A New Biology. Cassell, 1917). The taking advantage of the discoveries of Science has been prompted by the widespread desire for 'wealth,' security, comfort, and pleasure. Similarly the great steps that Man has taken, especially since Pasteur's day, in the control of disease, have been largely due to sheer seientific inquisitiveness, but they have been prompted also by Man's sympathy with and dislike of suffering. Man's shrinking from disease or desire to be rid of it probably still supplies a stronger motive than his ambition to be positively healthy.

Let us recall a few instanees of Man's control of disease. The story of the mastery of malaria, for instanee, is like an illumined picture, and we cannot help wondering that it does not move men more. Laveran discovers the minute animal that causes the mysterious disease. Major Ross discovers that its early stages are passed 
inside the spot-winged gnat or mosquito (Anopheles). He goes on to show that if we can avoid being bitten by a mosquito we may live without malaria in the midst of a malaria-rife swamp; that if we can keep the mosquito from sucking the blood of malarial patients we can greatly lessen the disease; and that a film of paraffin on the pools in which the larval mosquitos develop will abolish the disease from the area.

Another very instructive case concerns the disease known as bilharziasis. It must be explained, first of all, that a common disease in sheep, called liver-rot, is due to a fluke-worm (Distomum hepaticum) which spends the early part of its life in a tiny fresh-water snail (Lymnous truncatulus). The more of these snails that wagtails and lapwings eat, the less liver-rot in sheep. Now, in warm countries, such as Egypt, there is a distantly related worm, called Bitharzia, which occurs in man. It has the peculiarity, shared by the formidablc hookworm, of being able to pass as a microscopic larva by boring right through the human skin. It causes very serious and painful disease and occurs in not less than a half of the total population of Lower Egypt, and in every third child born in Cairo. Its life-history, which involves several kinds of fresh-water snail, e.g. Melania and Bulinus, has been revealed by Dr. Leiper's careful tracking, so thoroughly revealed that he has bcen able to protect all who are willing to take a few simple precautions. Thus, the frec-swimming larva cannot live for more thai thirty-six hours in drawn water. Eventually, by getting rid of the snails 
in the canals and the like, man will get finally rid of the discase. This illustrates the control of life.

§6. Social Ideals : Eugenics, Eutechnics, Eutopias

When we consider the social sphere, the part of the Kingdom which is most distinctly Man's own, we have cause to be at once proud and ashamed. There is magnificence, but cheek by jowl with misery; the sublime is jostled by the sordid. What literature, what art, what science! And yet, what trash, what ugliness, what ignorance! At times it seems as if Man as organism lagged behind the externally enregistered gains of evolution, as if the citizen were not worthy of the city. At other times it seems as if Man handicapped himself with external impediments, as if the machinery he fashioned became too strong for him, as if the slum got the better of the citizen. Yet those are wisest who keep brave hearts. "What is Man?" said the chaplain, quoting the Psalmist to Richard Yea-and-Nay. "What is Man not?" thundered back the King. And that is the right spirit.

The three great objective ideals of mankind are: Eugenics, the improvement of the human breed; Eutechnics, the improvement of occupations and activities ; and Eutopias, the improvement of surroundings. These correspond to the three facts-Folk, Work, Place ; Organism, Function, Fnvironment; Le Play's Famille, Travail, Lieu.

Fugenics was defined by Sir Francis Galton as "the study of agencies under social control that may improve 
or impair the racial qualities of future generations, either physically or mentally." It is often spoken of with an indulgent smile, as if it was an amiable weakness to be interested in an ideal which yielded the Hebrew prophets and is an ancient art in China. There is no difficulty in vindicating the ideal; the difficulty is in regard to practicable Eugenics. We cannot here do more than make a few suggestions:-

(1) While men and women cannot select their parents, they do to some extent select their partners in life, and in this subtle process it is possible that an enthusiasm for health in the widest and highest sense may have an influence in a eugenic direction.

(2) If men and women who are handicapped by serious constitutional unsoundness permit themselves to marry, they should not permit themsclves to be parents. No one can contemplate without grave regret the spoiling of more or less good stock by the introduction of defects like deaf-mutism, or predispositions to well-defined mental instability, or to certain forms of diabetes and epilepsy. But it is a little suspicious that it is always the other fellow, not oneself, that one thinks of as not a good parent! Professor G. H. Parker expresses the wholesome dread that people have of inquisitions-scientific or otherwise. "My neighbours are charitably inclined, but some of them, I am sure, would give what seemed to them good reasons for not having my particular personality repeated in the future, and yet, with all due respect to the welfare of society, I confess to a slight measure of feeling that I be allowed some indi- 


\section{THE KINGDOM OF MAN}

vidual freedom in this matter." If there is to be a marriage inquisition, one would like to stipulate for a peripatetic, non-local tribunal, on which the family physician might be an assessor, and for a court of appeal.

(3) For natural selection from which man struggles away there is need to substitute rational and social selection. But it does not follow that all the modes of this deliberate selection are for the good of society or the race, or are wholly in that direction. It is often suggested that obviously undesirable types who heve fallen back upon the community for support should be prevented from reproducing their kind. But limits to repression and segregation will be found in the prevailing social sentiments of freedom and solidarity, and it has to be borne in mind that in some measure society may be itself responsible for the making of the failures alluded to, so that we are bound to do something to prevent their production as well as their reproduction!

(4) It is often suggested that there should be some deliberate return to " the purgation of the State" which Sparta to some extent practised and Plato approved. It has been recornmended that weakly infants, whose life must be more or less miserable, should be allowed to pass away in their sleep. This may be justifiable in certain very clear cases, but it is open to serious objections:-(a) that many weaklings have been the makers and siakers of the world, $(b)$ that the Spartan proposals outrun our present sccure knowledge, (c) that their operation would remove the results of cvil without touching the causes, and $(d)$ that we cannot go 
far in social surgery without outraging social sentiment in its finest expressions, and shaking the foundations of our modern system.

(5) Given an understanding of natural inheritance and the influence of nurture, given a pride of race and a pride in having a vigorous family, given an enthusiasm for health, many more positive methods of 'improving the breed' will occur. A community which realises the racial value of fine types, of men, let us say, with high artistic gifts and vigorous physique, will in its criticised expenditure tend to secure their continuance. The applications of this economic idea of "the criticism of consumption " are endless and far-reaching. All expenditure which promotes unhealthy rather than healthy occupations, which helps to multiply undesirable types, which makes for sweated labour and slums rather than for well-paid work and gardens, is necessarily dysgenic and not eugenic.

(6) There is hopefulness also in a practical criticism of those processes which at present thin the ranks of mankind to little or no purpose. Thus, it is certain that many microbic diseases are not discriminatively selective, but effect only a wasteful thinning of the population.

(7) Much betterment may be looked for from a patient persistence in education -if only that could be readjusted to modern conditions and informed with sound psychology. Apart from mere discipline, it may bc said that there are threc main 'subjects' in cducation : -(a) the history of our race, (b) the world in which we 
live, and (c) the conditions of health, happiness, and effective work. Even an optimist must find it hard to maintain that our present-day methods of education are gripping in any one of these three fundamental subjects. When improved methods begin to grip, eugenics will become a dominant social ideal.

As to Eutechnics, there is a growing sense of the fact that even from the point of view of maximum production it does not pay to treat workers as if they were mere machines, and much of the disgrace of the occupational conditions of the Victorian period has been wiped out. As to Eutopias, much has been done in the way of removing utterly inhuman surroundings, but there is little reduction in the supply of materials for a disgraceful scrap-heap ; and compared with, say, Japan of yesterday, English-speaking peoples do little towards securing what is positively beautiful.

A good sign is the spread of the conviction that there is no one line of betterment,-that all secure biological progress must be along three lines, and must be supplemented by progress in social organisation and in the kingdom of the Spirit. Vigour is a eugenic ideal, but a vigorous serf is not a human ideal, nor is vigour in a slum. A beautiful countryside or a beautiful city is a eutopian ideal, but it is not a human ideal if the people are dull and joyless, or if their work is unrelieved toil. Wholesome occupation is a eutechnic ideal, but it fails of human completeness unless the workers have vigorous 
health and pleasant houses to dwell in. We cannot be equally interested in all three kinds of amelioration, but we have ceased to disparage our neighbour's enthusiasm because it is not ours.

Science as Torch.-We must pause at this point to re-emphasise the idea that the hopefulness of the modern vision of the old ideals to which we have been referring lies in a slowly growing appreciation of the value of Science as torch. If Man is to win his kingdom, it must be in part by putting more brains into the campaign. By brains we here mean primarily scientific controlthat is to say, control based on knowledge-verifiable and communicable knowledge-gained from actual experience of the things, the forces, the lives, or the societies to be controlled. Science is truly a crystallised systematisation of observed sequences-( "If this, then that") like Newton's Principia; but it is more. It is a living thing, like Philosophy; it is a life.

The common phrase "a knowledge of science " betrays a misunderstanding. There are, of course, fundamental facts and laws to be mastered, and they become part and parcel of the expert, - the permanent furniture of his mind; but beyond a certain limit of convenience no wise man dreams of increasing this furniture except at a particulan time for a particular purpose. The root of the matter is a habit of mind which insists on getting at the facts in regard to any particular problem, which knows the methods of getting at the facts, which has a high standard of accuracy, which is disciplined to criticise inferences from facts and is alert to detect 


\section{THE KINGDOM OF MAN}

clues. This type of mind is in its finest expression rare, but in its serviceable expression not uncommon, and on its utilisation survival largely depends.

No one need suppose that we are even for a moment forgetting that social progress depends in part on feelings of kinship, on generous good-will, and on the sentiment of solidarity, so characteristic of the Christian religion. We are not for a moment forgetting the impetus that may be given to any good cause by social organisations sufficiently resolute ethically (as in regard to slavery), or sufficiently enthusiastic (as in regard to pacificism and women's suffrage), or sufficiently determined on lines of self-interest (as in the case of tradeunions). But there are many problems which only Science can solve. We need more knowledge and more use of the knowledge we have. Knowledge is foresight, and foresight is power.

\section{§7. Selection in Manisind}

The Biological Theory of Selection.-The method of evolution which a study of living creatures reveals is a method of trial and error, the sifting of organic experiments. It is called the natural selection of variations. Organisms are characteristically changeful from generation to generation. Some of these changes are advantageous and give their possessors a better chance in life than their neighbours have. They have 'survival value.' Others are positively disadvantageous and handicap their possessors. The theory of natural selection is centred in the fact that the conditions of 
life are such that there is a continuous sifting of the novelties that crop up. The variants with advantageous variations tend to form the surviving type; those with disadvantageous variations tend to be eliminated. The result is what Darwin described as "the preservation during the battle of life of varieties which possess any advantage of structure, constitution, or instinct."

We have already referred to an interesting calculation, which we owe to Professor Punnett, that if in a population of 10,000 animals in a district there are 10 with an advantageous novelty that gives them 5 per cent. of a better chance than their neighbours, then, if sifting goes on persistently and consistently, the new departures will represent the species in a hundred generations. The process works on the whole automatically, but it is more than mechanical, since we cannot give a mechanica] account of variation and heredity, and since organisms often take a hand in their own evolution-for instance, in selecting or changing their surroundings.

There is an overlooked aspect of Nature's sifting which is of great interest to man. In the course of ages of evolution living creatures enter into complex relations with one another, they form a web of life, they establish a system of linkages. Thus, it was a great step when flowers and insects got linked up together. There is an external registration of steps of progress, and this forms part of the sieve by which future new departures are sifted. It seems likely that we have here one of the reasons why there has been persistent advance in evolution, why slipping down the rungs of the ladder is 
relatively rare. The established system of inter-relations has often a progressive influence; when the interrelation is parasitism the influence is retrogressive.

Selection in Mankind.-In the early days Man was very thoroughly in the sieve of Natural Selection and also in the grip of Natural Forces which destroyed indiscriminately without sifting. The serpent bit his heel, the poisonous thorns cut his skin, the beasts of prey devoured him, the floods drowned him. But as age succeeded age and man's brain grew, his mastery of Nature increased. He cared less and less for what serpent or thorn, wild beast or flood could do; his struggle for existence changed in tone and colour. Civilisation has meant in part a throwing off of the yoke of Natural Selection. Even famine and pestilence can be controlled.

We have recalled the modern achievements by which diseases like smallpox, diphtheria, typhoid fever, malaria, and others have been conquered. Why has Man with magnificent patience persisted in this campaign against disease? Partly, of course, because of selfpreservative instincts, because he is a sympathetic being, because he does not like to be beaten, but partly also because he discerned that many of the diseases that beset him are not sifting agencies, but indiscriminate in their operation, as in the case of those mentioned above. Sifting is hard to bear, but thinning without sifting is hideously wasteful. In the language of one of Man's familiar ideals, "it is not good business."

There is evidence of some natural selection still in 
progress in mankind-probably in the case of phthisis -but on the whole, as Professor Karl Pearson says, "Consciously, or unconsciously, we have suspended the racial purgation maintained in less developed communities by natural selection." Without weapons save his wits, without armour save his mutual aid, primitive man was Nature's rebellious child, and in later days of fine equipment he has continued his insurgence, as Sir Ray Lankester puts it, hurling back against Nature's sentence "You must die!" the virile challenge: "Nay, but I will live."

In his magnificent lecture "The Kingdom of Man" (1907), Sir Ray Lankester points out how Man transcends Nature by insisting not only on surviving, but on surviving along a line that pleases himself. "The standard raised by the rebel man is not that of 'fitness' to the conditions proffered by extra-human nature, but is one of an ideal comfort, prosperity, and conscious joy in life-imposed by the will of man and involving a control and in important respects a subversion of what were Nature's methods of dealing with life before she had produced her insurgent son."

\section{$\S 8$. The Dilemma of Civilisation}

One of the constantly recurrent thoughts in the mind of the biologist is the contrast between wild animals and mankind. Among wild animals disease does not grip, healthfulness is the rule, parasites are rarely troublesome, senility is unknown: among men disease is rife, healthfulness has to be striven for, parasites are fre- 
quently fatal, senility is common. Moreover, most wild animals show what we admire as exceptional in civilised mankind, an all-round fitness, a buoyant selfmastery, an abandon of vigour, an absence of fatigue, a freedom from worry, and an exemption from 'bad habits.' Walt Whitman felt the contrast keenly.

Perhaps this aspect of the contrast between Man and animals, which we may emphasise without losing any grip of the fact that he is nevertheless " crowned with glory and honour," is the biological equivalent of what theologians call "the Fall." Why is Man so extraordinarily shackled by disharmony, lack of control, disease, bad habits, unhappiness? Transcendental answers have been given to this question, let us try to discover the biological answers.

(1) Just as moral evil is the tax on moral freedom, and instability the penalty of genius, so the constitutional diseases of mankind express to some extent the seamy side of variability. For constitutional diseases are just types of metabolism which are a little out of place, out of time, and out of tune. A disease may be a new departure that has gone a little too far ; it may be a slipping down the ladder of evolution to an oldfashioned way of doing things. The hideous subtlety of disease and the trail of misery that it involves must often blot out the sun, but from a detached biological view-point disease cannot be regarded as unintelligible or portentous.

(2) Man's intelligence has made it possible for him to operate on the outer world in a unique way, and 
this has led to much artificiality of surroundings and functions, of food and drink. His nurture has become extraordinarily subtle and divergentfrom that of animals. Thus his body is exposed to multitudinous assaults from without and from within which have to be met, and are not always met successfully. It must be understood that some bodily disturbances, such as inflammation, which are popularly ranked under the heading of disease, represent the body's best endeavour to deal with intruding microbes, irritants, or poisons.

(3) Intelligence and instinct are usually developed in inverse ratio. The ant with its rich endowment of inborn capacities for instinctive behaviour does not seem to have much intelligence. Man with his rich endowment of intelligence has relatively few instincts, and these are mostly of a generalised type. Thus he is peculiarly liable to stumble. He has, for instance, very little resting instinct, very little awareness of when he is overtaxing his strength. It is intelligently rather than instinctively that he has come to understand that insomnia and pain are danger-signals. Human instincts in regard to sex are very vague.

(4) But perhaps the biggest reason of all is what is often called "the dilemma of civilisation." In a magnificent way Man has rebelled against Nature's régime; but it must be admitted that he has not yet substituted for Natural Selection an adequately effective rational and social selection. Thus an opportunity is offered for deterioration and disintegration. Hence the dilemma of civilisation so well stated by Herbert Spen- 
cer : " The law that each creature shall take the benefits and the evils of its own nature has been the law under which life has evolved thus far. Any arrangements which, in a considerable degree, prevent superiority from profiting by the rewards of superiority, or shield inferiority from the evils it entails-any arrangements which tend to make it as well to be inferior as to be superior, are arrangements diametrically opposed to the progress of organisation and the reaching of a higher life."

What is to be done? (a) In face of this dilemma some say: "Interfere less with life-saving devices." "The undesirables have made their bed, let them lie on it." And probably some people are, what they are often told they are, "too kind." It is difficult to be enthusiastic about the marriage of deaf-mutes, and the evils of indiscriminate charity are well known. Yet we are solidary with our whole society and more or less responsible; we cannot reverse our tactics; we cannot outrage social sentiment. The order of the day is: Save life wherever possible. Moreover, as we have seen, not a few of man's interferences are with indiscriminate thinning, which is not sifting, with agencies like typhoid which remove the fit as well as the unfit. On the other hand, there is good common-sense in the advice that coddling of the waster may mean cruelty to the worthy.

(b) Another suggestion is made by men of sterner stuff, who advise nipping diseased buds and pruning off deleterious twigs-a scientifically conducted infan 
ticide, in short. Now, it is possible that the time will come when the noblest social sentiment and a mature science will agree that this or that kind of bud, e.g. certain well-understood types of defectives, should not be allowed to open, but the time is not quite yet. It is easy to picture the life of misery that they have even under the humanest institutional treatment, and the sadness with which they fill the lives of their relatives; but we do not know enough to nip their buds. It is so easy to make mistakes. We must remember the weaklings who have been among the movers and shakers.of the world. We cannot surgically get rid of our liabilities ; the idea makes the foundations of society tremble.

(c) A third suggestion is less drastic; it aims primarily at preventing multiplication either by sterilisation or by segregation. The suggestion of this always arouses the worthy champions of "the liberty of the subject," but the phrase is a mockery when applied to those who have no true freedom, whom we know not how to emancipate. When we read of the six hundred weak-minded living descendants (1916) of the five "Juke" sisters, we feel that restriction of the multiplication of such undesirable types is overdue. It takes a lot of different kinds of people to make a world and keep it a-going, but there is no help to be got from the weak-minded and the innately licentious. Certain insane types are already taken care of in asylums, must we not look forward to an extension of the policy of segregation for a century or two? It might be kindest and most in the interests of freedom, after all, that those who, 
by inborn fecklessness and irresponsibility, have to fall back on the State for support, should be looked after, but permanently and without opportunity for multiplication.

(d) The fourth suggestion is that we must work out our salvation by the substitution of rational or social selection for natural selection. This is already proceeding along many lines. Thus there is the well-known agency called by economists the "criticism of consumption" or "criticism of expenditure." If we have a margin to spend for super-necessaries (which are more necessary sometimes than the necessaries), and if we consistently spend that in what promotes, let us say, a healthy occupation (like gardening) and things of beauty, then we are indubitably selecting in the line of progress. Few will boast that they have gone as far as they could along this line.

There is great selective power in what may be called. efficiency requirements. Thus in certain occupations, a standard of reliability is exacted. No matter how desirable a man may be, it is necessary to get rid of him if he proves unreliable. This does not necessarily improve matters socially, for the man may slide into an easy job at a lower level and have a large family; but on the whole it is for good. It works against " arrangements which tend to make it as well to be inferior as to be superior," as Spencer put it. 


\section{THE CONTROL OF LIFE}

\section{§ 9. The Social Heritage}

In considering the rôle of natural selection among animals, we saw that great importance probably attaches to the external system of linkages, or web of life, which is always becoming more intricate from age to age. It is very useful to apply this idea to Man, whose nature varies slowly in its hereditary fibre, though its expression in the individual is extraordinarily modifiable and educable. The hope of social selection working well is obviously increased by the fact that man can register so many of his evolutionary gains outside of himself in social organisations and institutions, laws and traditions, literature and art. $\mathrm{He}$ cannot move very fast himself, but his face is in the right direction on the whole, and his extrinsic registration of stable things that last helps to keep him from slipping down the rungs of his steep ladder.

Perhaps we do not sufficiently realise the extent to which man projects himself into outside things, enregistering in them his ideas and ideals. The streets of a city are often hung with invisible memorials-an inspiration to the educated eye, the regionally trained mind. In a good, as well as in a bad sense, it is triue what the prophet Habakkuk said: "The stone shall cry out of the wall." The pity is that we are so badly educated and have so little imagination.

It may not be a waste of time to linger over a familiar instance of Man's power of enregistering his gains outside himself. We know how some of the great pieces of literature, which are common property among men 
and bind their hearts together, as melodies also do, are enriched by associations so that every word is dear. The authorised version of the Bible is the highest example, grand in itself, but doubly potent in what has been gathered into it. This has been very beautifully expressed by Canon Faber, who followed Cardinal Newman in leaving the Communion of the English Church for that of the Church of Rome :"Who will not say that the uncommon beauty and marvellous English of the Protestant Bible is not one of the great strongholds of heresy in this country? It lives on the ear like the music that can never be forgotten, like the sound of church bells, which the convert hardly knows how he can forego. Its felicities often seem to be almost things rather than mere words. It is part of the national mind, and the anchor of national seriousness. The memory of the dead passes into it. The potent traditions of childhood are stereotyped in its verses. The power of all the griefs and trials of a man is hidden beneath its words. It is the representation of his best moments, and all that there has been about him of soft and gentle and pure and penitent and good speaks to him forever out of his English Bible."

And again as to Art, how well Emerson understood its rôle as evolutionary registration :-

"Let statue, picture, park and hall, Ballad, flag, and festival, The past restore, the day adorn, And make to-morrow a new morn. So shall the drudge in dusty frock Spy behind the city clock 
Retinues of airy kings,

Skirts of angels, starry wings,

His fathers shining in bright fables,

His children fed at heavenly tables.

'Tis the privilege of Art

Thus to play its cheerful part. ..."

Again, to descend from the sublime to the tedious, all the innumerable societies and associations that seem to crowd us in our life are, when regarded with biological detachment, more or less fit and proper parts of the external systematisation on which progressive human evolution largely depends.

Coming down to a homely example, let us go to the ant which has carried state-socialism to such extremes. Several generations of ants inhabit the same anthill, and what we are trying to express is that the ants' permanent products, and all that these stand for as liberating stimuli, mean much in the evolution of ants. So much the more in the evolution of men.

\section{§10. MAN'S IMPERIUM IN IMPERIO}

There is a Latin proverb that asks "who watches the watchman?" One must raise this question in regard to social selection. How can we be sure that the social selection is working in the right direction? In point of fact, we are sure that it often does not. To advertise for a gardener "without encumbrances," to penalise maternity, to "sweat 'labour, to underpay some teachers and ministers so that they are bound to remain celibate, to acquiesce in arrangements that tend to break up family life, all this is selective in effect-and selective 
in the wrong direction. A long-continued severe war in which a large proportion of the population shares is likely to select in the wrong direction, as far as the biological qualities of the race are concerned. Shortsighted, one-sided economies are apt to do great harm.

How are we to select modes of selection? The first half of the answer is the truth that lies behind theories of conservatism-namely, that amid much uncertainty we do know that some organisations and institutions have proved themselves beneficial. They have stood the test of time and we should give them the respect due to their antiquity provided that it can be shown that they have worked well. The family is a good institution, monogamy is a good institution, representative government is a good institution, freedom in thought and in speech is a good institution, so are mutual aid and mutual improvement associations, so are educational institutions and organisations. Prove all things and hold fast that which is good. Select in the direction of those institutions that have proved themselves at once progressive and enduring.

The second half of the answer is in line with the principle already hinted at, that in difficult cases a criterion of the soundness of operations in a given field is to be found in terms of values in a higher field. It is not enough to ask whether the gold mine is run on lines of economical exploitation as regards the conservation of energy; we must ask, as is increasingly done : "What about the conservation of life?" The exploitation of the sea by trawling yields enormously 
bigger results than in the old days of line-boats, and we cannot retrace our steps. But we must not brush aside as irrelevant the question: Is it fostering as fine a set of men? Turning to a biological case, we are assured by those who know, that the miseries inflicted on innocent women and children by venereal diseases are so appalling that no one can venture to do anything which would retard the curing of men who by indulgence are primarily infected. But it cannot be said that this disposes of the question of the consequences of readily annulling the penalities of anti-social conduct. Hesitation in regard to this question may not warrant any relaxation in combating venereal diseases, but it suggests the urgent need for moral as well as biological therapeutics and prophylaxis. On the more positive side, it is easy to think of liberties which might be condoned biologically, but which would probably be very detrimental socially. The principle is to judge operations in a part of Man's kingdom not only by the criteria especially relevant there, but also by those which are known to hold good in higher fields. So, returning to the question, How are we to criticise social selection? we know the answer to be that the criticism must ultimately refer to what we hold as our highest ideals the true, the beautiful, and the good.

We all know a little about the true, the beautiful, and the good. We know that when we are at our best we set great store on them. The best in us desires them as rewards in themselves. The best in us, which some philosophers call our spirit, has intellectual, æsthetic, 
and moral activities which reach forward to the true, the beautiful, and the good. It is the experience of mankind that man reaches out most successfully when he desires these things for their own sake. If he desires them for some side issue, he is likely to miss them altogether. This is in its way a sort of philosophy-as is beautifully explained in a little book by Mr. Clutton Brock called The Ultimate Betief (Constable, 1916, 2s. 6d.).

Normal children have desires after the true, the beautiful, and the good; and these fundamental desires of the spirit, which are the best things we have, can be encouraged, especially indirectly. To make fun of them is the fundamental disloyalty. It is not possible exactly to teach what is true, beautiful, and good, but the desires after them can be respected and nourished, and the freedom from which the desires spring can be guarded. Why do we speak here of these things? Because in difficult cases the criterion of humbler operations is to be found in the way in which they affect what is of highest value to us. The final criterion of the Kingdom of Man is the Kingdom of God.

The important idea may be put in another way. The growth of Science is always to the good, but its value is increased in proportion as it is unified, and that requires philosophy. The diffusion of the scientific mood is always desirable, but its value is increased in proportion as it makes for the integration of man's intellectual life. The application of Science need not be for good at all; the degree to which it will be for good will 
depend on its congruence with man's organisation of ideals-of those ideals which have seemed best to men at their best.

There is obviously nothing evil in machinery or mining as such; there can be nothing evil in applying science to industry; but the danger of our weak humanity is in allowing practical organisation to be dominated by some one-sided ideal such as greed. And, as has been shrewdly said, the reason for the ugliness of the nineteenth-century factory and railway station and "tenement" was the idea-system of those who built them. They expressed indifference to beauty and common weal. "Their hideousness was but the outward and visible sign of the motive of their builders. They carried the signature of private greed, not of public spirit."

In the same way, as we pass from the age of steam to the age of electricity, it is not enough to have the utilisation of electrical power organised; what is wanted is organisation related to great ends. These ends are not confined to the most economical supply of power to an industrial area; they must be national rather than local, and social as well as economic. Thus, country districts require to be electrified as well as towns.

But is not this getting into spheres where the Bible, not Biology, should give man counsel ? Of a truth man needs all the counsel he can get, but our present point is that more attention to the biological control of life might make it possible for man to go further with that higher control which will lead him past the desires of the flesh to the desires after the true, the 
beautiful, and the good. For these desires spring from a certain freedom of spirit, and that may be best conserved, or attained, or reached towards, as the case may be, if man has attended first to what Biology has to tell him r egarding heredity, development, nurture, health, childhood, adolescence, sex, marriage, ageing, and the biological aspects of Man's endeavours to enter more fully into his Kingdom. 


\section{CHAPTER IX \\ PROGRESS IN EVOLUTION}

$\S 1$. What is Meant by Progress ?-§ 2. Progress a Fact.-§ 3. A Contribution to a Critique of Progress. $-\S 4$. Towards a New Stoicism. - §5. Looking Forwards.

§1. What is Meant by Progress?

$W^{\text {HEN we ask if the gardener is making progress }}$ wath his work, if the patient is making progress towards health, if the investigation is making progress towards a solution of the problem, every one knows what we mean by progress. We mean getting nearer a desired result, which is clearly defined. But what do we mean when we speak of the progress of the human race or of a nationality? We cannot say that we mean evolution or improvement or betterment, for that is merely using another word. It is not satisfactory to say that progress is movement to a desired result, for what is the criterion of the value of the desired result? It is a common argument in favour of some scheme that it makes for progress. But what is this mysterious progress, this racial, or national, or civic progress ?

Cosmic Development.-Long, long ago our solar system was established around a central sun. It seems likely 256 
that the earth was heaved off from the central mass as a spiral nebula, and that the other planets had a similar origin. During a prolonged period, the earth consolidated and became fit to be a home of life. Is increase of intricacy and definiteness necessarily progressive, or is the note of progress in the possibility of something new? The integration of the earth and all that in it was, opened up the possibility of living creatures. If it was not progress, it was surely in that direction.

Organic Evolution.-Many millions of years ago, in some unknown way, living creatures began to be upon the earth ; and as age followed age, they were succeeded by forms on the whole more complicated, controlled, emancipated, and intelligent. Now, if the advent of more masterful, controlled, free, intelligent forms of life means progress, then organic evolution shows progress. There has been frequent retrogression and degeneracy, there are many parasites, there are blind alleys of great complexity which are puzzling to the hasty-minded; but the larger fact is an onward sweep.

On the whole, common-sense regards it as certain that there has been in Organic Evolution something like what Lotze thought he discerned-" an onward advancing melody." There was a time when there were no backboned animals except Fishes; ages passed and there were Fishes, Amphibians, and Reptiles; ages passed and there were also Birds and Mammals. Was not this progress? And yet, why do we feel sure that Birds and Mammals mark an advance on Reptiles? It cannot be mere complexity. It is because they are 
more controlled or integrated, more masters of their fate, with more mentality. So progress means movement towards certain ideals which we cherish. It is a verdict based on our sense of values. There is a clue here that we must hold to. Evolution on the whole is integrative; it makes against disintegration and disorder, against instability, against the entropy or degradation of energy which marks the inorganic.

It has to be borne in mind that with the evolution of the type there was correlated an evolution of interrelations binding lives together in a systema naturce, a web of life whose pattern becomes more and more significant. This external registration acted along with the organismal or hereditary registration in conserving evolutionary gains once made ; it was at once a condition and an organon of progress. The higher animal was able to see more meaning in the world, but there was also more meaning to discover.

In any case, it is plain that there has been an increasing solidarity in Animate Nature, and much that seemed at first insignificant is now known to contribute fundamentally to the stability of the super-structure in which we discern progressiveness most clearly. The Kingdom of Man depends on a peculiar quality of a green pigment ; the vigorous life of higher animals depends on another pigment; flowers depend on insects; fishes depend on water-fleas, infusorians, and sea-dust. Even when a race becomes extinct, it would be rash to say that it has lived in vain.

The critic may intervene, however, and say: "No 
doubt Mammals, for instance, have more control, more freedom, more mind than Reptiles have; but are you not forgetting that they began to run new risks, to make new kinds of mistakes, to suffer pain, to fear ?" To which the answer may be made: "Granting the taxes on progress and the pains of progress, it was worth while that Mammals should have evolved." Yet if pressed to say why we feel sure that it was worth while, must we not answer (1) that the evolutionary process which led to Mammals was making in the direction of Man and of Man's kingdom, and (2) that it was making towards a fuller realisation of what we value most-control, freedom, understanding, and love. Progress, is, of course, a modern and sociological concept, meaning increase in the realisation of what the racial consciousness has most persistently held to be of the highest value, but our point is that there is something analogous to this in the great trends of integrative evolution.

The Ascent of Man.-The evolution of organisms has its climax in the ascent of Man, the establishment of societary forms, the process of civilisation, the march of human history. Now, no one will say that the march of human history is in itself progress, in the sense of necessarily leading to the enrichment of life. Many of the changes-perhaps inevitable-have been very miserable at the time and of dubious benefit when effected. Many aspects of the so-called Industrial Revolution in Great Britain were full of misery and it is open to question whether we are the better of Industrialism. And what does "the better" mean? 
When we contrast the Bird and Mammal world with the world before they emerged, we say " progress," meaning movement towards the actualisation of what we regard as of the highest value. We have a gamut of millions of years and we get a good contrast. But can the same be said of the much shorter span covered by human history. Is not humanity like Sisyphus, ever rolling the stone up the hill, only to have it tumble down again? And yet, whoever doubts human progress should think of our ancestors-as Eschylus pictured them-living in caves, without fire, without wood-work, without system, without seasons, without foresight. A fairly accurate picture to be contrasted with Man's conditions to-day. As we have already said, modern Man has made the ether carry his messages; he can hear from afar the cry of the ship in distress upon the sea; he can make Niagara drive mills and illumine cities hundreds of miles from the Falls. Science has harnessed electricity to Man's chariot, and added the depths of the sea and the heights of the air to his navigable kingdom. Already Science is making bread out of the thin air, working miracles in the conquest of plague and pestilence, and controlling the inheritance of generations unborn. Can anyone doubt human progress on a long view?

\section{§2. Progress a Fact}

The facts of organic evolution, considered broadly, compel us to believe in progress, and the same is probably true in regard to human history. But reasoned 
scepticism as to the reality of progress (as in the recent studies by Professor Bury and Dean Inge) is very useful. For we have no right to assume that mere carrying on, or even struggling on, is progress, i.e. movement in the direction of realising what the racial consciousness holds to be of most value. We cannot trust to ratiocination, for we invent political and economic theories, which are conscious or unconscious attempts to justify our practice before the tribunal of reason.

Scepticism as to Progress.-Is progress at present demonstrable or may this be a period of retrogression in the species or in part of the species? We are only a few hours from scenes of horrible starvation and agony among women and children and old people; we are only a few miles from slums and warrens; we are only a few steps from dull, stupid, oppressed lives without outlook or uplift; we are perhaps only a few hours from being ourselves bedrugged by some miserable microbe which we call influenza, or from being pushed off the stage by a typhoid bacillus brought to us by one neighbour's flies from another neighbour's leaking drains. Is progress so clear in our midst? The answer, "In some things Yes, in others No ; in some circles Yes, in others No," is true; but it suggests that our definition is still incomplete. When we think of the seamy side of modern life (e.g. our present-day panem et circenses : subsidised bread and cinemas); when we remember that the glory that was Greece was largely based on slavery, and was contemporary with an intolerable view of womankind, and eventually with little in the way of 
home life-one of man's surest gains in well-being, we see that we must add to our definition,-progress is a balanced or harmonious movement towards a fuller embodiment of the highest values. We are tired of cackle about progress when it is cheek by jowl with the misery of multitudes. A social body cannot be making progress as a whole if it has a long tail-of those who do not have their chance. Equalitarianism is biologically a fantastic fallacy, but we must work towards a reasonable equality of opportunity to allow those who believe that they are more than equals of their superiors to prove their claim. We see, then, that the idea of progress is in process of evolution, for we have added to it the idea of social integration. A social body cannot be making more than particulate progress, if it contains a large proportion of members who do not get a fair chance.

The Higher Values.-Man's ideals are the reaching forward of his desires when he is at his best, and progress is an integrated movement towards their fuller embodiment. So in our definition of progress we must give first place to those values that we are surest about - the truth and the seeking of it, the beautiful and the making of it, the good and the doing of it. These values we call absolute, because they are desirable as ends in themselves, because we cannot have too much of them, because they never bring satiety, because they are their own reward, and because as civilisation deepens they have an increasing survival value.

Ideatist and Realist.-Here we meet a familiar difficulty. We are surest about the true, the beautiful, 
and the good. When we are at our best the best part of us declares that these are best. A certain type of mind, idealistic we may say, keeps close to these highest values, and conquers the world by other-worldliness. Another type of mind, realistic we may say, is more matter-of-fact, finding the supreme values too aërial. The realists wish to see the goodness of God in the land of the living - that is to say, to see progress in the here and now, not so much in the cosmos as in their own region. There is no contradiction, of course, but there is a difficulty. We are facing one of the deepest dichotomies of human temperament, that between idealists and realists, that between the philosophical and the scientific.

One way of meeting the difficulty may be briefly stated. The true, the beautiful, the good are supreme values-intellectual, emotional, moral-the ideals of head, heart, and hand-but below them there are fundamental values, especially two, (1) the economical use of energy and the increase of material resources, and (2) health (including adaptation to bracing surroundings). Without these there cannot be stability or persistence. Would it be progress to have a race of very wise men and women, all invalids? A vigorous fool would be a great relief. Would it be progress to have a beautiful race, relatively sterile? Would it be progress to have a very good race, without joy? So must we not say that there are physical and biological pre-conditions of social progress, the physical pre-condition of mastering the powers of Nature, the biological 
pre-condition of good breed, good work, and good place eugenics, eutechnics, and eutopias?

Definition of Progress.-Co our definition now runs : -Progress is a balanced movement of a social whole towards the fuller embodiment of the supreme values, but at the same time towards a fuller realisation of the physical and biological pre-conditions which secure persistence.

There is probably more than verbal value here. On the one hand, insistence on the biological and physical pre-conditions may help to make idealism more practical. Is a vote of much moment if we cannot have a bath? Is even beauty of great price if we have not time to look at it. "A poor life this, if, full of care, we have no time to stand and stare." The fundamental is as necessary as the supreme. Little use in a fine torso, if the feet are of clay.

But a recognition of the pre-conditions of social progress has another aspect. It is all very well to say to your horse, "Come on, then, like a good fellow,"- - that is the psychological stimulus ; but it is not very well if we forget to give him his oats in the morning,- - that is the biological pre-condition. On the other hand, if we treat our horse simply as a thermodynamic engine, we will not get either the most or the best out of him; if we treat him simply as a mammal, we shall also fail, though not so egregiously; we must treat him as a brother mind-body- "Brer Horse." We should beware, then, of thinking that eugenics (good breeding) will necessarily engender a good heart; we should not be 
too sure that eupsychics (good education) may not be the shortest way to eutopia (good environment). Progress is manifold, but the organism is one.

\section{§3. A Contribution to the Critique of Progress}

We are here in sight of a principle, a contribution to the critique of progress. Civilisation has been handicapped in the past by insufficient use of Science as a torch to well-being. This handicap continues, but it is lessening. The more we use Science for life the better, but there is the risk of being guided too much by one science.

Our kindly social sentiment and sense of solidarity is a sign of progress; every right-minded person hopes for more. And yet, we help the sickly, the diseased, the thriftless, the feckless, and we must go on helping them, for we have thrown off forever the old rat-againstrat theory. We have thrown off the yoke of Natural Selection. And yet, if we persist in sheltering inferiority from the penalties of inferiority, if we persist in not allowing superiority to reap anything like the full rewards of superiority, we are assuredly making for trouble. So some brave men would return to Lycurgan methods, to Plato's purgation of the State. But we cannot do this wisely, we have not knowledge enough; and we would not if we could. We must think out subtler ways, conservative of such higher values as good-will, and yet safeguarding us from being kind to the present and cruel to the future. If we generalise this we get a glimpse of a critique of progress,-we must 
judge any social change by the criteria of successively higher ideals. Is it sound physically, biologically, psychologically, socially? But we must judge physical operations not only in themselves but in the light of biological ideals, and biological operations in the light of the psychological, and psychological changes in the light of the social, which includes the ethical.

Increased productivity is a physical ideal-will it mean increased health? It has often meant a black country and a short drab life. Increased efficiency is an ideal for engines, will it mean increased freedom of the spirit? Increased health is an ideal for the animal, but man does not live by bread alone, he is a mind-body as well as a body-mind. Pruning off diseased branches is a biological ideal,but Herodian methods would probably sap the spiritual vitality of society. The principle of guidance is this-judge the physical in the light of the biological, and the biological in the light of the psychological, and the psychological in the light of the social. More simply, our proposals for progress must in the long run be submitted to the august tribunal of the true, the beautiful, and the good.

The big things are truth, beauty, and goodness; but the scientific realist wishes instalments in the concrete. So we have suggested, to get the question clear, that there are fundamental pre-conditions of the realisation of the supreme values. These pre-conditions are twofold-physical and biological. The physical pre-conditions are increased material resources and increased economy in using them. We have already quoted Sir 
William Ramsay, who declared that "real progress consists in learning how better to employ energy-how better to effect its transformation." The biological preconditions are: vigour, energy, initiative, adaptation to enriching and conserving surroundings: health, for short.

\section{§4. A New Stoicism}

But there is another way of looking at our question, -a new light on the old maxim : Follow Nature. What does Animate Nature make for? What is rewarded by prolonged survival without degeneracy? We must answer, on the whole, the healthy and the knowing in the widest sense, the beautiful, and those that care for others as well as themselves, such as Birds and Mammals.

First, take the beautiful. Here Nature's unconscious ideal and Man's desire are in harmony, except that artifice counts for more in Man's case, and we do not know of animals more than beginning to try to express. ideas in modifications of matter and energy, which is art.

Second, take the good. Nature is always taking advantage of her children's capacity for self-forgetfulness. The highest success is with the creatures that care for others and work well, with creatures who, though they do not think ' the ought,' are beginning to be good.

Third, take truth-seeking. Surely that is not one of Nature's ideals. But knowing the facts is on the way to truth, and the knowing creatures survive. 
Moreover, every one agrees that Animate Nature is all for health. But beauty is in part an expression of healthy harmonious living, and though all sorts of exceptions have to be made for man, some of these, like the invalid's fine face, chiselled from within, prove the rule.

Again, for those who start fair, health is a subtle index of goodness, while goodness makes for health.

Yet again, what if truth-seeking is just the natural activity of the active healthy mind? What if lucidity, beauty, health are all congruous-implying unified and harmonious life such as Nature sanctions? Thus concrete and abstract harmonise. Thus Man's progress, which Huxley said must be against the cosmic process, is really in a line with it.

\section{$\S 5$. Looking Forwards}

We have been seeking after a definition of the concept of progress, and we have not attempted to discuss the factors (the initiatives, the sifting, and the holding fast), or the various lines of progress (organismal, functional, environmental, and social), or the shadows on progress (especially of non-participation and non-persistence). All these questions demand separate treatment. We must notice, however, an addition to our definition which seems to be demanded by the fact that many who share in the struggle do not in any way share in the victory,--take the men of Neanderthal, for instance, our predecessors but not our ancestors. They were on a human side-track. It is customary to try 
to dispel the shadows of non-participation and nonpersistence by considering the possibilities of mundane and transmundane conservation of values.

\section{Work a Satisfaction in Itsele}

These lights are surely worthy of our most serious consideration, but we venture to make a practical suggestion. Sometimes we live a day so very fine that we say to ourselves: Well, this justifies it all. We warm both hands-of soul and body-at the fire of life, and are content. We would willingly enjoy more, but we would not grumble. We have spent a pleasant day with our host, and we are not angry if he does not ask us to stay the night. So, though not on any easy terms, would we have it with our life, that it be on the whole, and in many of its parts, sufficient reward in itself. So would we have it for all mankind. For the past it has not been so; but these conditions are slowly passing. We would that all men of good-will should find their lives good in themselves. As it says in Ecclesiastes: "So I recognised that there is no greater satisfaction for a man than to be happy in his work-that is his reward." Thus in reference to mankind, progress may be defined as a balanced movement of a social whole towards fuller embodiment of the supreme values (the true, the beautiful, and the good) in circumstances which increasingly realise the fundamental physical and biological pre-conditions of stability and persistence, and in lives which are increasingly rewards in themselves, both individually and socially. 


\section{In Conclusion}

We have seen that the application of sound biology might do much to raise the standard of individual healthfulness and that it can help towards 'the improvement of the human breed,' to use Sir Francis Galton's phrase which points to racial evolution as well as to individual development. Increased healthfulness of the human organism as a whole, body-mind and mind-body, is one of the pre-conditions of progress.

We have also seen that the application of sound biology can do much to remove shackles which inhibit the higher adventures of the human spirit. It may seem to some like a bathos to refer to the handicapping of human life by hookworm disease; if they knew more about it they would count the conquest of that disease (and many another) as a climax. The facts warrant the belief that many of the shadows and disharmonies of human life can be got rid of when good-will joins hands with Science. But there is more. Our studies indicate for mankind a mundane future which is irradiated with hope. This hope is grounded on the fact that evolution in the past has been on the whole progressive, towards integration, towards increasing fullness, freedom, and fitness of life. There has been "a constant if chequered advance." Will it stop ?

We see in evolution the possibility of turning even mistakes and failures to some advantage; we have the same hope for ourselves and for our race.

Man's highest conception, his conception of God, must enlarge as his thoughts are widened; but it is 


\section{PROGRESS IN EVOLUTION}

surely interesting that the modern idea of a God-a God of evolution-brings us back to the God of our fathers, whose name-the scholars tell us-meant not "I am that I am," but "I will be what I will be." 



\section{INDEX}

Acquired characters, 92

Adolescence, 176

Adrenal bodies, 175

Ageing, 185

Ante-natal life, 162

Bacon, 21, 22, 33

Ballantyne, 164

Bateson, 22, 40, 120

Bayliss, 144

Bergson, 60

Bilharzia, 148, 232

Biologism, 225

Biosphere, 223

Birth-rate, decline of, 211

Blending inheritance, 66

Body and mind, 137, 155

Bordage, 102

Bragg, 21

Brain, 142

Branford, B., 20

Brock, Clutton, 253

Bruce, 38

Butler, Samuel, 178

Callosities, 103

Canon, 156

Carlson, 156

Castle, W. E., 67

Chambers, Robert, 162

Child, C. M., 91, 160, 188
Childhood, 170

Chinese Primrose, 88

Clouston, 108

Colour of eyes, 70

Comte 184

Correlation of organs, 143

Cosmosphere, 222

Crile, 156

Criminals, 110

Crookes, Sir Wm., 13

Darwin, 32

Davenport, 106

De Vries, 60

Dewey, 28

Disease, defined, 146

Disease, kinds of, 73

Drosophila, 89

Dugdale, 113

East, E. M., 207

Easterbrook, 110

Education, biologically con. sidered, 172

Ellis, Havelock, 202, 218

Emerson, 249

Estabrook, 112

Eugenics, 234

Eutechnics, 237

Evergreens, 102

Evolution idea, 30 
Faber, Canon, 249

Fates, 45

Fatigue, 151

Fortility, 193

Filial regression, 78

Fraunhofer, 12

Fruitfly, 89

Fuller, Thomas, 118

Galton, 59, 77

Geddes, 48

Genes, 61

Germinal continuity, 59

Grassi, 37

Gregory, 16

Groos, 170

Gudernatsch, 88

Health, 123

Heape, Walter, 180

Heredity, facts of, 56

Heritage, 47

Heron, 210

Hobhouse, 29

Hobson, 17

Hookworm, 38

Hormones, 132, 144

Humanities, 24

Huxley, 18

Industrial age, 201

Infancy, 165

Inge, Dean, 219

Inheritance, 47,49

Inheritance, Mendelian, 67

Instincts, 52

Instincts, Man's, 126

James, 23

Jukes family, 112

Keble, F., 207

Keith, Arthur, 127

Kelvin, 10
Lamarckism, 98

Lankester, Sir Ray, 242

Lqveran, 37

Lead poisoning, 154

Leiper, 148

Iife curves, J 58

Life, duration of, 167, 203

Liver fluke, 232

Locusts, 36

Loeb, 90

Love, 179

Maartens, 28

MacDougal, 90

Malaria, 37, 231

Malthus, 203

Man, ascent of, 239

Man, origin of, 31

Marriage, 188

Materialism, 225

Mendel, 39

Mendelian inheritance, 67

Metchnikoff, 124, 188

Microbes, 148

Millard, 206

Modifications, 61

Modifications, defined, 95

Monogamy, 183

Morgan, T. H., 84

Mosquitoes, 37

Mott, F. W., 76, 109

Muscles, 129

Mutations, 55

Myres, J. L., 201

Nature and nurture, 83

Nervous system, 134

Neurons, 135

Nersholme, 211

Night blindness, 70

Nougaret, 82 
Old"age, 186

Oliver, F. W., 14

Oliver, Sir T., 154

Osler, 41

Overpopulation, 203

Parker, G. H., 142, 234

Pasteur, 17, 35

Pavlov, 155

Pearl, Raymond, 56

Pearson, 77, 79, 86, 242

Phagocytes, 149

Planarians, 91, 160

Play, 170

Population, 190

Population, rise and fall in, 200

Progress, defined, 264

Punnett, R. C., 121, 192, 240

Ramsay, Sir William, 12, 226

Recapitulation, 167

Re日d, 38

Reflexes, 137

Regulative system, 143

Reversion, 72

Rhondda, Lord, 13

Romanes, 102

Ross, 37

Rowland, 21

Ruskin, 26

Russell, Bertrand, 183

Science, aim of, 15

Science, defined, 10, 42

Secretion, 144
Selection, in mankind, 239

Sex, 177

Shaw, Bernard, 181

Sherrington, 134

Social heritage, 248

Sociosphere, 224

Spencer, 98, 99, 165, 198, 244

Starling, 144

Stockard, 90

Stoicism, a new, 267

Tadpoles, 88

Temperaments, 107

Tennyson, 139

Thomson, Mary Florence, 120

Thyroid gland, 41, 144

Trotter, 10

Trypanosome, 38

Tsetse fly, 38

Unit characters, $\tilde{5} 4$

Variations, 64

Web of life, 228

Webb, Sidney, 211

Weismann, 59

Wells, H. G., 113, 178

Whitehead, 16

Wilson, E. B., 119

Wilson, James, 39

Wood Jones, 165

Youth, 160 




\section{DATE DUE}

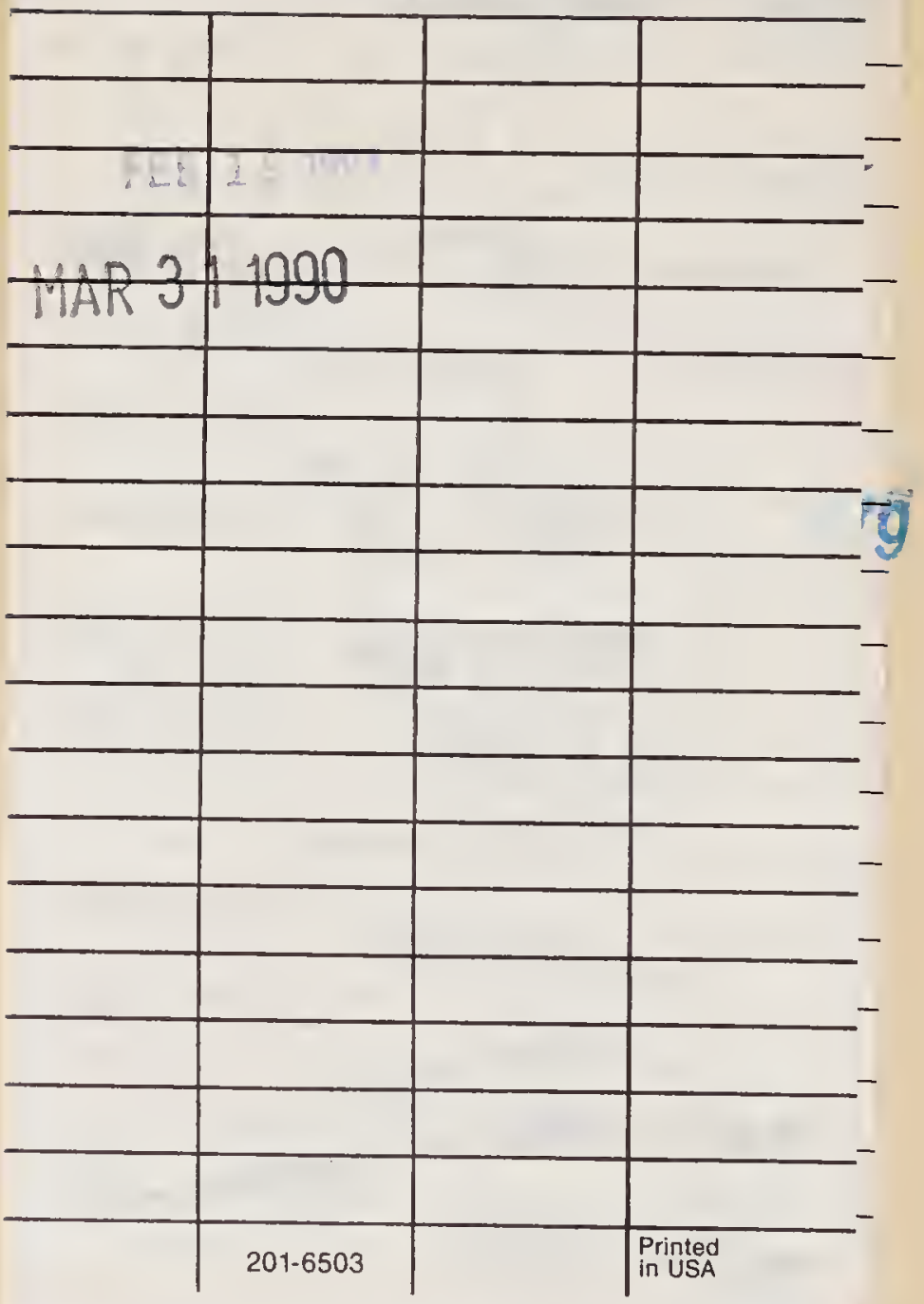




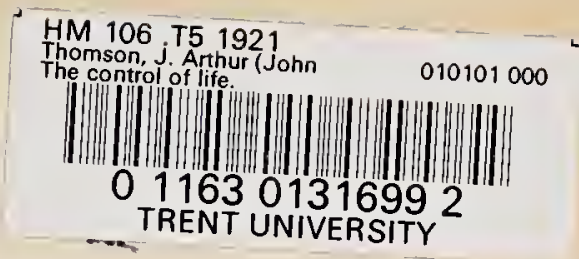

...

Hiv106 .T5 1921

Thomson, J. Arthur

The control of Iife.

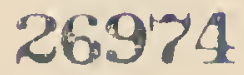


